\title{
Independent Review of the X-701B Groundwater Remedy, Portsmouth, Ohio: Technical Evaluation and Recommendations
}

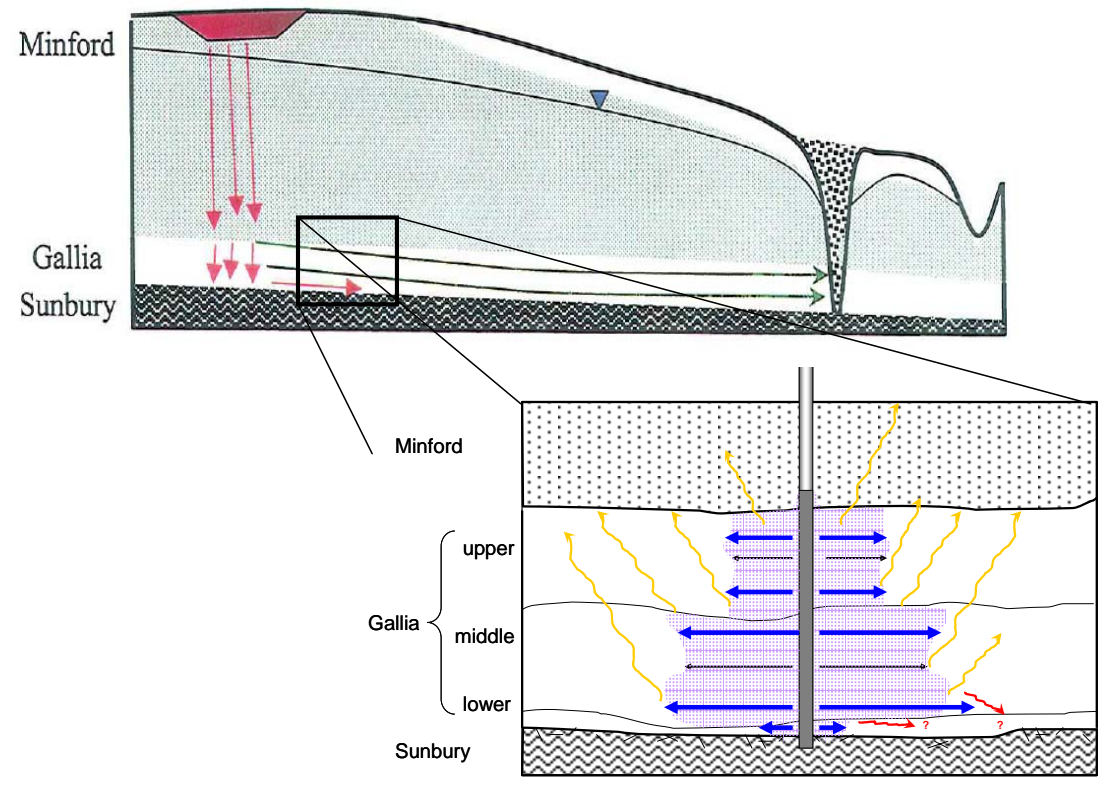

\section{Prepared for}

Department of Energy Office of Environmental Management / Groundwater and Soil Remediation (EM-22)

Washington, DC

Prepared by

DOE EM Center for Sustainable Groundwater and Soil Solutions

Savannah River National Laboratory

Aiken SC

December 2008
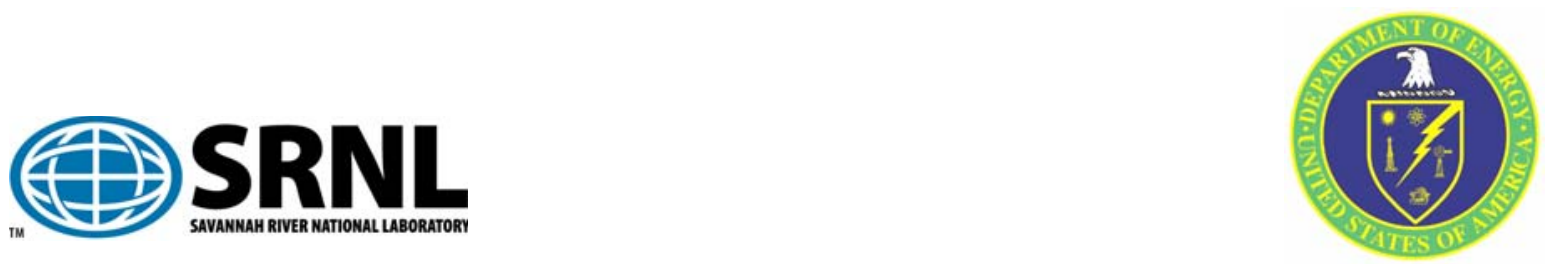

Technical input and coordination for this effort was provided by the Savannah River National Laboratory in conjunction with Contract No. DE-AC09-08SR22470 with the U.S. Department of Energy. 
Cover Photo: Schematic diagram of the hydrogeology in the vicinity the former X701B basin with a diagram detailing some of the key processes that occur near a peroxide injection point

\section{DISCLAIMER}

This work was prepared under an agreement with and funded by the U.S.

Government. While the authors have taken care in the preparation of this report, neither the U. S. Government or its employees, nor any of its contractors, subcontractors or their employees, makes any express or implied: 1. warranty or assumes any legal liability for the accuracy, completeness, or for the use or results of such use of any information, product, or process disclosed; or 2. representation that such use or results of such use would not infringe privately owned rights; or 3. endorsement or recommendation of any specifically identified commercial product, process, or service. Any views and opinions of authors expressed in this work do not necessarily state or reflect those of the United States Government, or its contractors, or subcontractors.

Printed in the United States of America

Prepared For U.S. Department of Energy Office of Engineering and Technology (EM-20) 


\title{
Independent Review of the X-701B Groundwater Remedy, Portsmouth, Ohio: Technical Evaluation and Recommendations
}

\author{
Authors: \\ Brian B Looney ${ }^{1}$ \\ Carol Eddy-Dilek ${ }^{1}$ \\ Jed Costanza ${ }^{2}$ \\ Joe Rossabi $^{3}$ \\ Tom Early ${ }^{4}$ \\ Karen Skubal ${ }^{5}$ \\ Claude Magnuson ${ }^{5}$ \\ Prepared for \\ Claude Magnuson \\ Department of Energy (DOE) Office of Groundwater and \\ Soil Remediation, EM-22 \\ Washington, D.C. \\ December 2008 \\ ${ }^{1}$ Savannah River National Laboratory, Aiken SC \\ ${ }^{2}$ U.S. Environmental Protection Agency, Washington DC \\ ${ }^{3}$ Redox-Tech, Cary NC \\ ${ }^{4}$ GeoConsultants, LLC, Knoxville TN \\ ${ }^{5}$ US DOE EM-22, Washington DC
}


\{blank page $\}$ 


\section{INDEPENDENT REVIEW OF THE X-701B GROUNDWATER REMEDY, PORTSMOUTH, OHIO: TECHNICAL EVALUATION AND RECOMMENDATIONS}

\section{Table of Contents}

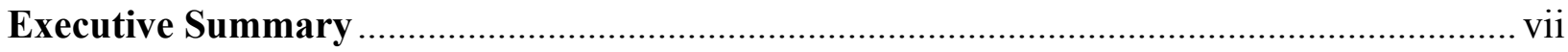

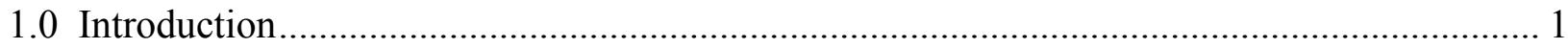

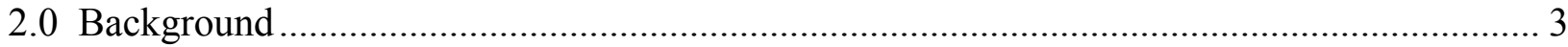

3.0. Review of Phase II Oxidant Operations and Performance ............................................. 9

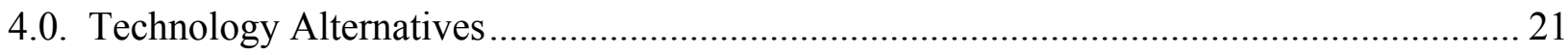

5.0. Recommendations - Combined Remedy ................................................................ 50

Appendix A -Charter for the Technical Review

Appendix B - Review Team Biographies

Appendix C -Attendance Sheets for Team Briefing

\section{List of Figures}

Figure 1. Conceptual model of the contaminant hydrogeology for the X-701B Area ................ 6

Figure 2. X-701B TCE Plume in the groundwater of the Gallia Member.................................. 7

Figure 3. Major divisions within the TCE plume ............................................................ 8

Figure 4. Simplified conceptualization of Phase II oxidant deployment.................................. 10

Figure 5. Location of transects used to evaluate soil and groundwater data ............................ 14

Figure 6. Soil concentration transects in the upper middle and lower Gallia .......................... 15

Figure 7. Groundwater concentration transects in the Gallia ............................................... 15

Figure 8. Suspect DNAPL locations after Phase IIe......................................................... 16

Figure 9. TCE plume downgradient of the former X-701B pond during and after the pilot

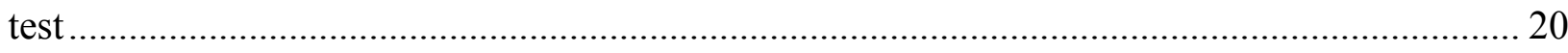

Figure 10. Example scenario with relocated extraction wells ................................................ 32

Figure 11. Steam flushing pilot study area and full-scale system layout................................ 24

Figure 12. Conceptual arrangement of surfactant/cosolvent injection and extraction wells ........ 36

Figure 13. Schematic of potential constructed wetland system at X-701B ........................... 47 


\section{Acronyms and Abbreviations}

AFCEE

$\mathrm{COC}$

$\mathrm{C}_{\mathrm{s}}$

cu.

$\mathrm{cVOC}$

$\mathrm{C}_{\mathrm{w}}$

DNAPL

DOE

EM-22

FY

gal

gpm

$\mathrm{H}_{2} \mathrm{O}_{2}$

ITRC

$\mathrm{K}_{\mathrm{d}}$

$\mathrm{KMnO}_{4}$

LIF

MIP

$\mathrm{MnO}_{2}$

$\mathrm{msl}$

$\mathrm{NaMnO}_{4}$

NAPL

OEPA

PGDP

PITT

PPPO

PRB

PRG

RCRA

RTDF

TCE

TOD

VOC

$\mathrm{wt} \%$

yds

ZVI

$\rho_{b}$

$\gamma-\mathrm{FeOOH}$

$\alpha-\mathrm{FeOOH}$

$\theta_{\mathrm{w}}$

$\mu \mathrm{g} / \mathrm{L}$
Air Force Center for Environmental Excellence

Contaminant of concern

Contaminant concentration in soil

Cubic

chlorinated volatile organic compound

contaminant concentration in groundwater

dense nonaqueous phase liquid

U.S. Department of Energy

DOE Office of Groundwater and Soil Remediation

fiscal year

Gallon

gallons per minute

hydrogen peroxide

Interstate Technology and Regulatory Council

partition coefficient of a contaminant between soil and groundwater potassium permanganate

laser induced fluorescence

membrane interface probe

manganese dioxide

mean sea level

sodium permanganate

nonaqueous phase liquid

Ohio Environmental Protection Agency

Portsmouth Gaseous Diffusion Plant

partitioning interwell tracer test

Portsmouth Paducah Project Office

permeable reactive barrier

preliminary remediation goal

Resource Conservation and Recovery Act

Remediation Technologies Development Forum

Trichloroethene

total oxidant demand

volatile organic contaminant

percent by weight

Yards

zerovalent iron

soil bulk density

Lepidocrocite

Goethite

soil porosity

micrograms per liter 


\section{Executive Summary}

An independent technical review funded by the Department of Energy (DOE) Office of Environmental Management (EM-22) and organized by the DOE-EM Center for Sustainable Groundwater and Soil Solutions was held at the Portsmouth Gaseous Diffusion Plant (PGDP) in November 2008. The review workshop was convened at the request of the DOE Portsmouth Paducah Project Office (PPPO) and was focused on evaluation of the ongoing X-701B groundwater remedy for trichloroethene (TCE) contaminated groundwater and sediment. The remedial activities for the X-701B plume are divided into four phases: Phase I - Initial Source Area Treatment, Phase II Expanded Source Area Treatment, Phase III - Evaluation and Reporting, and Phase IV Downgradient Remediation and Confirmation of Source Area Treatment. Phase I of the remedy was completed during FY2006. DOE has now completed six oxidant injection events within Phase II.

The technical review team comprised a cross section of representatives with backgrounds in industry, universities, federal agencies, and laboratories, and with particular knowledge about in situ oxidation technology. During the first day of the review, the technical review team members visited the field site and conducted a full day of discussions with site technical and regulatory personnel. The team also reviewed applicable regulatory documents, numerous site reports documenting remedial actions at the site, as well as reports from other technology pilots that were conducted at the X-701B site and other sites at PGDP. The charter for the review team defined three major activities: 1) assess the performance of an ongoing oxidant-based treatment technology that uses lances to inject catalyzed hydrogen peroxide, 2) provide specific recommendations for PPPO and the Ohio Environmental Protection Agency (OEPA) to consider if oxidant injections are to be continued, and 3 ) provide recommendation of alternatives to the current remediation strategy for the X-701B plume. These three topics are addressed below.

\section{Assess the performance of ongoing oxidant-based treatment}

Injections of catalyzed hydrogen peroxide have been completed during six Phase II injection events. Currently, PPPO and OEPA are evaluating the effectiveness of these hydrogen peroxide injections towards achieving the preferred remediation goal of reducing groundwater TCE concentrations to less than $5 \mu \mathrm{g} / \mathrm{L}$ or an alternate remediation goal such that the remedy is determined to be "no longer effective." It should be noted that the second criterion, lack of effectiveness, indicates that continued injection of catalyzed hydrogen peroxide is not warranted and further indicates that alternative actions will be needed to achieve remediation goals.

During the first five rounds of Phase II catalyzed peroxide treatment (Phase IIa through IIe), the mass of TCE in the middle and upper Gallia source zone significantly decreased as a result of the oxidant injection - indicating measurable progress in the remediation. This decrease was considered a positive impact and is the net result of oxidation/destruction, displacement and gas stripping of dissolved TCE, and coalescence and mobilization of separate phase TCE (i.e., NAPL). However, the mass of TCE in the lower Gallia (near the contact with the underlying Sunbury Shale) was unchanged overall 
and increased in some areas. Groundwater concentrations were unchanged (or trended upward) after each Phase II injection, and all measurements of TCE in the groundwater were 100 to 10,000 times greater than the remediation goal of $5 \mu \mathrm{g} / \mathrm{L}$. The review team recognizes that groundwater concentration is a trailing indicator and contaminant concentrations often increase temporarily during source remediation using oxidants or other reagents. The team determined that the quantity of oxidant injected during the Phase I pilot and the subsequent five Phase II injections was significantly less than the amount required to meet the measured soil oxidant demand. The team concluded that the rapid decomposition of hydrogen peroxide and limited injection volumes hindered progress toward remediation goals.

Based on the preponderance of all of the data - groundwater and soil data, combined with technical and engineering estimates of the oxidant requirement, pore volumes of oxidant injected, potential gas production, and other factors - the technical review team determined that the criteria for completing Phase II have not been met, and that continuation of the current Phase II technology, lance injection of catalyzed hydrogen peroxide, is unlikely to achieve the desired remedial goals.

\section{Develop specific recommendations for PPPO and OEPA to consider if oxidant injections are continued}

The team recommended that longer lived oxidants such as permanganate or persulfate be considered, as well as alternative deployment methods, such as direct blending or injection of high strength oxidant solutions into specific zones to target the remaining source TCE. The team provided a related set of recommendations encouraging the use of innovative characterization tools to refine the target zones where large amounts of TCE solvent potentially remain. Completion of high-resolution characterization could potentially result in significant cost savings by delineating smaller regions for targeted oxidant injections or for application of other remediation methods that may be selected to address this type of high strength TCE source.

3. Provide recommendations of alternatives to the current remediation strategy for the $X$ $X-701 B$ plume

The team evaluated several classes of technologies including in situ oxidation, pump and treat, in situ thermal, excavation, surfactant and cosolvent flushing, permeable reactive barrier, bioremediation and constructed wetland, and physical, hydraulic and chemical isolation/immobilization. A scenario for each technology, along with estimated costs, was prepared for application to the X-701B site. For each technology and scenario, the team identified strengths and weaknesses, and developed an overall statement on the relative applicability for the technology at X-701B (used alone or in combination with other methods). The team determined that if these technologies are used alone, they would be unlikely to achieve remedial objectives in a timely manner. The technical review panel recommended that the Portsmouth team consider a combination of technologies that would work synergistically together. The idea of a "combined remedy" is particularly attractive at this site where the different plume segments (separate phase, high concentration dissolved phase, low concentration dissolved phase concentration) can be reasonably identified and targeted. 
The panel strongly recommended that Portsmouth consider implementation of several specific technologies to optimize active remedial systems; some of these at a relatively small marginal cost. Notably, the panel recommended a modification to the current pump and treat system in which the extraction wells would be moved further downgradient. The extraction wells currently intercept water flowing into the upgradient edge of the plume thereby capturing mostly clean water and limiting the capture of TCE containing water. Moving the extraction wells downgradient would increase the capture of water after it flows through the source zone and could potentially increase the TCE extraction rate from $60 \mathrm{lbs}$ per year to over $300 \mathrm{lbs}$ per year. In a few instances, technologies were determined to be minimally effective for any implementation scenario at this site. For example, given that groundwater recharge through $\mathrm{X}-701 \mathrm{~B}$ pond and basins is relatively small, isolation and immobilization methods, including surface capping of the former X-701B pond and nearby basins, would have minimal impact on, and no clear benefit to, the remediation of the X-701B groundwater plume. In cases such as this, the team recommended one or more technology alternatives that would accelerate progress toward remedial objectives at a similar cost. In this example, the alternative to a surface cap was blending solid oxidant into the subsurface beneath the former basin to remove any residual TCE.

One example of a combined remedy would include soil blending of oxidant in the former basin, focused DNAPL characterization, targeted injection of a long-lived oxidant solution, and relocation of the pump-and-treat extraction wells. This combination of technologies could be used to reduce source mass and dissolved plume concentrations and flux, followed by future transition to a passive technique such as a PRB or wetland.

The general consensus of the technical review team was that success in achieving remedial objectives for the X-701B plume is possible. The timeframe for that success, however, may be many decades rather than a few years. Decisions related to the selection of technologies will hinge on the short vs. long term costs. For example: What is the cost benefit realized by completing a high-cost remediation in 1 to 2 years versus a lower-cost remedy that may require 20 to 30 years to achieve similar contaminant concentrations and risk reduction? How does this relate to natural resource availability or damage? What actions are needed to demonstrate that DOE is willing and able to repair damages in a timely fashion? The summary assessments and input provided in this report were aimed at supporting the Portsmouth team in its efforts to address these difficult questions. 
\{blank page\} 


\section{$1.0 \quad$ Introduction}

The Department of Energy Portsmouth Paducah Project Office requested assistance from Department of Energy Office of Environmental Management (EM-22) to provide independent technical experts to evaluate past and ongoing remedial activities at the Portsmouth facility that were completed to address TCE contamination associated with the X-701B groundwater plume and to make recommendations for future efforts.

The Independent Technical Review team was provided with a detailed and specific charter. The charter requested that the technical team first review the past and current activities completed for the X-701B groundwater remedy for trichloroethene (TCE) in accordance with a Decision Document that was issued by Ohio EPA on December 8, 2003 and a Work Plan that was approved by Ohio EPA on September 22, 2006. The remedy for X-701B divides the activities into four phases: Phase I - Initial Source Area Treatment, Phase II - Expanded Source Area Treatment, Phase III - Evaluation and Reporting, and Phase IV - Downgradient Remediation and Confirmation of Source Area Treatment. Phase I of the remedy was completed during FY2006, and DOE has now completed six oxidant injection events within Phase II.

The Independent Technical Review team was asked to evaluate Phase II activities, including soil and groundwater results, and to determine whether or not the criteria that were defined in the Work Plan for the Phase II end point had been met. The following criteria are defined in the Work Plan as an acceptable Phase II end point: (1) Groundwater samples from the identified source area monitoring wells have concentrations below the Preliminary Remediation Goal (PRG) for TCE in groundwater, or (2) The remedy is no longer effective in removing TCE mass from the source area.

In addition, the charter specifies that if the Review Team determines that the Phase II endpoint has not been reached, then the team should address the following issues:

- If additional injection events are recommended, the team should identify the type of injection and target soil horizon for these injections.

- Consider the feasibility of declaring Technical Impracticability and proceeding with the RCRA Cap for the X-701B.

- Provide a summary of other cost-effective technologies that could be implemented (especially for the lower Gallia).

The Independent Technical Review team focused its evaluation solely on the X-701B source zone and contaminant plume. It did not review current or planned remedial activities at other plumes, waste areas, or landfills at the Portsmouth site, nor did it attempt to integrate such activities into its recommendations for X-701B. However, the ultimate selection of a remedy for X-701B by site personnel and regulators should take into account potentially synergistic efforts at other waste areas. Assessment of remedial alternatives in the context of site-wide management practices may reveal opportunities for leveraging and savings that would not otherwise be identified. For example, the cost 
of source-zone excavation or construction of a permeable reactive barrier at X-701B might be substantially reduced if contaminated soil could be buried on site at an existing or planned landfill. This allowance would improve the feasibility and competitiveness of both remedies. A comprehensive examination of ongoing and future environmental activities across the Portsmouth Gaseous Diffusion Plant is necessary to optimize the selection and timing of X-701B remediation with respect to cleanup efficiency, safety, and economics.

A selected group of technical experts attended the technical workshop at the Portsmouth Gaseous Diffusion Plant from November 18 through 21, 2008. During the first day of the workshop, both contractor and DOE site personnel briefed the workshop participants and took them on a tour of the X-701B site. The initial briefing was attended by representatives of Ohio EPA who participated in the discussions. On subsequent days, the team reviewed baseline data and reports, were provided additional technical information from site personnel, evaluated work plans, determined critical issues and uncertainties, and recommended alternatives. This report documents the findings and recommendations of the independent technical review team. 


\subsection{Background}

\subsection{Review of Decision Documents}

The charter for the technical review specifically identified two key decision documents that address remedial actions at the X-701B site. These documents have descriptions of both the Remedial Action Objectives and the specific criteria for determining acceptable Phase II end points.

Section 5.6.2 of the Ohio EPA Decision Document for X-701B (2003) establishes the following Remedial Action Objectives (RAOs) for the groundwater remedy:

1. Achieve Preliminary Remediation Goals (PRGs) for groundwater when practicable.

2. Prevent migration of chemicals of concern (COCs) at concentrations exceeding PRGs from groundwater into surface water.

3. Prevent exposure of future off-site residents to COCs in groundwater at concentrations exceeding residential PRGs through potential exposure pathways.

4. Prevent exposure of on-site personnel to COCs in groundwater at concentrations exceeding future on-site worker PRGs through potential exposure pathways.

Section 3.2.3.1 of the Work Plan for the Groundwater Remediation at the X-701B SWMU (2006) contains specific criteria for the Phase II end point. Phase II injections will continue until at least one of the following criteria is met:

1. Groundwater samples from the identified source area monitoring wells are below the PRG of $5 \mu \mathrm{g} / \mathrm{L}$ for TCE in groundwater, or

2. The remedy is no longer effective in removing TCE mass from the source area.

The Work Plan further identifies the following two processes that are to be used to determine when the remedy is no longer effective in removing TCE mass:

a) TCE concentrations in soil are less than the soil PRG of $48 \mu \mathrm{g} / \mathrm{kg}$, or

b) A smooth curve of the average TCE concentration in soil over time shows less than a $10 \%$ change between the last two injection events.

In addition, the Work Plan provides the option of partitioning the source area for the purpose of applying either process $2 \mathrm{a}$ or $2 \mathrm{~b}$ for determining when the remedy is no longer effective. When either process $2 \mathrm{a}$ or $2 \mathrm{~b}$ is satisfied for the selected portion of the source area, then criterion 2 above will be achieved for that portion of the source area, and Phase II injections will cease for that portion. 


\subsection{Site Conceptual Model}

Conceptually, the contaminant hydrology of the X-701B area is relatively straightforward (Figure 1). Trichloroethene (TCE) was the primary contaminant in the various types of disposed wastes. TCE is an industrial solvent that is considered a DNAPL (dense nonaqueous phase liquid) because of its limited aqueous solubility and density greater than that of water. The primary sources of contamination were associated with processes and waste disposal activities at the X-701B basin and nearby facilities. Contamination from these source(s) penetrated the Minford Silt and Clay Member of the Teays Formation, a fine grained lacustrine deposit consisting of silt, clay, and fine sand. The water table occurs in the Minford so that the uppermost portion of this unit is partially saturated and the lower part is saturated. As depicted in Figure 1, contaminant migration in the Minford was predominantly downward penetrating into another unconsolidated unit, the Gallia Sand and Gravel Member of the Teays Formation.

The Gallia is a fluvial deposit consisting of red-brown sands and clayey sand, poorly sorted gravel, and pebble size cobbles and fragments. Undissolved DNAPL solvent reaching the Gallia formed separate phase fingers that migrated downward until they encountered the first "bedrock" layer, the Sunbury Shale. As the DNAPL migrated downward through the Gallia, it left a strong residual source in the form of trapped and isolated solvent ganglia - this source material occurs primarily beneath the original release location(s). DNAPL solvent that reached the Sunbury Shale formed a thin layer and migrated along the upper Sunbury surface, controlled by the structure and topography of the surface toward areas of lower elevation or structural depressions. The uppermost portion of the Sunbury is weathered, allowing limited penetration and emplacement of a persistent source in the upper Sunbury wherever DNAPL has migrated along the contact between the lower Gallia and upper Sunbury formations.

Consistent with this conceptual understanding of DNAPL at this site, the three target zones where significant DNAPL source is expected to be found are designated by red dashed lines in Figure 1b. A high concentration dissolved plume (designated by green dashed lines in Figure 1b) would emanate from these source zones. Groundwater in this area migrates naturally toward the nearby Little Beaver Creek, and currently flows toward an interceptor trench installed upgradient of Little Beaver Creek. In a thin, moderately permeable aquifer such as the Gallia, with groundwater flowing toward a local discharge, the dissolved plume would be expected to have minimal dispersion, forming a concentrated and narrow plume (Figure 2). This plume shape is further defined by the structure of the upper surface of the Sunbury Shale.

The review team was provided a set of data that were collected in an informal study in 2001 by the site contractor that was focused on identifying the elevation of the top of the Sunbury shale. The elevation of the horizon identified as the top of the Sunbury was identified in the X-701B at elevations ranging from 635 to 645 above mean sea level. Although the data set did not provide sufficient data in the X-701B area to resolve the detailed topography of the surface of the Sunbury, the surface appears to be relatively 
high to the south and west of the basin (greater than $640 \mathrm{ft} \mathrm{msl}$ ) and relatively lower to the east of the basin. The limited data suggest the possibility of topographic lows towards the east. These features likely represent original structure as influenced by historical interaction of the concentrated plume with the underlying shale surface. Such topographic lows would serve to control the migration and local accumulation of the DNAPL source materials toward the east. This migration path located at the top of the Sunbury appears to be coincident with the centerline of the plume and the identified X701B source area (Figure 3).

The structural control exerted by the topography of the top of the Sunbury Shale in the conceptual model highlights the importance of accurate mapping of the potential migration pathway(s) for DNAPL near the X-701B source. Structural information, combined with detailed three dimensional concentration data, can serve to focus any future remediation activities to the most promising target regions. Consequently, the technical review team recommends that Portsmouth assemble available geologic characterization data from the X-701B area and supplement it as needed to develop a robust and well supported structure contour map of the top of the Sunbury shale.

The description above is consistent with the prevailing site conceptual model and identical to the conceptual model used in 2002 when options for source treatment were being developed by DOE and its support contractors in collaboration with Ohio and federal regulators. The technical review panel revisited this model and discussed the potential need for refining it with more detailed and nuanced processes (such as potential impacts of co-disposed aqueous wastes). After much discussion, the panel consensus was that the current conceptual model is reasonable and that the site data do not support substantive modification. Further, the review team did not believe that any potential conceptual model refinements would alter the current assessment and decision process related to TCE source and plume treatment. 


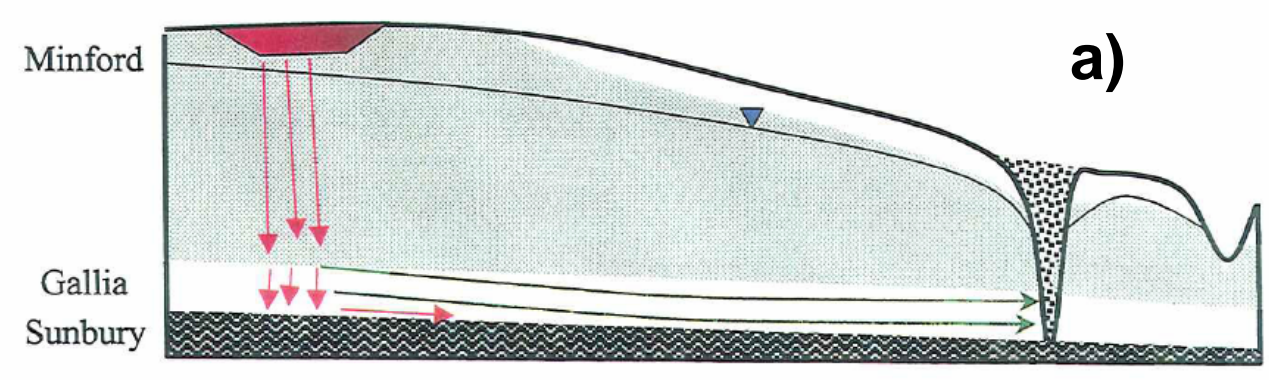

Source

(Minford)

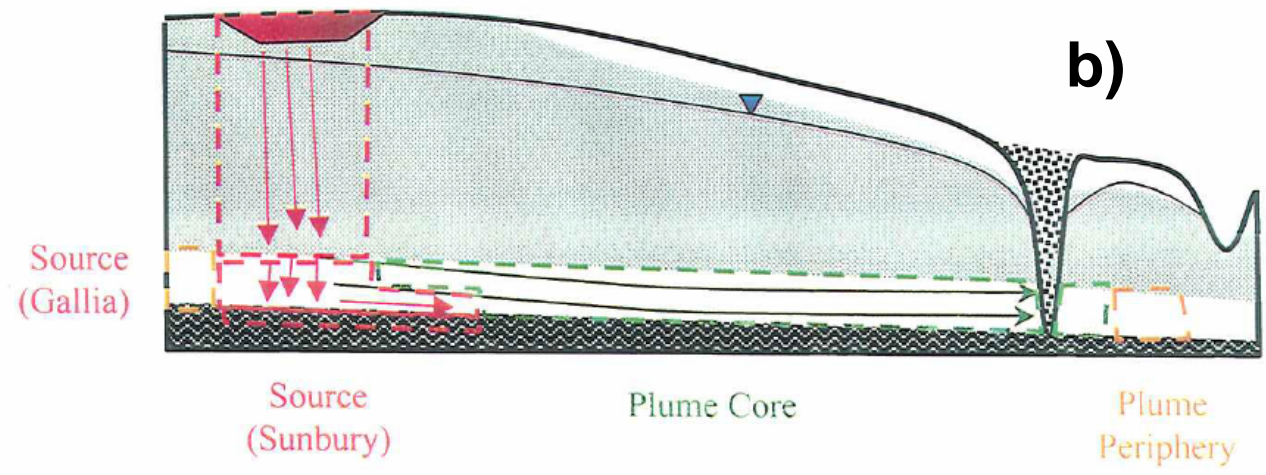

Figure 1. Conceptual model of the contaminant hydrogeology for the X-701B Area of the Portsmouth Gaseous Diffusion Plant. a) schematic diagram, b) annotated diagram delineating target TCE sources (red) and groundwater (green) 

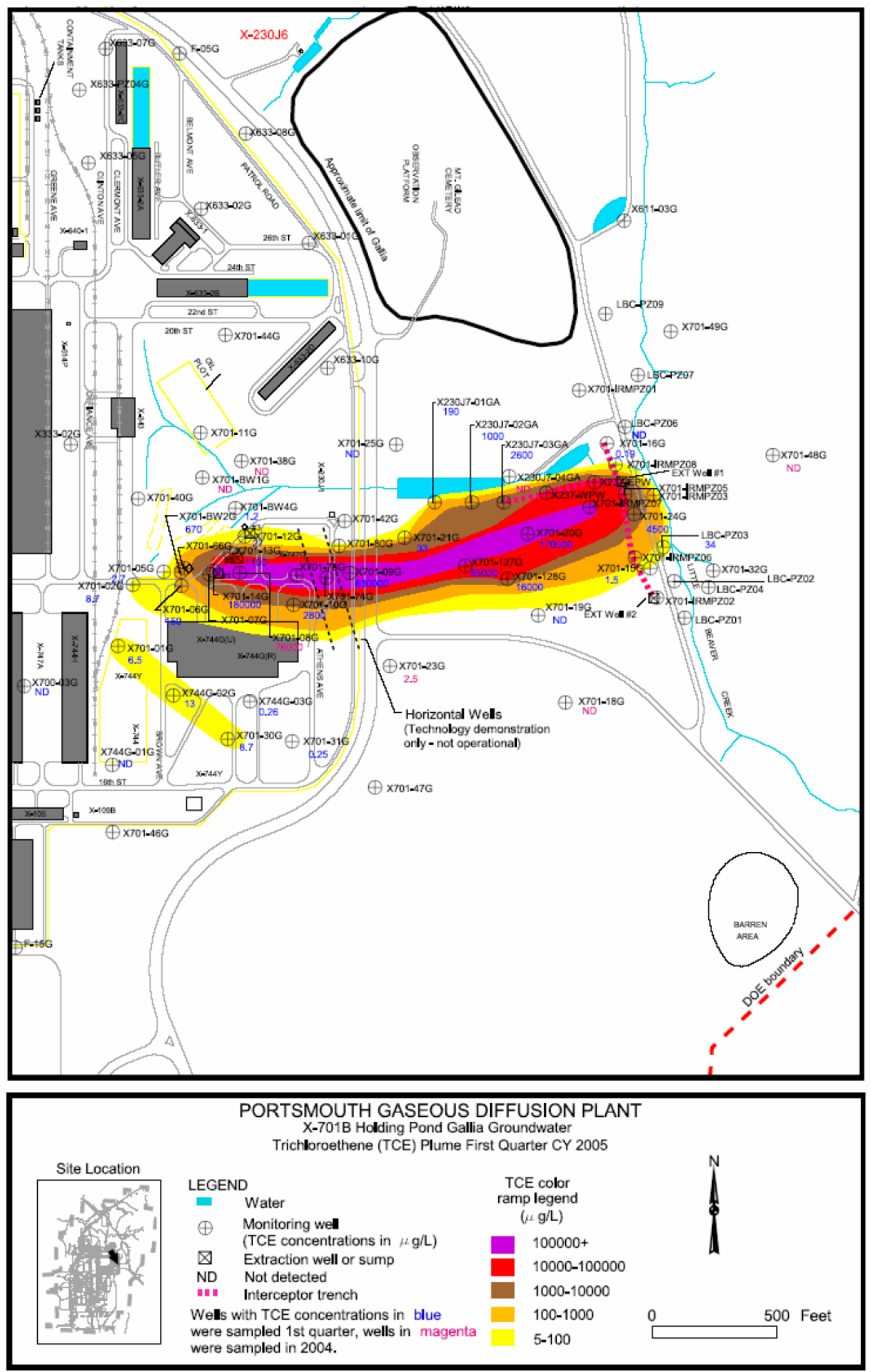

Figure 2. X-701B Area of the Portsmouth Gaseous Diffusion Plant - TCE Plume in the groundwater of the Gallia Member 


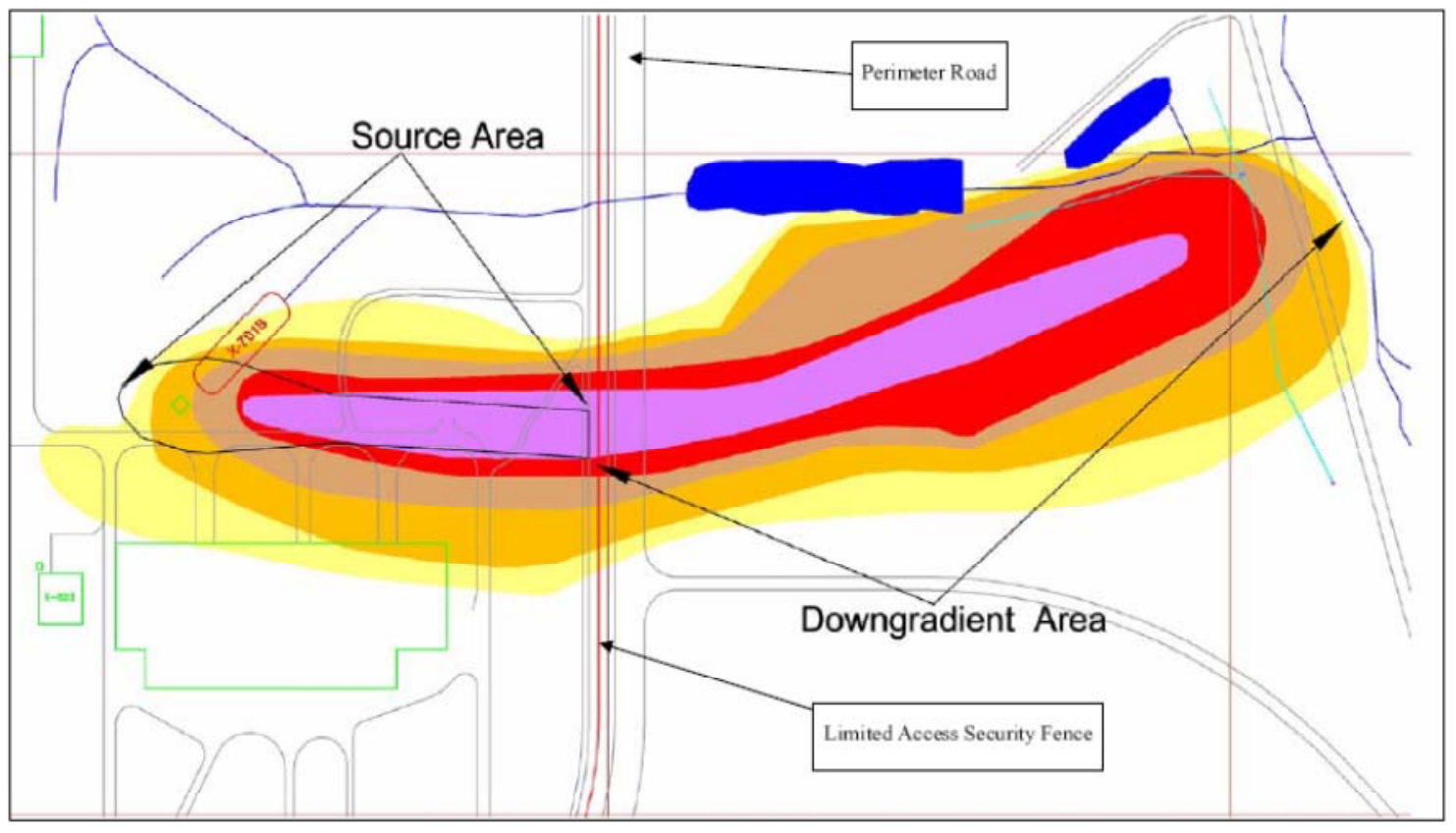

Figure 3. Major divisions within the TCE plume in the X-701B Area of the Portsmouth Gaseous Diffusion Plant (contour colors defined in Figure 2). 


\subsection{Review of Phase II Oxidant Treatment Operations and Performance}

\section{Overview}

As described in the work plan, Phase II of the oxidant operations will be complete when:

1. Groundwater samples from source area monitoring wells are below the PRG of $5 \mu \mathrm{g} / \mathrm{L}$

or

2. The remedy is no longer effective as determined by:

a. TCE in soil is less than $48 \mu \mathrm{g} / \mathrm{kg}$, or

b. A smooth curve of average TCE over time shows less than a $10 \%$ change between the last 2 injection events

During Phase II, TCE mass in the middle and upper Gallia source zone decreased as a result of the oxidant deployment. This decrease was considered a positive impact and is the net result of oxidation, displacement and gas stripping of dissolved TCE and coalescence and mobilization of DNAPL TCE.

Based on groundwater and soil data, combined with technical and engineering estimates of the theoretical oxidant requirement, pore volumes injected, potential gas production, and other factors, the technical review team determined that the criteria for completing Phase II have not been met, and that continuation of the current Phase II technology, lance injection of catalyzed hydrogen peroxide, is unlikely to achieve the desired PRGs. The supporting data analysis and discussion are in the following sections.

\subsection{Conceptualization of Lance Injection Process}

Lance based injection of catalyzed hydrogen peroxide was selected as the method for delivering the oxidant to treat the TCE source area in the X-701B plume at Portsmouth. This approach was selected over alternative oxidant methods such as flushing the source zone with longer-lived oxidants (e.g., persulfate or permanganate). The peroxide system was determined to be less costly, primarily due to the elimination of infrastructure needed for flushing and hydraulic control. Lance based injection of catalyzed hydrogen peroxide has been successfully applied at a number of sites and is a defensible strategy, but the complex multiphase behaviors during deployment in a heterogeneous environment introduce uncertainties. Moreover, the short lifespan of catalyzed hydrogen peroxide means that only TCE directly contacted by peroxide is destroyed which leaves the potential for TCE leaching from uncontacted sources (such as the Sunbury Shale and the Minford Member) to impact the groundwater plume. Some of these topics are conceptually depicted in Figure 4. 


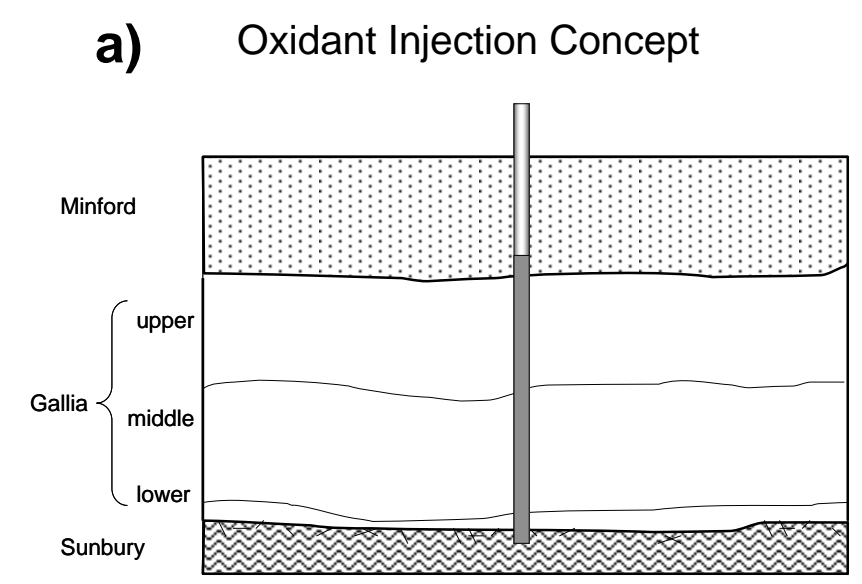

b) Heterogeneity Impact on Reagent

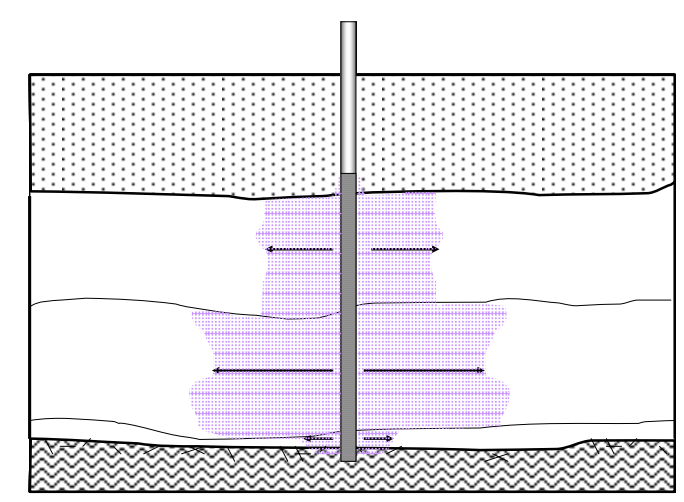

c) Water, Gas and DNAPL Movement
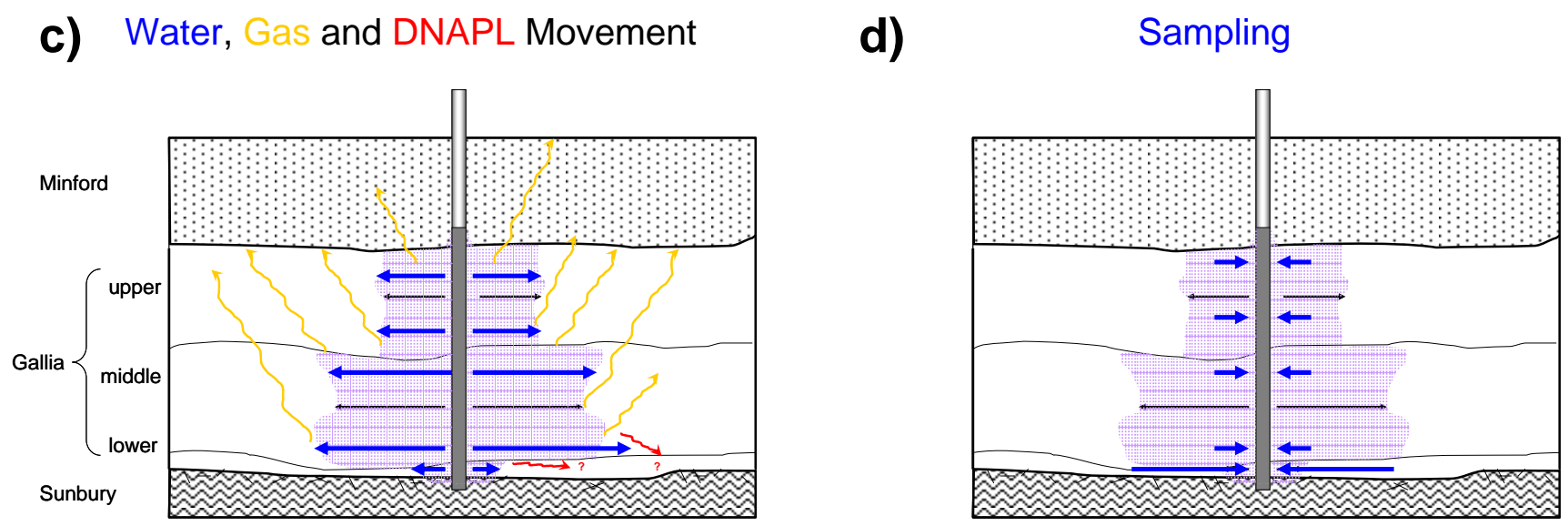

Figure 4. Simplified conceptualization of Phase II oxidant deployment. a) lance geometry, b) heterogeneous reagent spread, c) behaviors of various phases, d) sampling 
Figure 4a provides an approximate diagram of the geometry for an individual lance injection targeting a zone extending from the upper Sunbury Shale, through the Gallia Member and into the Minford Member. As shown in Figure 4b, reagent will preferentially enter more permeable materials (note that this figure is illustrative and the nature and pattern of preferential flow will vary from one location to another). A complication that is not depicted in Figure $4 \mathrm{~b}$ is the sequential injection of catalyst solution and peroxide (with water flushes) in each lance - this adds additional complexity related to subsurface mixing and the ability to reliably mix catalyst, oxidant, and contaminant for the desired destruction reactions to occur.

The most significant issues associated with lance injection of catalyzed hydrogen peroxide are depicted in Figure 4c. This panel highlights the difficulty in understanding and controlling the process to achieve the coincidence of catalyst-oxidant-contaminant described above. The flush of reagents (e.g., water-oxidant-water-catalyst-water) will displace dissolved TCE. The short-lived peroxide-catalyst reaction reacts aggressively in the formation and generates gas and heat. The gas generated will also displace and strip TCE. A simplified calculation (assuming that one mole of gas is generated per mole of peroxide added) suggests that approximately one pore volume of gas was generated based on the total hydrogen peroxide injected during the Phase II deployments to date. These various processes (pressure, heat, etc.) also have the potential to mobilize DNAPL and allow it to coalesce and migrate to a new location. A potential benefit of the vigorous nature of the reaction and gas generation is that the process would provide some mixing that would help the reagents move into a larger volume of the formation - increasing the treatment effectiveness for any TCE that was not displaced.

One aspect of the conceptualization shown in Figure 4 that the technical review panel could not fully explain was the impact of the injections on the follow-on groundwater sampling. As discussed below, the post injection samples appear to be most representative of the lowermost portion of the Gallia Member (Figure 4d) while the most significant concentration reductions in the soil samples occurred in the upper and middle portions of the Gallia. The panel developed a variety of hypotheses for this observation but could not objectively determine a clear conceptual basis for the observed behaviors related to sampling/monitoring.

\subsection{Groundwater and Soil Data}

The Phase IIc Report (2007) and data provided for Phase IId and IIe showed equivocal results for the injections; some of the results were positive $(+)$ while others were negative $(-)$ :

- None of the groundwater monitoring results for TCE in the source area was below the PRG of $5 \mu \mathrm{g} / \mathrm{L}$. (-)

- Groundwater monitoring results for uranium, technetium $\left({ }^{99} \mathrm{Tc}\right)$ and hexavalent chromium $\left(\mathrm{Cr}^{+6}\right)$ show that the concentration of these metals has remained below their respective PRGs. $(+)$ 
- Some soil samples from isolated locations showed progress toward the Phase II endpoints [S-02 (progress toward 2a) and S-01, S-02, S-05 and S-06 (progress toward $2 b)] .(+/-)$

-Within the entire soil data set, several individual samples are below the PRG for TCE in soil $(48 \mu \mathrm{g} / \mathrm{kg})$ and several locations show a downward trend in concentration, but most of these samples are in the upper and middle Gallia. The underlying lower Gallia samples remain high (typically unchanged or increasing concentrations) so that continued treatment would be needed in almost all locations. $(+/-)$

These trends are more clearly demonstrated using a transect of soil and groundwater samples down the centerline of the plume and comparing the pre-oxidant data to the data collected after the latest round of injections (Phase IIe). As shown in Figure 5, the soil sample transect includes S-01, S-06, S-08, S-14, S-16 and the equivalent groundwater transect includes monitoring wells BW2G, 131G, 133G, 78G, 74G. Note that the soil samples were collected at three depths within the Gallia Member (upper, middle and lower) while the groundwater wells were fully screened throughout this zone.

Figure 6 visually documents the impact of five rounds of oxidant injection on the soil concentrations in the various intervals of the Gallia Member. Note that the y-axis (TCE concentration) in Figure 6 is a log scale so that small changes in the vertical position of the graph represent relatively large concentration changes. Two reference lines are provided to assist in the interpretation. The upper reference line is at a typical Phase II baseline soil concentration of approximately $10,000 \mu \mathrm{g} / \mathrm{kg}$ and the lower reference line is approximately positioned to represent the soil PRG of $48 \mu \mathrm{g} / \mathrm{kg}$. The centerline transects indicate that soil concentrations have decreased in both the upper and middle Gallia. As noted above, the soil concentrations in some upper and middle Gallia locations meet the soil PRG following oxidant Phase IIe. Note however, that the lower Gallia soil transects show some reductions near S-08 and S-14 but the other soil borings increased - notably near the distal portion of the transect. This suggests the potential that source TCE may have redistributed as a result of remediation-induced mobilization and displacement. In the soil transects, particularly in the lower Gallia, there has been significant variability in contaminant concentration from round to round. This makes determination of the Phase II endpoint criterion related to a soil concentration plateau difficult to document or justify.

Figure 7 provides data for the equivalent baseline and post oxidant Phase IIe groundwater transects. In this case, the upper and lower guidelines are at approximately $10,000 \mu \mathrm{g} / \mathrm{L}$ and the groundwater PRG of $5 \mu \mathrm{g} / \mathrm{L}$ (the technical review team noted that the soil and groundwater PRGs are not consistent since soil containing $48 \mu \mathrm{g} / \mathrm{kg}$ TCE located below the water table would result in groundwater concentrations 10 to 30 times the groundwater PRG). The most significant observation for the groundwater is that hydrogen peroxide injections have not decreased TCE concentrations toward the groundwater PRG. As noted by Portsmouth comments on a draft of this report, groundwater concentration is a trailing indicator and contaminant concentrations often increase idiopathically and temporarily during source remediation using oxidants or other 
reagents (e.g., for bioremediation). The review team acknowledges this phenomenon. Concentrations in the distal portion of the transect are increasing and appear to track the soil concentrations in the lower portion of the Gallia. Further, the groundwater concentrations are consistent with levels that would be expected from water in contact with soil at the concentrations measured in the lower Gallia and are substantially higher than water in contact with the upper and middle Gallia. Since the wells are screened throughout the aquifer, the technical review panel concluded that the samples from these wells may preferentially sample the lower Gallia. While this preferential sampling could result from a number of mechanisms (e.g., gas trapped in the middle and upper Gallia), the team did not have sufficient data to determine a clear explanation. Following Phase IIe, all of the groundwater samples on the centerline transect exceeded the groundwater PRG by a factor of more than 100 and several samples exceeded the PRG by a factor of 10,000 .

Based on the TCE concentrations in groundwater and soil samples from the lower Gallia, the technical review team performed a scoping calculation to identify areas that would potentially have TCE DNAPL following Phase IIe injections. For this evaluation, the method of Feenstra et al. (1991) was used and the designation of suspect DNAPL locations was determined using the following equation:

$$
C_{s}^{i}=\frac{C_{w}^{i}\left(K_{d}^{i} \rho_{b}+\theta_{w}\right)}{\rho_{b}}
$$

where $\mathrm{C}_{\mathrm{s}}$ and $\mathrm{C}_{\mathrm{w}}$ are the co-located soil and groundwater concentrations, respectively, and $\mathrm{K}_{\mathrm{d}}, \rho_{\mathrm{b}}$ and $\theta_{\mathrm{w}}$ are the partition coefficient, soil bulk density and porosity, respectively (all in traditional units). A location was designated as a suspect TCE DNAPL source location if the $\mathrm{C}_{\mathrm{s}}$ calculated from this equation based on the measured groundwater concentration was substantively less than the measured $\mathrm{C}_{\mathrm{s}}$ for a particular location. All of the source area wells were evaluated and Table 1 summarizes the wells/boreholes where the calculated soil concentration was similar to or less than the measured soil concentration. These locations are mapped in Figure 8. Note that following the Phase IIe injection, suspected DNAPL source is identifiable in the lower Gallia formation from the mid-spoon area toward the horizontal wells. If the DNAPL is confirmed using the characterization techniques described above, these areas would be appropriate to target by injecting long-lived oxidants into the deep Gallia near the contact with the Sunbury Shale. 


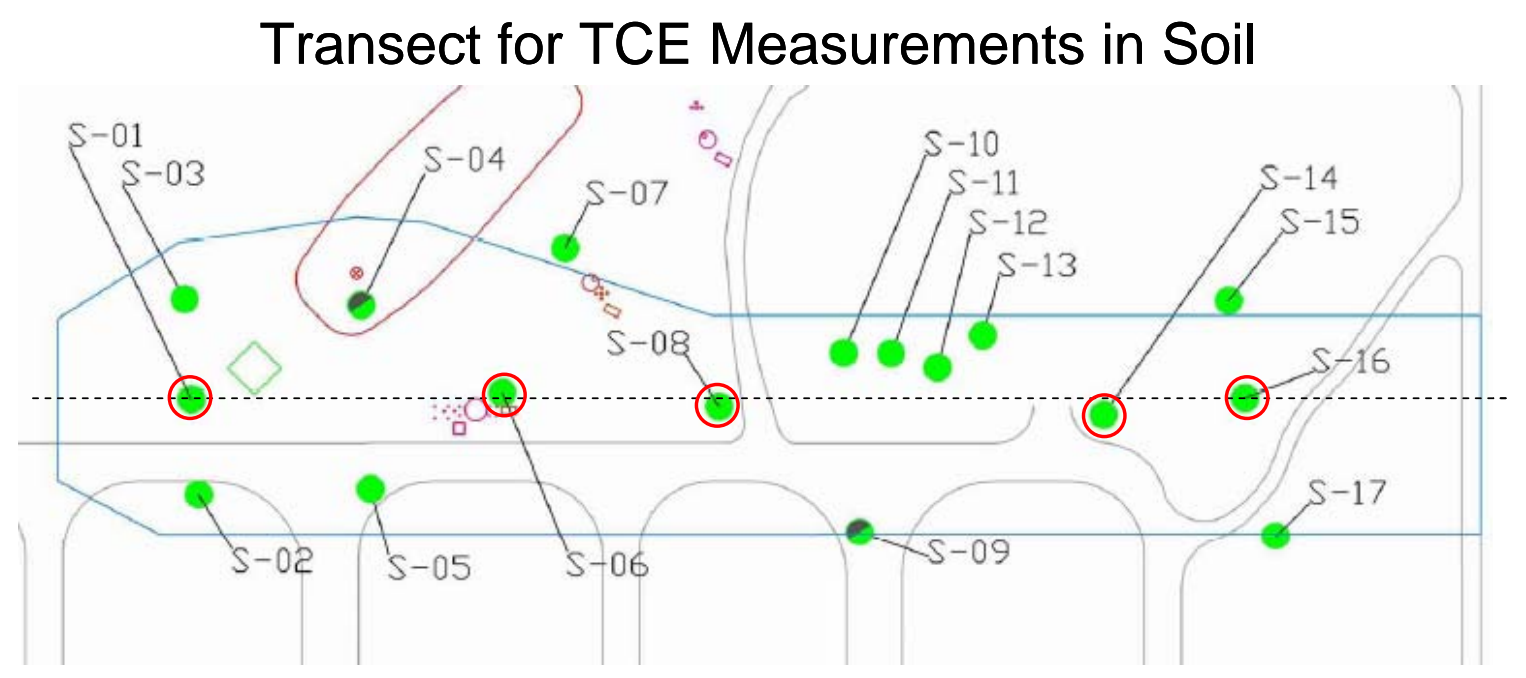

\section{Transect for TCE Measurements in Groundwater}

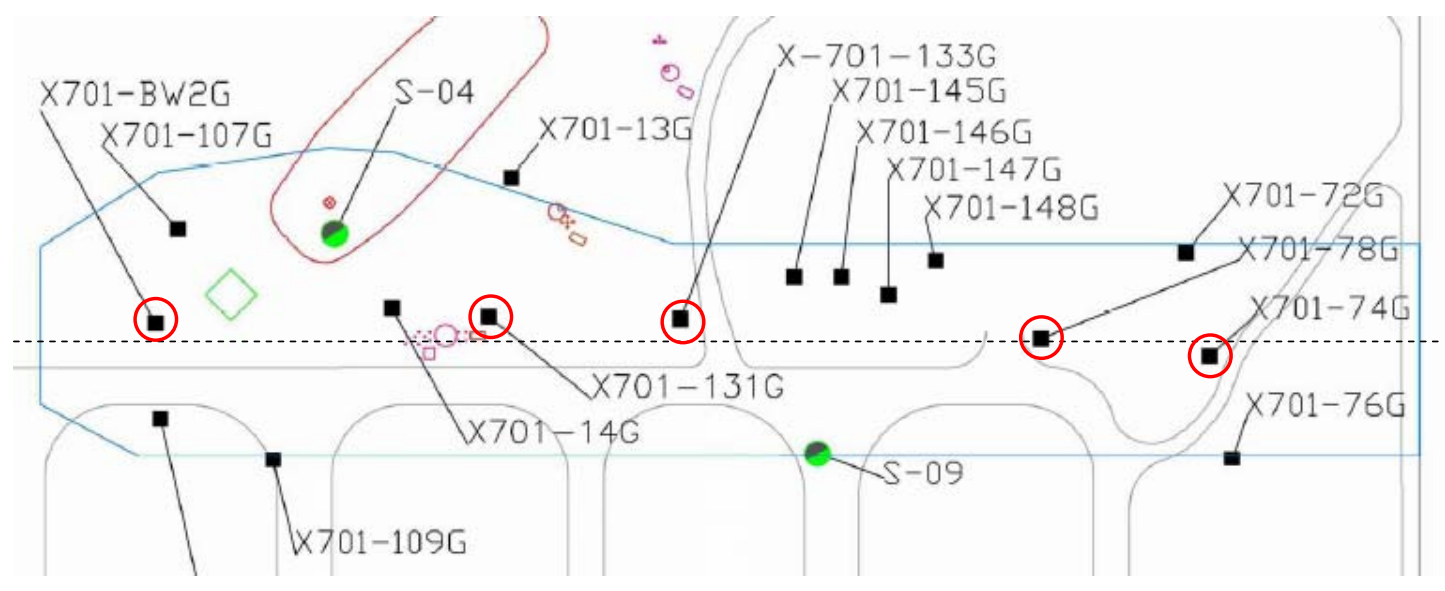

Figure 5. Location of transects used to evaluate soil and groundwater data 


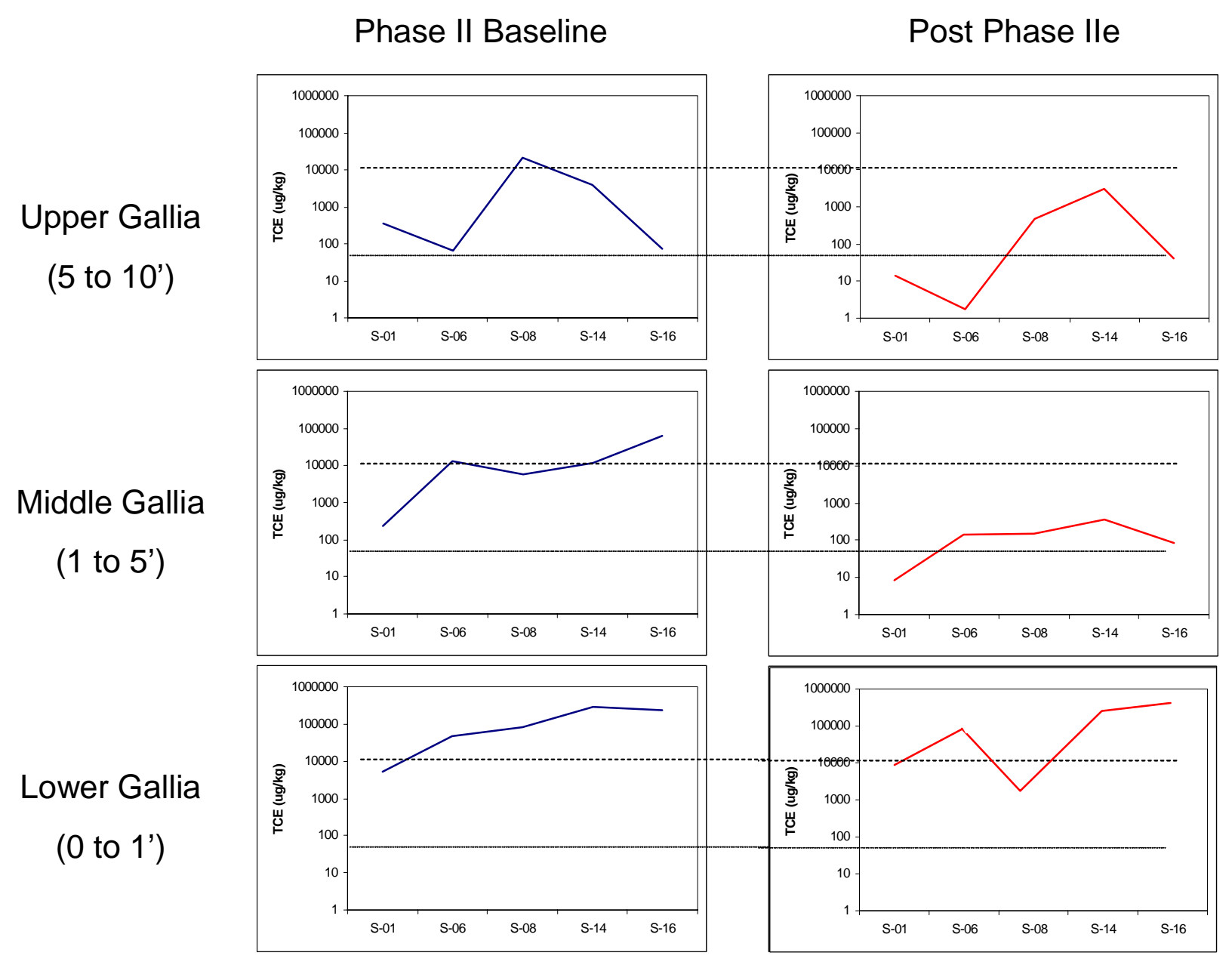

Figure 6. Soil concentration transects in the upper middle and lower Gallia from baseline data and samples collected after five rounds of Phase II oxidant injection. Guidelines are provided at approximately $10,000 \mu \mathrm{g} / \mathrm{kg}$ and at the soil PRG of $48 \mu \mathrm{g} / \mathrm{kg}$

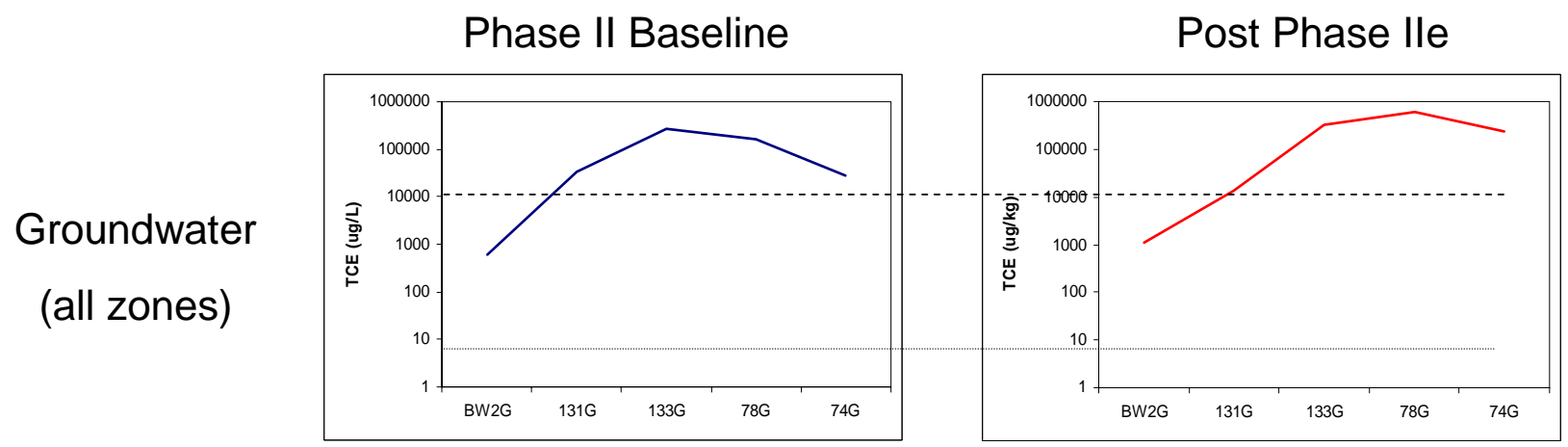

Figure 7. Groundwater concentration transects in the Gallia from baseline data and data collected after five rounds of Phase II oxidant injection. Guidelines are provided at approximately $10,000 \mu \mathrm{g} / \mathrm{L}$ and at the groundwater PRG of $5 \mu \mathrm{g} / \mathrm{L}$ 
Table 1. Suspect DNAPL scoping calculation (includes source wells where the soil concentration calculated from the groundwater is similar to or less than the measured soil concentration)

\begin{tabular}{|c|c|c|c|c|c|c|}
\hline $\begin{array}{c}\text { Monitoring } \\
\text { Well }\end{array}$ & $\mathrm{Cw}(\mathrm{mg} / \mathrm{L})$ & $\begin{array}{c}\text { Soil } \\
\text { Sample }\end{array}$ & $\mathrm{Cs}(\mathrm{mg} / \mathrm{kg})$ & $\begin{array}{c}\text { Calculated } \\
\text { Cs }(\mathrm{mg} / \mathrm{kg})\end{array}$ & $\begin{array}{c}\text { NAPL } \\
\text { Present? }\end{array}$ & $\begin{array}{c}\text { NAPL Saturation } \\
(\%)\end{array}$ \\
\hline $\mathrm{X} 701-78 \mathrm{G}$ & 550 & $\mathrm{~S}-14$ & 540 & 548 & No & -- \\
\hline $\mathrm{X701-72G}$ & 180 & $\mathrm{~S}-15$ & 280 & 179 & Yes & 0.04 \\
\hline $\mathrm{X701-74G}$ & 200 & $\mathrm{~S}-16$ & 660 & 199 & Yes & 0.19 \\
\hline $\mathrm{X701-76G}$ & 330 & $\mathrm{~S}-17$ & 410 & 329 & Yes & 0.03 \\
\hline $\mathrm{X701-133G}$ & 160 & S-08 & 430 & 159 & Yes & 0.11 \\
\hline
\end{tabular}

$\mathrm{C}_{\mathrm{s}}$ and $\mathrm{C}_{\mathrm{w}}$ are the co-located concentrations of TCE in soil and groundwater, respectively.

\section{Suspect DNAPL Locations}

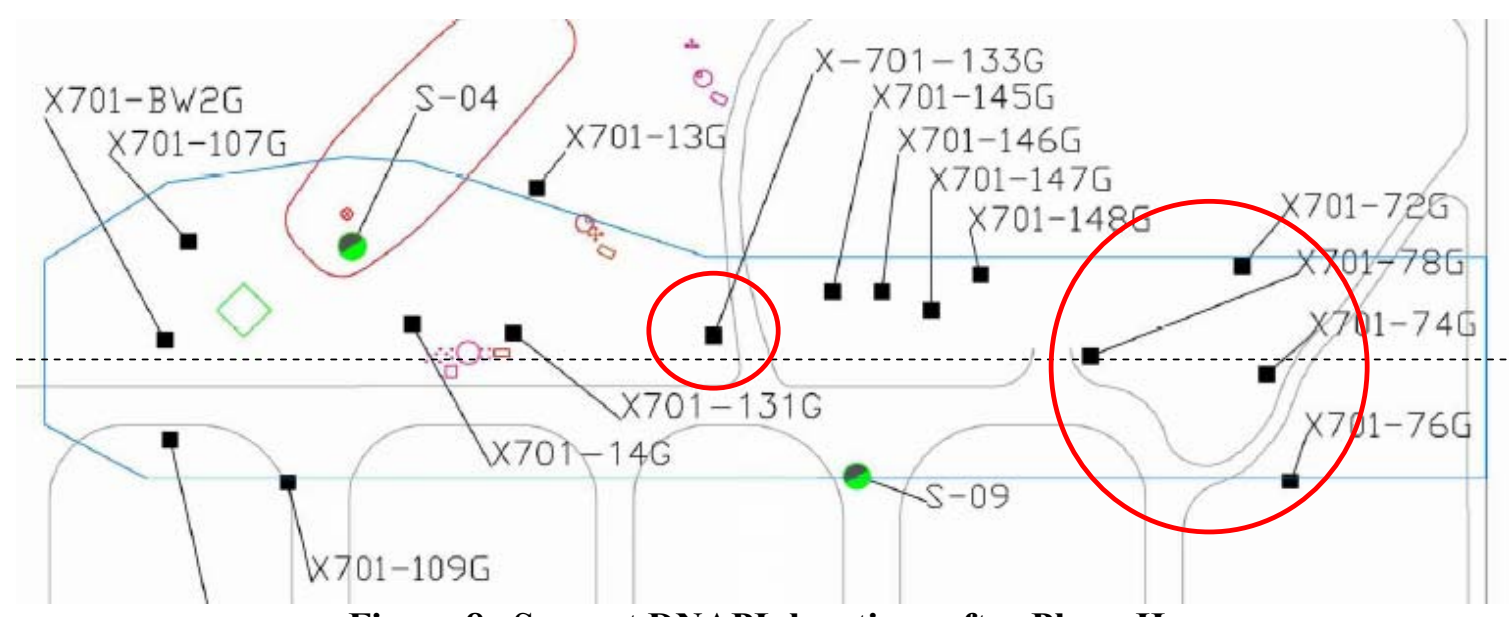

Figure 8. Suspect DNAPL locations after Phase IIe 


\subsection{Technical and Engineering Evaluation}

During the six injection events throughout Phase II, more than 185,000 gallons of reagent (including oxidant, catalyst solution and flush water) were injected at 790 locations through $5 \mathrm{ft}$ and $8 \mathrm{ft}$ screens placed in Geoprobe rods (Table 2). The target zone for these injections encompasses an area of approximately 100,000 square feet with an assumed thickness of eight feet that comprises the Gallia formation. Assuming a nominal porosity of the target zone of 30 percent, the pore volume is approximately 1,800,000 gallons. Although migration of oxidant during injection (day-lighting or blow-by) was reported during Phase II operations, this was a rather uncommon event. The cumulative volume of oxidant injection is estimated to be approximately $10 \%$ of the total target pore volume.

A summary table of the oxidant injection data to date is provided in Table 2. An additional injection event is scheduled to take place in spring of 2009.

Table 2. Modified Fenton's reagent injections to date

\begin{tabular}{l|l|l|l|l|l|l|l}
\hline $\begin{array}{l}\text { Phase II } \\
\text { treatment } \\
\text { event }\end{array}$ & $\begin{array}{l}\text { Number of } \\
\text { injection } \\
\text { points }\end{array}$ & $\begin{array}{l}\text { Volume of } \\
12 \mathrm{wt} \% \\
\text { peroxide } \\
\left(\mathrm{H}_{2} \mathrm{O}_{2}\right), \\
\text { gallons }\end{array}$ & $\begin{array}{l}\text { Equivalent } \\
\text { volume of } \\
35 \mathrm{wt} \% \\
\text { peroxide, } \\
\text { gallons }\end{array}$ & $\begin{array}{l}\text { Mass of } \\
35 \mathrm{wt} \% \\
\text { peroxide, } \\
\text { bs }\end{array}$ & $\begin{array}{l}\text { Equivalent } \\
\text { mass of } \\
\text { pure } \\
\text { peroxide, } \\
\text { lbs }\end{array}$ & $\begin{array}{l}\text { Cost of 35 } \\
\text { wt\% } \\
\text { peroxide } \\
\text { at } \$ 0.50 / \text { lb }\end{array}$ & $\begin{array}{l}\text { Total } \\
\text { volume of } \\
\text { peroxide, } \\
\text { catalyst, } \\
\& \text { water, } \\
\text { gallons }\end{array}$ \\
\hline $\mathrm{a}$ & 135 & 11,453 & 3,926 & 36,907 & 12,918 & $\$ 18,454$ & 31,938 \\
\hline $\mathrm{b}$ & 140 & 11,848 & 4,062 & 38,180 & 13,363 & $\$ 19,090$ & 33,275 \\
\hline $\mathrm{c}$ & 120 & 9,843 & 3,374 & 31,719 & 11,102 & $\$ 15,859$ & 26,109 \\
\hline $\mathrm{D}$ & 134 & 12,336 & 4,229 & 39,753 & 13,913 & $\$ 19,876$ & 30,666 \\
\hline $\mathrm{E}$ & 140 & 12,893 & 4,420 & 41,548 & 14,542 & $\$ 20,774$ & 32,085 \\
\hline $\mathrm{F}$ & 121 & 13,085 & 4,486 & 42,166 & 14,758 & $\$ 21,083$ & 31,098 \\
\hline
\end{tabular}

*Scheduled for spring 2009.

Compounding the limited ability to treat the entire source zone (based on total pore volumes versus pore volumes injected and the short oxidant lifetime), the oxidant deployed to date was only a fraction of the amount required based on the measured sitespecific total oxidant demand (TOD) of $6 \mathrm{mg} / \mathrm{kg}$. Based on this design parameter, approximately 264 tons of oxidant would be required to treat the target volume. The oxidant injected through Phase IIe was approximately 40.3 tons (or about 1/5 of the required volume). Using the current operating protocols, the total injection volume (of peroxide, catalyst solution and water) to meet the remaining oxidant would be almost one million gallons or about half of the total 1.8 million gallons of pore volume in the target zone. Injecting one million gallons of additional hydrogen peroxide mixture would require significant time and resources. Furthermore, such a large injection, without hydraulic control, could have adverse impacts on the TCE source in terms of facilitating additional spreading or migration. The technical review panel did not support continuation of the current oxidant protocol (alternative protocols and technologies are described in the following sections). 
However if oxidant injection is continued, the following issues should be addressed during future activities:

- Concentrations of TCE in soils measured in similar locations indicate that contaminant mass has been displaced as a result of injections and significant increases in concentration were observed at several locations. This often occurs when injections are conducted in areas where NAPL or groundwater with high aqueous concentrations of TCE exists. The advective push or displacement of NAPL and/or contaminated groundwater associated with injection can occur. In addition, there is the potential for increased mobilization of contamination due to some surfactant effect of the injectate, and localized production of gas and heat associated with Fenton's reaction.

- Strategies to mitigate the displacement of contamination could include using an injection pattern that begins from downgradient regions and continues toward the source area while employing hydraulic control to target known locations of TCE DNAPL with a small volume of longer-lived oxidant.

- Many laboratory TOD tests have been conducted on soils representative of the Gallia and Sunbury shale with values ranging from approximately $3.5 \mathrm{~g}$ of oxidant per $\mathrm{kg}$ soil to more than $15 \mathrm{~g} / \mathrm{kg}$ with an average value of $6 \mathrm{~g} / \mathrm{kg}$. However, the total amount of oxidant provided to date is less than one-fifth of the amount of oxidant required based on the average oxidant demand. In addition, hydrogen peroxide demand is typically much higher than persulfate or permanganate oxidant demand because $\mathrm{OH}$ radicals are scavenged by carbonates, natural organic matter, and reduced minerals in addition to oxidizing the target contaminants. Permanganate and persulfate are generally less susceptible to these scavengers. The importance of addressing the natural oxidant demand is specifically called out in the work plan.

- Injections have been conducted through screens placed in the Geoprobe rods and exposed for lengths of $8 \mathrm{ft}$ and, later, $5 \mathrm{ft}$. With uniform permeability, injectate will preferentially flow in the upper portion of the screen during a pressurized injection. With non-uniform permeability, injectate will flow preferentially in the zone of highest permeability. If a screen is deployed straddling the Gallia and upper weathered portion of the Sunbury shale, most of the injectate will flow into the Gallia and not into the underlying weathered shale. This could be a contributing factor for the continuing high concentrations of contaminant found in the shale. Injecting directly through the bottom of rods (via sacrificial tip) driven into the Sunbury shale may help to focus oxidant contact with contaminants in the weathered shale. 


\subsection{Is Remediation of the X-701B Source Area Possible?}

The limited success of the lance based injection of catalyzed hydrogen peroxide in achieving the PRGs leads to a philosophical question of whether cleanup of this source is possible, or if the site should simply continue pump-and-treat operations for an extended timeframe (e.g., hundreds of years). The panel did not develop a final determination on this topic, but the general consensus of the panel was that cost-effective activities directed at the X-701B source zone have the potential to be relatively effective (given the shallow depth and ease of access, thin target aquifer and well-defined persistent sources, etc.). The information gathered during the Phase I and Phase II peroxide oxidation, and the various technical and engineering weaknesses and problems identified during this fullscale deployment highlight potential challenges and potential opportunities. Similar information on issues and challenges are available from historical technology demonstrations at this site (e.g., steam remediation, permanganate oxidation and surfactant flushing).

The review team factored all of this historical information into an unconstrained assessment of remediation technologies and alternatives. That assessment, which is in a following section of this report, resulted in a range of options for the site to consider. Some of the identified options are similar in cost to currently planned actions (e.g., a surface cap) but have the potential to significantly improve the remediation progress at the site and accelerate the achievement of remedial objectives. As an example of the possibility that remediation of the X-701B source zone may be possible, the groundwater plume maps during and after the horizontal well permanganate oxidation are illuminating (Figure 9). The recirculation of permanganate oxidant resulted in a clean groundwater zone that persisted and moved downgradient over the following multiyear time period. This figure suggests the possibility that success for the X-701B plume may be possible; the timeframe for that success, however, may be many decades rather than a few years. It should be noted that at any given location in the source area, groundwater concentrations tended to rebound in time, suggesting that effective remediation of the contaminant source had not occurred at that level of treatment. The decision for the Portsmouth team will hinge on the desirability of accelerating the achievement of remediation goals (i.e., what is the value of remediation completion in 30 to 50 years versus 100 to 300 years? What are the costs now and along the way? How does this relate to natural resource availability or damage?). 


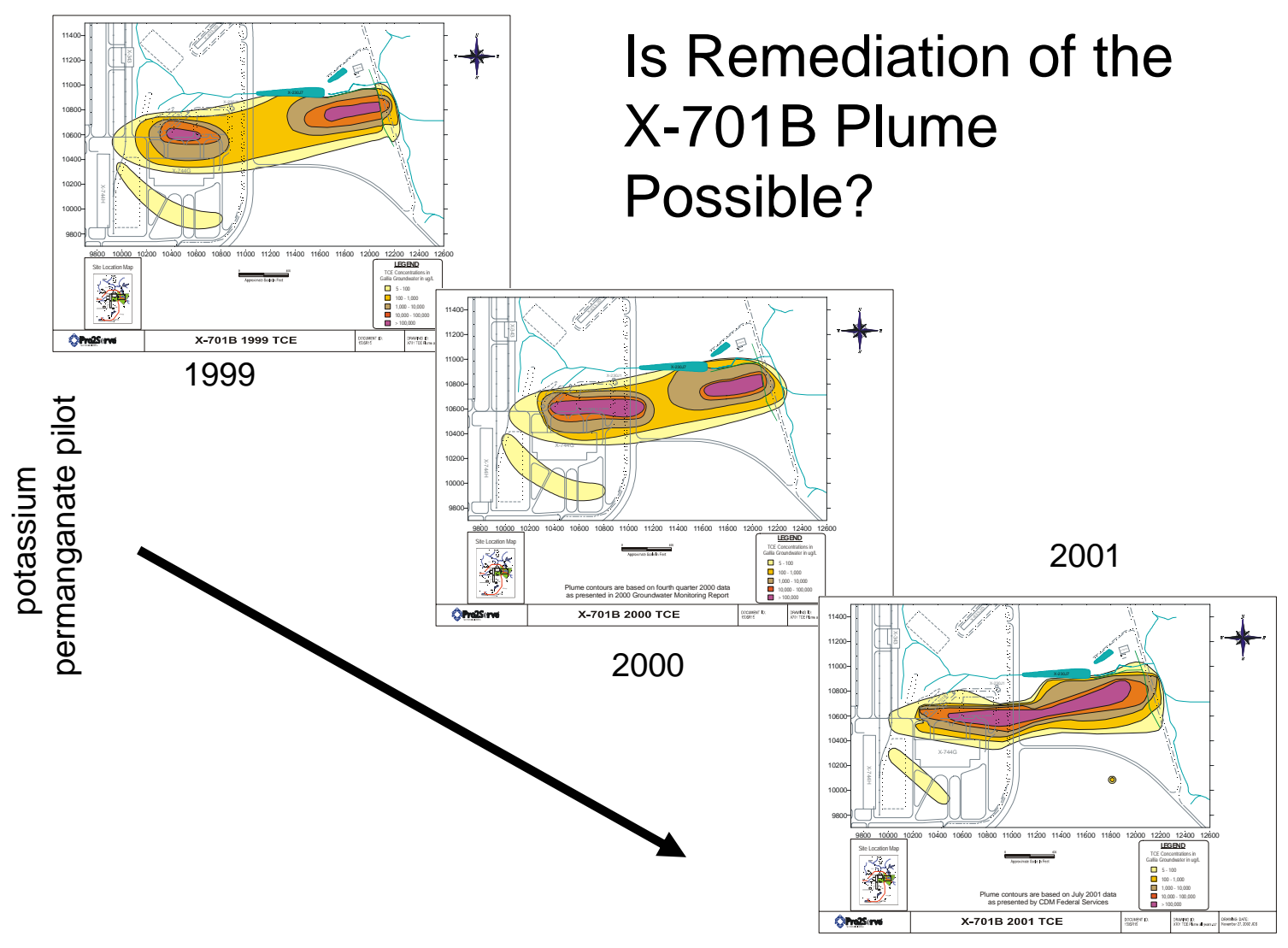

Figure 9. TCE plume downgradient of the former X-701B pond during and after the pilot test of potassium permanganate in the horizontal wells 


\subsection{Technology Alternatives}

The technical review team used a structured stepwise process to develop and evaluate technology alternatives. First, a consensus was developed on key assumptions and the relevant scientific and technical background information. The team also developed a site specific geologic and hydrologic conceptual model for the nature and extent of TCE contamination at the $\mathrm{X}-701 \mathrm{~B}$ site. This evaluation and matching process proved to be a powerful tool to focus the team and assist in identification of a number of viable technology alternatives to address both source and dissolved phase contamination at the site. In the end, the team did not identify a single technology, but instead identified a combination of viable technologies that have the potential to achieve the remedial goal of $5 \mu \mathrm{g} / \mathrm{L}$ TCE groundwater concentrations.

Each of the technologies considered by the technical review team is described in the following sections. The team considered a wide array of possible technology choices and included some that were not considered viable or preferred options in order to provide a complete review. Table 3 contains a summary of the technologies evaluated along with their advantages and disadvantages. The technology recommendations represent a consensus opinion agreed upon by the team.

\section{Key Assumptions}

The following volume and mass assumptions were used for estimation of costs for the different technology alternatives.

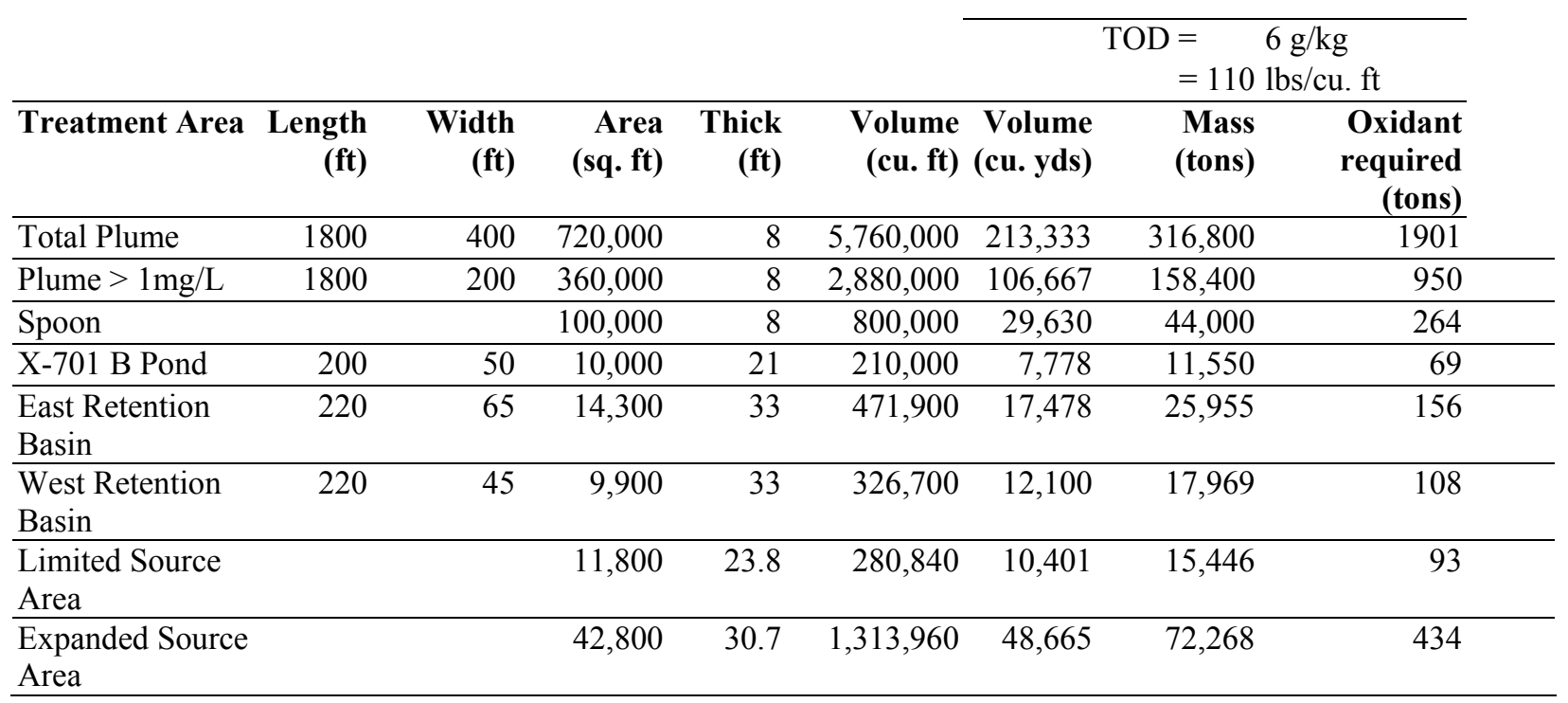




\subsection{Innovative Characterization Options (LIF, MIP, DNAPL Field Testing)}

The site currently uses groundwater and sediment sampling to characterize the distribution of contamination and to monitor remedial activities. For future remedial operations, especially to support and focus future source zone treatment, the team recommends consideration of alternative sampling and analytical techniques that have the potential to efficiently refine the site conceptual model in order to support specific remedial decisions. Specifically, if the nature and extent of separate phase material (presence or absence of DNAPL) is a key concern, direct push sensors would produce a robust evaluation of the distribution of contamination that could be used to focus future remediation activities. The technical review panel strongly advocated a focused effort on delineating the target residual separate phase material as a component of optimizing and reducing costs for future DNAPL treatment/removal (e.g., oxidant injection or thermally enhanced removal).

\section{Baseline sediment collection and analysis}

The site currently uses EPA SW-846 Method 5035 for collection of sediment and soil samples preserved with methanol in gas tight jars. The site might consider using EPA Method 5021 for headspace analysis of the samples as an alternative to Method 5035. Using Method 5021, a small amount of soil is placed in a container that is immediately sealed. The analysis is done in the lab by sampling the vapors that have partitioned into the headspace portion in the container. The primary advantage of this method is that it significantly simplifies sample collection and preparation procedures at a similar, or potentially reduced, cost compared to Method 5035.

\section{Baseline water analysis}

The team noted that the detection limits reported for the potential breakdown products of TCE are variable. This problem most significantly impacts wells that have high concentrations of TCE, for which sample analysis requires a high dilution factor, resulting in a loss of data (i.e., high detection limits) for all other chlorinated volatile compounds including potential degradation daughter products. This limitation impacts many key wells and limits the ability to comprehensively assess all of the processes impacting contaminants in the subsurface at Portsmouth. The high dilution factors and the associated high detection limits for potential breakdown products have the potential to compromise the conceptual model for the site and the resulting decision process. The technical review team recommends that the site perform a special study to determine daughter product concentrations across the Portsmouth site. In this study, the lab should be instructed to run samples from high concentration contaminated wells at two dilutions to provide accurate measurement of TCE (at a high dilution factor) and daughter constituents (at a low dilution factor) with reasonable detection limits. Note that the data for TCE at the low dilution factor will be out of range (and should not be recorded in the database), whereas recorded data for the daughter products should be only from the lower dilution factor samples. The technical review team recognizes that this will result in extra cost and special coordination with the laboratory and does not recommend that this type of activity be a routine requirement for the program. Following the recommended special study, however, future rounds of special sampling should be considered for 
specific areas if there is a reason to suspect that the biogeochemical conditions have changed significantly (e.g., if a surfactant or cosolvent is used).

\section{Delineation of DNAPL zones}

If there is to be a significant effort directed at better delineation of separate phase material to support additional source zone remediation, there are several field-based and direct push methods that will yield improved definition of the nature and distribution of DNAPL in the subsurface. These methods are available from commercial vendors.

\section{Identification of DNAPL in core samples}

At many sites the presence of DNAPL in retrieved core material can be qualitatively determined in the field using hydrophobic dyes (e.g., Sudan IV or Oil Red O dye). A small amount of sediment $(5 \mathrm{~g})$ is placed in a $20 \mathrm{~mL}$ clear glass vial with approximately $5 \mathrm{~mL}$ of deionized water to cover the soil. A small amount $(<0.1 \mathrm{~g})$ of Oil Red O (Fisher Scientific, Suwanee, GA) hydrophobic dye (i.e., a xylylazo-naphthol compound) is then added to the vial and then the vial is sealed with a screw-thread cap. The $20 \mathrm{~mL}$ vial is then hand mixed for one minute and the dye color noted. If the dye color changes from brown to bright red, a positive dye test result is recorded, while no change in dye color is recorded as a negative dye test result. An additional dye test can be performed by adding dye crystals directly to the entire soil core when the $20 \mathrm{~mL}$ vial test is negative. The whole-core dye test is performed to determine if small NAPL drops are present that may have been missed in the 5 gram sub-sample.

\section{Identification of DNAPL using subsurface methods}

Several direct push methods are currently available to delineate subsurface DNAPL rapidly and efficiently.

\section{Laser Induced Fluorescence Probe}

The Laser Induced Fluorescence (LIF) Probe has been used successfully at sites to characterize the distribution of DNAPL. LIF is a technique that uses a sensor to collect fluorescence excitation and emission spectra for depth discrete delineation of contaminants that fluoresce. It is deployed using direct push systems allowing for quick screening for DNAPL compounds. Although DNAPL does not fluoresce at standard excitation wavelengths, organic matter or co-contaminants that do fluoresce often dissolve preferentially into DNAPL. Thus the fluorescence is used to infer the presence of DNAPL. This technique should be considered at Portsmouth due to the reported dark color of the DNAPL previously recovered at the site that indicates the inclusion of organic matter into the DNAPL. The LIF system is most appropriate for source zone characterization under these conditions since it will only react with DNAPL, not high concentration dissolved phase.

Membrane Interface Probe

The permeable membrane interface probe (MIP) was developed by Geoprobe Systems to allow for near real-time evaluation of subsurface volatile constituents. It is deployed using direct push systems allowing for quick screening for DNAPL compounds. The MIP consists of a thin composite membrane mounted along the outside of a push rod, 
which is in contact with a carrier gas line within the probe. The carrier gas line can be connected to several types of detectors, including flame-ionization, photoionization, and other detectors. The MIP membrane is typically heated to $80^{\circ} \mathrm{C}$ to $125^{\circ} \mathrm{C}$ as it is advanced through the subsurface. Volatile organic contaminants (VOC) present in the subsurface partition into the membrane and migrate through it by advective flux. Once through the membrane, the carrier gas sweeps the VOCs to the detector. Confirmation samples will be required when using the MIP for DNAPL source zone evaluation. One significant advantage of the MIP technique similar to LIF is that it can be coupled with lithologic sensors to provide a detailed vertical profile of the distribution of contamination in the subsurface. The sample collection process is continuous and does not require retrieval of the device between measurements unless the MIP membrane fails. The MIP cannot be used to measure DNAPL directly and requires that at least $10 \%$ of the in situ MIP measurements be confirmed using soil samples.

\subsection{Remediation Alternatives}

There are three basic strategies for addressing the X-701B source: removal, in situ destruction or isolation/immobilization. Example technologies for these three basic strategies are thermal treatments, oxidation, and surface capping, respectively. Because of the limited progress toward PRGs during the Phase I and Phase II (a-e) oxidant injections, the technical review team revisited the breadth of available technologies for TCE contaminated soil and groundwater to assist the Portsmouth team in developing an effective and efficient path forward for the X-701B plume. For each technology, the team identified strengths and weaknesses, developed a generalized site-specific application scenario (or a few alternative scenarios), and developed a consensus summary recommendation. Importantly, the review team recognized that the various strategies/technologies can be used alone, or can be combined. Thus many of the consensus summary recommendations describe how a technology can be beneficially used to address a specific target within the overall X-701B plume area and how the various technologies and particular application scenarios might work synergistically. The following technologies (strategies) were addressed by the team:

Oxidant Injection / blending (in situ destruction)

Pump and Treat (removal)

Thermal Treatment (primarily removal)

Excavation (removal)

Surfactant and Cosolvent Flushing (primarily removal)

Permeable Reactive Barrier (primarily in situ destruction)

Bioremediation and Constructed Wetland (destruction)

Physical, Hydraulic and Chemical Isolation/Immobilization (isolation/immobilization)

The following subsections address these individual technologies in the order listed above. The technology specific sections are followed by a table summarizing the information for all of the technologies and proposing various combinations of technologies (Table 3 in Section 5 of the report). 


\section{Oxidant Injection / Blending}

Given that oxidants are currently being used to remediate the X-701B plume, they were one of the most important technologies addressed by the review team. Three alternative liquid reagents (peroxide, permanganate and persulfate) are examined below along with a scenario that utilizes solid oxidant blended into the soil beneath the former basin.

\section{Hydrogen peroxide/modified Fenton's/catalyzed hydrogen peroxide}

Although the hydrogen peroxide based strategies provide a powerful oxidant that is capable of remediating all of the organic contaminants in the plume, and has already remediated a significant amount of the original contamination, these methods generate a large amount of heat and gas in the subsurface. This, in addition to the displacement of subsurface fluids resulting from the advective push during fluid injection, appears to have caused contaminant movement in the subsurface. On the whole, contaminant concentrations in soil and groundwater samples show a reduction in mass after oxidant injections, but significant increases in concentration were measured in some sample locations. This behavior is not uncommon after injections into aquifers containing high aqueous or NAPL concentrations. The displacement of contaminant is a likely source of rebound often encountered in these oxidant injections.

Another limitation of the selected technology is the short life of hydrogen peroxide in the subsurface. Because it reacts with other subsurface materials besides the target contaminant (like natural organic matter, reduced minerals, and carbonates), hydrogen peroxide has little opportunity to dissolve and infiltrate in all but the prominent advective pathways, leaving contamination in less mobile zones (often where the majority of residual contamination resides) untouched.

Hydrogen peroxide at $35 \mathrm{wt} \%$ is approximately $\$ 0.50$ per pound, making it one of the least expensive oxidants available.

\section{Permanganate}

This oxidant technology was used in a recirculating system involving the horizontal wells on the eastern portion of the plume. Groundwater in the area was remediated to nondetectable concentrations for a period of time, but concentrations rebounded to former levels within three to four months. This was most likely caused by diffusion from residual source in the area and limited transport from unaffected upgradient groundwater. Several generic issues regarding the use of permanganate were listed in the Technical Approach presentation. Most of these listed issues could be overcome with sufficient planning.

A list of the issues identified for permanganate is provided below with comment:

1. Forms $\mathrm{MnO}_{2}$ precipitates. Yes, but the significance of the formation of these precipitates is not clear with respect to achieving the goal of reducing contamination in the groundwater and soil at Portsmouth. $\mathrm{MnO}_{2}$ precipitation did not affect the success of treatment during the horizontal well application. 
2. Precipitates may reduce flow in the aquifer (especially fine grained materials). There was no evidence of this from the horizontal well test; however, limited oxidant was injected at the time.

3. Lower oxidation potential. Yes, but a higher oxidation potential is not necessary for oxidizing TCE, and permanganate has been proven to be effective on chlorinated alkenes in hundreds of commercial applications.

4. Less effective on DNAPL and sorbed phases. None of the chemical oxidants directly oxidizes NAPL. Although hydroxyl radicals will have a better chance of oxidizing natural organic matter (presumably sorbent material) than permanganate it is not clear if that is significant.

5. Manganese has a secondary drinking water standard of $0.05 \mathrm{mg} / \mathrm{L}$. This may be a temporary issue; however, current manganese concentrations are at $14 \mathrm{mg} / \mathrm{L}$. If necessary, manganese can be removed by standard treatment methods. In addition, Ohio regulators have indicated their willingness to discuss temporary exceedance of secondary drinking water standards for compounds such as sulfate.

6. Long term treatment and management of residual oxidant. This could be an advantage if dealt with properly, i.e., similarly to horizontal well recirculation. Could be used to reapply oxidant in the subsurface.

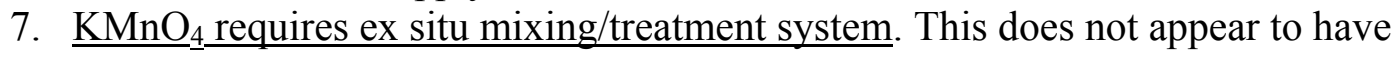
been an issue during horizontal well tests and is commonly performed by many commercial companies.

8. $\mathrm{NaMnO}_{4}$ may require an ex situ mixing/treatment system to reduce the plugging of injection wells. Although potassium permanganate may be a better choice than sodium permanganate for this site with respect to the history of activities at the site, this would be a non-issue if oxidant were directly injected through Geoprobe rods (through a sacrificial tip, no screen).

9. May cause an increase in dissolved chromium and technetium concentrations. Potential with any oxidant.

10. Because of limited solubility of potassium permanganate, a large injection volume will be required to satisfy oxidant demand.

Unstated advantages of permanganate:

1. Can be injected as a dense fluid which could potentially settle on and in low permeability zones. Concentrations as high as $10 \mathrm{wt} \%$ potassium permanganate have been injected through Geoprobe rods by increasing the temperature of injectate. As a relatively dense fluid it could potentially follow the transport path of DNAPLs.

2. Supersaturated potassium permanganate could potentially precipitate when temperature drops to ambient groundwater temperatures. The solid can then act as a long term source (months to years) of potassium permanganate to the system.

3. Reaction of potassium permanganate causes little heat and gas to evolve.

4. Easily traced both visually and by electrical conductivity - can be traced by direct push tools. 
Oxidant application would benefit from additional characterization that could limit the target treatment volume. Direct push Membrane Interface Probe and/or Laser Induced Fluorescence could identify depth intervals and limit lateral treatment extents. The current target volume is approximately 800,000 cubic feet $\left(100,000 \mathrm{ft}^{2}\right.$ area, $8 \mathrm{ft}$ depth). Assuming a total oxidant demand of approximately $6 \mathrm{~g}$ oxidant per kilogram of soil and groundwater (analyzed values range from approximately 3 to $16 \mathrm{~g} / \mathrm{kg}$ ); approximately 264 tons of oxidant would be required for treatment with a cost of chemical alone ranging between $\$ 264,000$ to $\$ 1,241,000$. Injection costs range from 1 to 3 times the chemical costs. If the target volume could be limited, for example to a 2-foot vertical interval around the interface of the Gallia and Sunbury shale, costs could be reduced by $75 \%$.

Potassium permanganate is sold as a dry granular material and costs approximately $\$ 2.35$ per pound. Sodium permanganate is typically sold as a $60 \mathrm{wt} \%$ liquid and costs more per pound of permanganate than potassium permanganate.

\section{$\underline{\text { Persulfate }}$}

In situ injection of sodium persulfate could also be used to oxidize contaminants. Sodium persulfate is a strong oxidant that can oxidize TCE and daughter products. If the sodium persulfate is properly catalyzed to produce sulfate radicals, more recalcitrant compounds (e.g., chlorinated alkanes, benzenes, etc.) can also be oxidized. Like permanganate, sodium persulfate produces little gas or heat while reacting. Sodium persulfate is soluble in the aqueous phase to approximately $36 \mathrm{wt} \%$, allowing the injection of a potent, dense fluid which may follow similar transport paths as dense nonaqueous phase liquids. Its reaction kinetics are much slower than hydrogen peroxide-based approaches and it can persist for several weeks or longer in the subsurface. As with permanganate, this persistence allows persulfate to reach less mobile zones containing residual contamination. An additional advantage of the slower reaction kinetics of persulfate is that it is less hazardous to workers during handling. Finally, laboratory tests conducted on $\mathrm{X}-701 \mathrm{~B}$ soils and groundwater in 2005 using persulfate indicate that uncatalyzed persulfate was capable of effectively degrading TCE.

One issue with persulfate is the uncertainty of effectively catalyzing it to produce sulfate radicals in the subsurface. Although several methods for catalyzing sulfate radical production have been used (heat, UV light, high pH, FeEDTA), only heat and UV light have been reliable enough to be used in manufacturing processes requiring generation of radicals. Another practical issue is that although the reaction kinetics of aqueous persulfate with organic material are relatively slow, reaction with metals is rapid. Persulfate corrodes metals (e.g., Geoprobe rods) in minutes to hours and can wreak havoc with standard Geoprobe injection procedures if not dealt with properly. Finally, after persulfate is spent as an oxidant it is converted to sulfate. High concentrations of sulfate are likely for a brief period (a few months) after injection of persulfate. As mentioned above, Ohio regulators have indicated their willingness to discuss temporary exceedances of secondary drinking water standards. Sulfate may also inhibit complete conversion of chlorinated ethenes to ethene and ethane during reductive dechlorination that may follow oxidation in time or downgradient. 
Despite these issues, sodium persulfate may be used to address residual contamination especially if it is used in combination with a heating technology to remove NAPL in the subsurface.

Miscellaneous injection issues

1. Injection would benefit from additional characterization by MIP or LIF. This would focus injection depths and locations.

2. Oxidant injection is generally done from downgradient to upgradient to help mitigate any advective push of contaminant downgradient.

3. For injections targeted to specific zones (particularly those with different permeabilities and of relatively small thickness) it would be more useful to inject through a smaller port rather than a screen. The injectate will follow the most permeable path it encounters over the length of the screen. If the one foot thick weathered shale is targeted and injections are done through a five foot screen straddling the target zone but including more permeable materials, little injectate will be forced into the targeted weathered shale.

4. Proprietary or patented oxidant processes should be avoided unless there is a clear advantage of the technology.

Oxidant Blending into Soil

In situ soil blending or mixing is a mature source treatment technology that directly addresses residual soil and groundwater contamination in a more comprehensive way than injections. Since the principal determinant of success for a chemical treatment of contamination is the effectiveness of contact of the treatment chemical with the contaminant, properly conducted soil mixing has obvious advantages over injections. Treatment chemical/contaminant interaction during injections is limited to the advective path of the injection plus any additional dissolution, fluid mixing or diffusion that occurs during the lifetime of the treatment chemical. Advective injection paths constitute a small portion of the aquifer volume although these might be important paths if they approximate the contaminant transport trace. Soil blending allows the distribution of treatment chemical throughout the mixed volume to increase the probability of contacting contaminant, which should ensure more complete remediation in the mixed volume. Soil blending can be performed with standard construction equipment for shallow depths (up to around 20 feet below grade) although it is important to have skilled equipment operators performing the work to ensure thorough mixing. Alternatively, soil mixing equipment has been designed recently that facilitates the thorough mixing required for soil and groundwater treatment. Specialized equipment includes custom tiller heads mounted on excavators, and large augers. The augers can often be used for larger vertical intervals and greater depths.

The X-701B basin would be a primary candidate for soil blending since it was the likely principal original source of contamination and probably has high concentrations of contaminant remaining throughout its footprint to the confining shale. Because the basin is still open to a depth of approximately $12 \mathrm{ft}$, the vertical thickness of contaminated soil to reach the top of the Sunbury shale is approximately $21 \mathrm{ft}$, which will allow soil mixing by many different types of standard or near standard construction equipment. Notably, 
the concept of mixing treatment chemicals into the basin as part of an effective closure strategy was suggested by OEPA staff in 2002 when potential options for addressing the contamination beneath the X-701B pond were being developed. A variety of oxidants can be selected to address the contaminated soil in the mixed volume including permanganate, persulfate, and hydrogen peroxide-based oxidants. Other chemicals can be blended in if an approach other than oxidation is used.

It would be prudent to select a persistent oxidant for at least two reasons. First, even though soil mixing distributes oxidant much more effectively than injection, it is still impossible to distribute the oxidant at the scale of the contaminant distribution. In other words, residual contaminant can exist in pores or small networks of pores (sub-centimeter scale) while soil mixing occurs at the scale of tens of centimeters. Therefore a persistent oxidant will be more effective at reaching reclusive contaminants. The second advantage for a persistent oxidant at the basin is that it can be used to "chase" the contaminant plume. Presumably an emplaced solid or liquid oxidant that gradually dissolves into groundwater will follow a similar path to that taken by solvents released to the basin. If no other treatment is used and sufficient oxidant is emplaced, we can assume that oxidant will trace the contaminant path within at most 50 years.

Soil blending costs are similar to standard construction excavation costs $(\$ 50$ to $\$ 100$ per ton). Assuming a TOD of approximately $6 \mathrm{~g} / \mathrm{kg}$, approximately 76 tons of oxidant would be required to treat the mixed soil volume of the X-701B basin (approximately 11,500 tons of target soil down to and including the upper Sudbury Member). Additional oxidant would be required if slowly dissolving oxidant is desired to treat the plume downgradient. At a nominal cost of $\$ 100$ per ton, oxidant blending treatment of the former X-701B basin would be approximately $\$ 1,150 \mathrm{~K}$.

The east and west retention basins can also be considered for soil blending since they probably contributed to the source releases. These basins would require mixing of a $33 \mathrm{ft}$ thick vertical soil interval. Either deep mixing tools (e.g., augers) can be used or the basins can be partially excavated and staged, then mixed with more standard equipment. Note, however, that total project costs for blending when including these basins would increase significantly over blending only in the X-701B basin. The soil oxidant blending costs for the retention basins would exceed $\$ 4,000 \mathrm{~K}$ based on the approximate target soil quantities (approximately 44,000 tons).

In summary, the technical review panel identified soil oxidant blending in the former X$701 \mathrm{~B}$ pond as a potentially viable and useful strategy, particularly when considered as an alternative to capping and if performed in combination with other activities such as modified pump and treat. 


\section{Pump and Treat}

A current and probable future part of any strategy for the X-701B plume is "pump and treat." This technology class includes traditional approaches that use extraction wells to supply the contaminated water for aboveground treatment and also includes alternative systems that capture water using interceptor trenches or outcrops. The X-701B plume is currently being addressed using extraction wells near the original basin and a collection trench in the distal portion of the plume (to protect Little Beaver Creek and the nearby influent tributary). Currently, that water is actively treated at the surface using standard technologies such as air stripping and sorption. The review team envisioned three future scenarios for pump and treat. The first is continuation of the status quo, the second is a modified version of the current system, and the third is an alternative in which the system is reconfigured to emphasize passive collection and passive treatment (or treatments that require minimal energy and intervention). These are example scenarios that are intended to represent the range of diverse options available for this site.

Continuation of the status quo is well understood in terms of costs and performance and is not discussed in detail herein. The primary modification assumed for a modified pump and treat is the relocation and redistribution of the extraction wells currently feeding the $\mathrm{X}-623$ system. The current system pumps from three wells near the upgradient boundary of the TCE plume. Two of the wells are located in areas with relatively low TCE concentrations (i.e., $<20,000 \mu \mathrm{g} / \mathrm{L}$ ). Pumping from the extreme upgradient portion of the plume has the negative impact of intercepting upgradient clean water and serves to stabilize the plume in place (rather than encouraging cleanup as water flushes through the system) and applies treatment resources (typically measured in engineering units of cost per 1000 gallons) toward handling of water containing less contaminant. Unless the active treatment system has a concentration constraint, this is suboptimal approach.

If pump and treat is to be considered, the review team recommends considering a modified scenario (Figure 10) in which the extraction is relocated in the core of the plume and moved downgradient (for example near the perimeter road). Alternatively the existing horizontal wells could be considered for the extraction with the potential advantages of reducing drilling costs and eliminating the need to cross the road with utilities (this assumes that minimal modifications would be required for the treatment train if there are residual geochemical impacts of past permanganate testing). Either modification of the active pump and treat scenario (Figure 10) would provide a significant increase in extracted concentration and extracted mass and would maximize the flow of water through the contaminated source zone and thus accelerate the cleanup. In the event that the modified pump and treat effectively treated the source zone upgradient of the perimeter road, future adaption could be considered to maintain increased mass removal performance. The primary advantage of this modified, or optimized, scenario is that it provides better performance if active pump and treat is selected as a significant activity within a combined remedy for the X-701B plume.

The primary disadvantage of active pump and treat, even when optimized, is that it may be inefficient and not substantially contribute to timely removal of the source mass. For example, in 2008, the existing X-623 system treated 264,708 gallons at an average 
concentration of $22,228 \mu \mathrm{g} / \mathrm{L}$, removing a total of $60 \mathrm{lbs}$ of TCE. If the wells were relocated to an area where the average concentration could be maintained at 100,000 $\mu \mathrm{g} / \mathrm{L}$, the extracted mass would increase to almost $300 \mathrm{lbs}$ per year (assuming similar or slightly increased flow rates). Concentrations in the vicinity of the proposed extraction are currently significantly higher than $100,000 \mu \mathrm{g} / \mathrm{L}$ indicating near term extraction rates greater than $600 \mathrm{lbs}$ per year are achievable. This is a large increase but may not be transformationally significant because of the large estimated mass (circa 50,000 to $100,000 \mathrm{lbs}$ ) originally released.

If active pump and treat is continued, the fundamentally limited effectiveness is an important consideration. When selecting among the two active pump and treat options, the potential to decrease operating time from several hundred to approximately 100 years needs to be weighed against the near-term investment required to make the required modifications to an engineered system in a disciplined and careful manner.

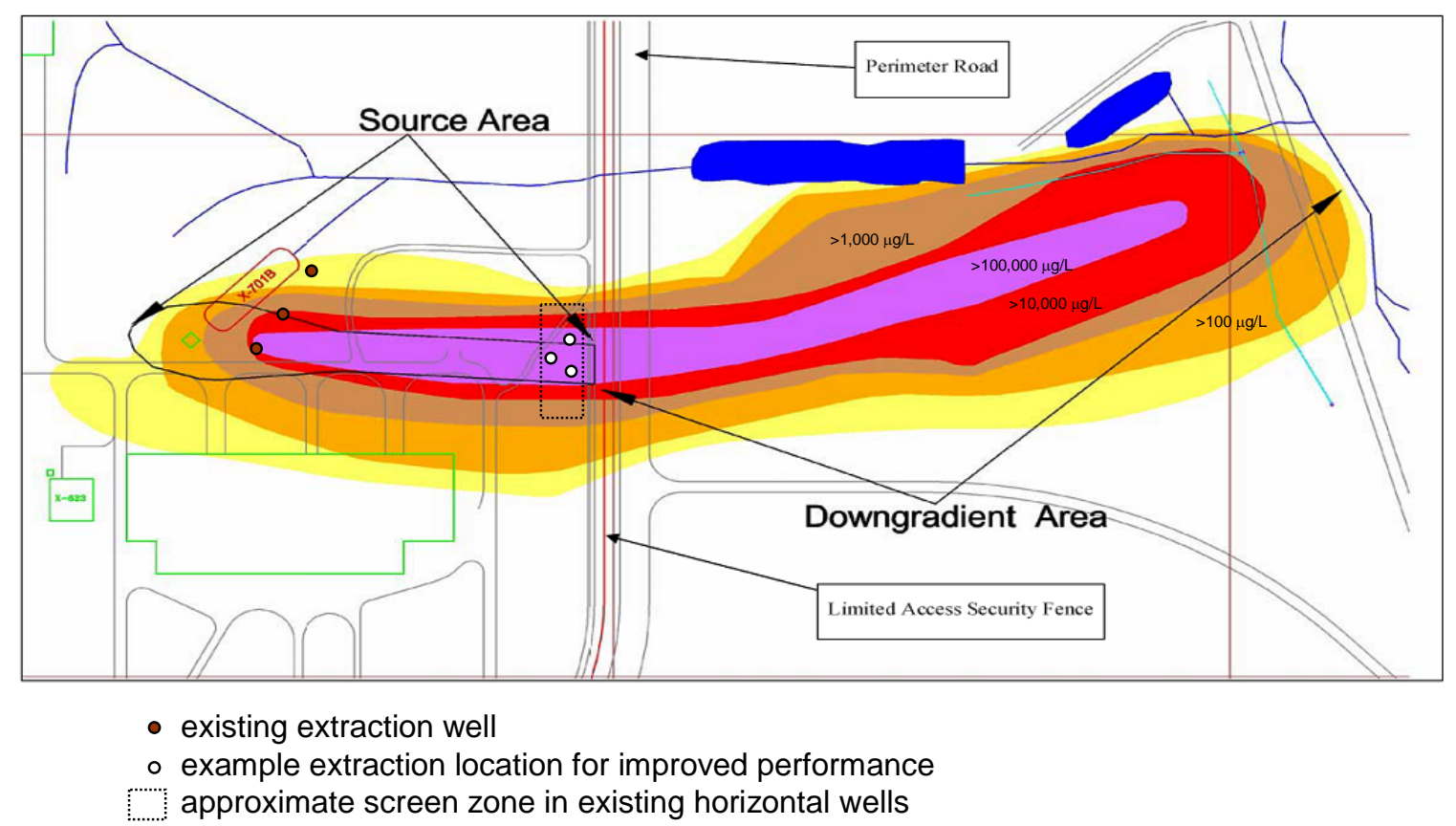

Figure 10. Example scenario in which extraction wells are relocated to maximize effectiveness

The third hypothetical scenario assumes that a passive collect and treat option is viable. This option is portrayed in the wetland treatment option in which water is assumed to crop out into a surface setting in which natural and passive processes are in place to attenuate the TCE and protect the identified receptors. While the wetland treatment option along with some variants of permeable reactive barriers are the primary exemplars of a passive collect and treat option, this section is included to encourage maximum diversity in the accounting of attenuation process and mechanisms (e.g., volatilization and mixing). Both open water, turbulent flow, and wetland features might be incorporated into a final solution. The challenge to any passive "collect and treat system" is the relatively high concentration (currently averaging approximately 2,000 to 20,000 
$\mu \mathrm{g} / \mathrm{L}$ from the X-624 distal collection trench) and the difficulty in achieving the required attenuation in the limited area available for the treatment prior to discharge into surface waters such as Little Beaver Creek.

\section{Thermal treatment}

The effect of thermal treatment is to raise subsurface temperatures to enhance the transfer of TCE from fine grained sediments to the mobile aqueous and gas phases. These mobile phases are then pumped from the subsurface for aboveground treatment and disposal. While thermal treatment systems involve the use of large-scale process equipment such as blowers, oil-water separators, air stripping towers, condensers, and activated carbon adsorbers, thermal treatment has been demonstrated to be effective at removing residual TCE NAPL at a significant number of sites. Thermal treatment targeting the Gallia member of the Teays Formation could involve the application of any one or a combination of conductive, electrical resistive, or steam heating technologies as described in the following sections.

\section{Steam Flushing}

A steam flushing pilot study was performed at X-701B (see Figure 11) by SteamTech in 1998 and 1999 and demonstrated that steam was effective at removing residual TCE NAPL from the Gallia member. The pilot study area comprised approximately 500,000 gal of pore space from which $875 \mathrm{lb}$ of TCE was recovered by injecting 7.5 million $\mathrm{lb}$ of steam. This equates to flushing 50 pore volumes of steam through the pilot study treatment volume to achieve an estimated $80 \%$ removal of residual TCE NAPL. While there were technical issues encountered during the pilot study such as the limited permeability of the Gallia member, fines clogging the air stripping unit, and the Ohio EPA air emissions levels for TCE, these limitations were overcome during the pilot test. It should be noted that the $875 \mathrm{lb}$ of TCE recovered during this pilot test was equivalent to approximately 10 years of TCE mass recovered by the currently operating pump and treat system.

Based on the pilot study results, SteamTech prepared a full-scale design for a steam flushing system that involve injecting steam into wells and extracting water from wells located within the TCE source area. The full-scale design included 150 steam injection wells and 70 extraction wells targeting the source zone area as shown in Figure 12. The full-scale system was projected to operate for 180 days with a cool down period of 60 days at an overall cost of approximately $\$ 10$ million at 1999 costs.

While SteamTech has since stopped offering steam flushing, the knowledge and experience developed was retained and is now available through TerraTherm. 


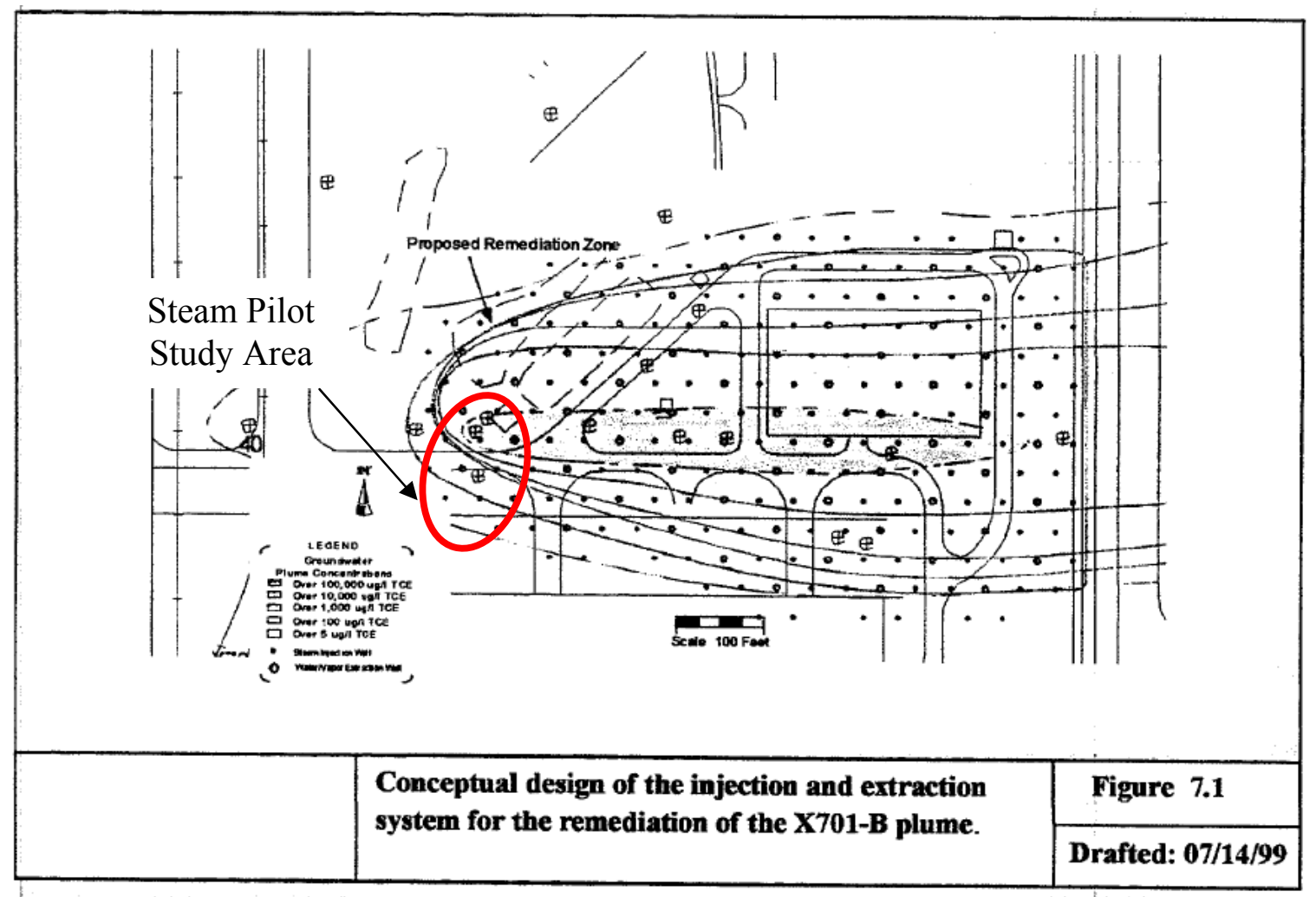

Figure 11: Steam flushing pilot study area and full-scale system layout based on design by SteamTech.

Conductive Heating

Conductive heating involves installing steel pipes equipped with cartridge heaters into the subsurface zones that are to be heated. Since only the steel rod is heated, thermal energy is transported into the nearby subsurface by thermal conduction alone. This results in a relatively small radius of heat influence as compared to steam or electrical resistive heating. The smaller radius of influence means that heater wells are closely spaced to uniformly distribute temperatures and that heater wells are operated at elevated temperatures (i.e. $800^{\circ} \mathrm{C}$ ). While these two factors are often considered limitations of conductive heating, the reliability of this heating technique and ability to precisely locate the heater wells makes this technology attractive for application at the X-701B TCE source area.

The heater wells could be installed in the weathered shale located at the interface between the Gallia and Sunbury members where residual TCE NAPL is thought to be located. By targeting this region, heat could be applied to drive TCE from this fine-grained layer into the Gallia member. Groundwater extraction wells located in the Gallia member would then be used to direct flow of groundwater from outside of the TCE source area to control the migration of TCE. Conductive heating requires the same process equipment as steam flushing.

The close spacing of the conductive heating wells required to distribute heat means that between 250 and 1,000 heater wells would be required to heat the TCE source area. 
Based on cost of $\$ 10,000$ per heater well, a full-scale system covering the X-701B TCE source area would be expected to cost between $\$ 2.5$ and $\$ 10 \mathrm{M}$. TerraTherm is the sole vendor of conductive heating systems.

\section{Electrical Resistive Heating}

Electrical resistive heating uses electrodes to apply electrical current to the subsurface where heat is generated as the electrical current passes through soil. Thus, the electrical conductivity (i.e. $\mu$ Siemens) of the soil controls the propagation of electrical current and the generation of heat. It is expected that more electrical current will pass through the Minford and Sunbury members than through the Gallia member given that the Minford and Sunbury members contain fine-grained soils as compared with the more permeable Gallia member. However, there are approaches to electrode placement and operation that can overcome this limitation, as necessary, and enhance the distribution of electrical current into the Gallia member.

The application of electrical resistive heating is similar to thermal conductive heating in that electrodes would be installed in the X-701B TCE source area with groundwater pumped into the source zone to control the migration of TCE. As with steam flushing and conductive heating, electrical resistive heating requires process equipment to handle and treat the groundwater and vapor recovered during treatment.

Electrodes are typically spaced from 10 to 20 feet apart, which means that 100 to 200 electrodes would be required to treat the X-701B source area. Using a per-electrode cost of $\$ 10,000$ to $\$ 40,000$ results in a full-scale cost that ranges from $\$ 1$ million to $\$ 8$ million. There are currently three electrical resistivity vendors including CES, Inc., TRS, Inc., and McMillan and McGee.

Combined Thermal Treatment Technologies

While any one of the thermal techniques may be sufficient to heat any portion of the Minford, Gallia, or Sunbury members, it may require a combination of these thermal techniques to facilitate the removal of TCE. One potential heating scenario involves installing conductive heaters into the Sunbury shale member, which would initially be heated to drive TCE upward into the Gallia member. After the Sunbury reaches operating temperature then the Gallia member would be flooded with steam to drive TCE towards recovery wells. This phased approach could also combine conductive and electrical resistance heating. The important principle would be to use a phased heating approach with the fine grain sediments being heated first, and the Gallia member being used to collect the mobilized TCE. The overarching objective on any combined thermal system would be to optimize the target zones and sequencing to maximize performance and achieve the thermal process remedial objectives at a minimum cost. 
Excavation - Physical Removal

Physical removal of source material beneath, and adjacent to, the former X-701B basin is potentially viable. Physical removal, or excavation, is a well understood non-proprietary approach to address shallow contamination and the concept is amenable to standard cost assessment. Excavation removes contaminant source completely from the portion of the subsurface that is removed, limiting rebound. Excavation does not eliminate rebound because some portion of the source, potentially a significant quantity, can be missed by excavation because it is inaccessible due to depth, interferences, safety, etc. Moreover, excavation is not appropriate for deep targets over large areas where large quantities of clean material must be removed and handled to access the contaminated zone (such as the downgradient portion of the X-701B source area).

For purposes of the technology matrix, the technical review team assumed that excavation, if performed, would address only the contaminant in the vicinity of the basin. Industry norms for excavation (without transport or disposal offsite) are typically $\$ 50$ to $\$ 100$ per ton. At a secure industrial and nuclear facility such as Portsmouth, costs would tend to be at or above the upper end of this nominal range (circa $\$ 100$ to $\$ 250$ per ton). Excavation is relatively rapid with a typical throughput of 300 to 500 tons per day. If a regulatory acceptable process existed for limited onsite treatment and onsite use of the excavated material (e.g., as backfill in a landfill), then excavation might be viable. Assuming a unit cost of $\$ 250$ per ton, costs for the former X-701B pond area $(11,500$ tons) would be approximately $\$ 2,900 \mathrm{~K}$. The need for offsite disposal would significantly increase costs; if the additional costs were in the range of $\$ 500$ per ton the costs for excavation would triple.

In summary, the technical review team determined that excavation of limited target areas (e.g., beneath the former X-701B pond) may be viable if there is a reasonable concept for onsite disposal. This was not the preferred alternative for this material, however. The team consensus was that the oxidant soil blending provided potentially superior benefits at a similar to lower cost.

\section{Surfactant and Cosolvent Flushing - Chemical Removal}

Performing a surfactant or cosolvent flush targeting the Gallia member of the Teays Formation would involve injecting fluids into a gallery of wells and recovering the surfactant and TCE from a second gallery of extraction wells. The wells could be aligned so that the injected fluids flow with the groundwater gradient or flow across the gradient. Well placement should be determined using groundwater particle tracking simulations to maximize TCE recovery while minimizing the volume of water that has to be extracted to achieve hydraulic control. The potential well arrangement shown in Figure 12 would achieve a sweep of surfactant/cosolvent through the Gallia member in the area where TCE residual NAPL is thought to be located. 


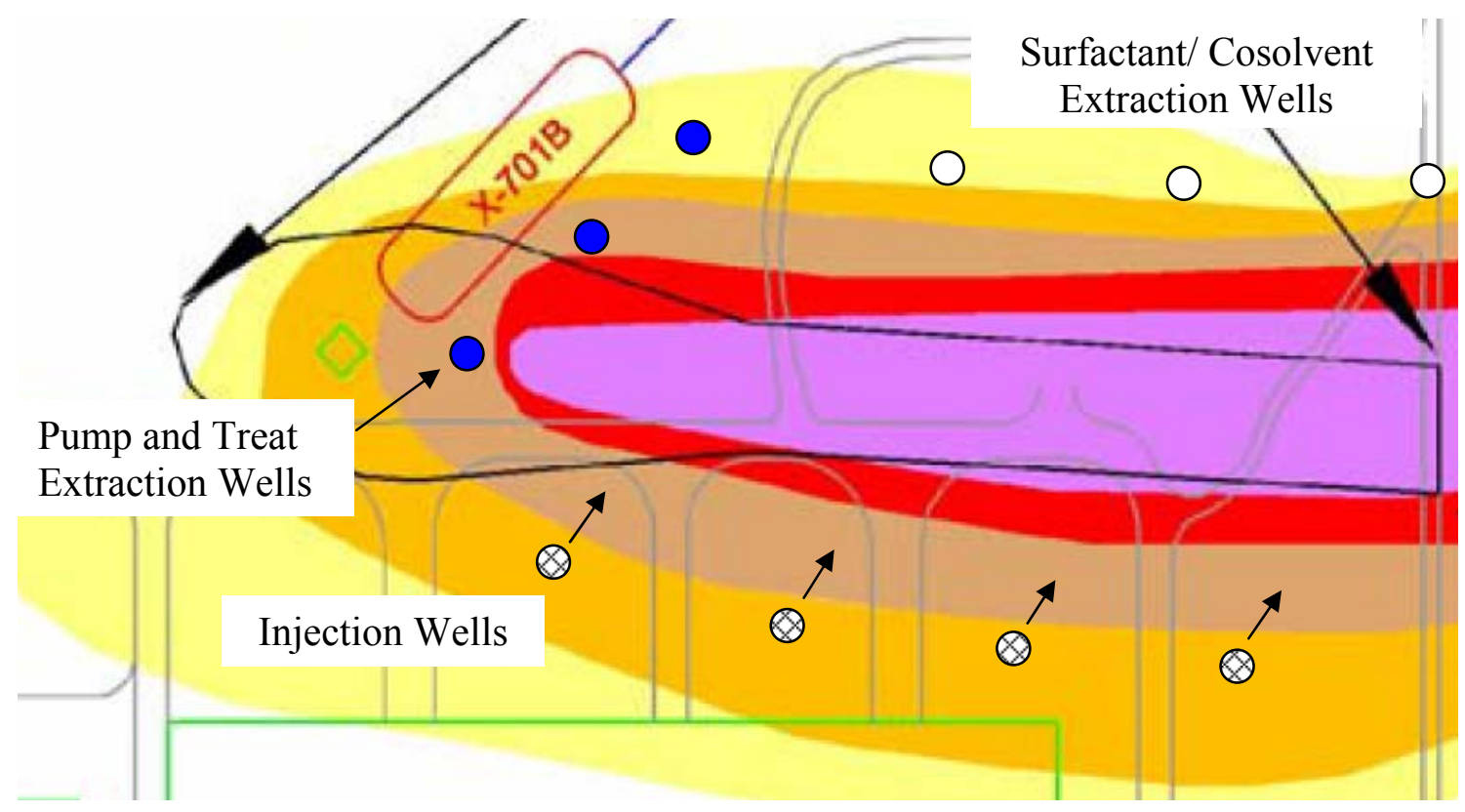

Figure 12: Conceptual arrangement of surfactant/cosolvent injection and extraction wells.

One serious complication to the application of any flushing technology at X-701B will be the hydraulic influence of the existing pump and treat system. Operation of the pump and treat system means that some fraction of the injected fluids will be recovered by the pump and treat extraction wells. This may impact treatment of the water recovered by the pump and treat system but could also be advantageous in minimizing the water that has to be handled by the surfactant extraction system.

One additional benefit of using a surfactant/cosolvent sweep would be that the residual surfactant/cosolvent may serve as a carbon source that may affect aquifer redox conditions and result in the development of reducing conditions. This may support bioaugmentation with injection of dechlorinating microbial consortia, such as Dehalococcoides strain KB-1, which have the potential to transform TCE to ethene and could be used to control the flux of TCE leaving the source area.

The surfactant/cosolvent costs are driven by the cost of surfactant/cosolvent and the equipment necessary to handle the large volume of injection fluids and water that will result from this treatment process. At least 2 pore volumes of surfactant/cosolvent should be used to effectively sweep the Gallia member. Assuming the source area to be treated is approximately 80,000 square feet and the Gallia member approximately 10 feet in thickness with a porosity of 0.3 , one pore volume equals approximately 1.8 million gallons. Thus, upward of 5 million gallons of surfactant/cosolvent solution would have to be flushed through the Gallia member to remove the residual TCE NAPL. Using a typical injection solution of 4 to $8 \%$ surfactant/cosolvent would translate to 200,000 to 400,000 gallons of surfactant/cosolvent to achieve the 2 pore volume flush. This equates to between 2 to 4 million pounds of surfactant. Using Tween 80 as an example surfactant at $\$ 2$ per pound yields an estimated cost of between $\$ 4$ to 8 million for the surfactant alone. 
At these costs, a surfactant recycle/recovery system should be considered, which would reduce the volume of surfactant needed and raise the potential for completing additional flushes should they be necessary. The equipment costs would probably be in the range of $\$ 1$ to 2 million, yielding a total cost of $\$ 5$ to 10 million for a surfactant/cosolvent flush.

The likelihood that a surfactant/cosolvent flush would be successful is low based on the results of the surfactant pilot test performed by Intera in 1996. Although Intera recovered $4 \mathrm{~L}$ of TCE NAPL via solubilization, they needed 28 pore volumes of a $4 \%$ dihexyl sufosuccinate (MA-80) and 4\% isopropanol solution. This mixture was found to have a TCE solubilization capacity of approximately $50,000 \mathrm{mg} / \mathrm{L}$ and to have minimal adsorption to the Gallia member sediments. The initial volume of TCE NAPL estimated to be present in the pilot test subsurface area was $20 \mathrm{~L}$ based on a partitioning interwell tracer test (PITT). The post-treatment PITT test yielded 7.5 L of TCE NAPL, indicating a change of $12.5 \mathrm{~L}$ of TCE NAPL after the 28 pore volume flush. Given that $4 \mathrm{~L}$ of TCE NAPL were recovered, this means that $3.5 \mathrm{~L}$ of TCE NAPL were not accounted for. Thus, the surfactant/cosolvent flood may have resulted in removal of $62.5 \%$ of TCE NAPL had all the TCE mass been recovered. However, the TCE recovery data did not exhibit a breakthrough peak and never exceeded $200 \mathrm{mg} / \mathrm{L}$. Instead, a decrease in TCE concentrations with increasing injection volumes was observed. This TCE recovery pattern suggests that the surfactant did not enhance TCE solubilization during the 28 pore volumes of flushing.

\section{Permeable Reactive Barrier}

Permeable reactive barriers (PRBs) utilize reactive material placed in the subsurface to sorb, precipitate, or chemically or biologically transform contaminants in groundwater flowing through the PRB. PRBs are able to remediate a number of contaminant classes and have been demonstrated to be effective in treating environments that have proven recalcitrant to management through other remediation methods. They are designed as passive treatment systems, with groundwater typically flowing under a natural gradient. Because contaminated groundwater must passively flow through the treatment zone, a thorough understanding of plume boundaries, aquifer hydrogeology, and reactive media characteristics is essential. The permeability of emplaced reactive materials must equal or exceed that of the aquifer over the operational lifespan of the PRB to ensure that contaminated groundwater flows through, not around, the reactive zone. PRBs generally have low maintenance costs and few operational costs aside from long-term performance monitoring, which is necessary to ensure sustained functioning of the system.

A number of reactive materials are available to convert contaminants to nontoxic or immobile species in PRB systems. Most PRBs currently utilize zerovalent iron (ZVI), which via reductive transformations is able to dehalogenate trichloroethene and other chloroorganics and to precipitate anions and oxyanions. Minerals such as limestone and organic materials including mulch, compost, and peat are also used as reactive media, alone or in combination with other materials, to address contaminants including chlorinated solvents, metals, and nitrate. 
Most PRBs are operated in either a funnel-and-gate configuration or a continuous configuration. Funnel-and-gate systems channel groundwater into a zone (gate) of reactive media using slurry walls or sheet pilings. Because the cross-sectional flowpath of contaminated water entering the PRB is constricted by impermeable walls, flow velocity increases. Continuous PRBs, on the other hand, use a reactive zone that is wider than the flowpath of contaminated groundwater and that does not impact flow velocity. Both types of PRBs are typically limited to treating contaminated zones of less than about seventy feet deep, although methods such as hydrofracturing and slurry injection can extend the depth to which reactive materials are emplaced. The transverse thickness of the reactive media is selected based upon groundwater flow rate; together, these parameters control the residence time of groundwater in the PRB.

Iron-based treatment of Portsmouth groundwater

The use of zerovalent iron to remediate TCE in groundwater at the Portsmouth Gaseous Diffusion Plant was assessed under simulated field conditions in a 1996-1997

demonstration at the X-625 Groundwater Treatment Facility (West et al., 1997). A horizontal well was used to extract TCE-contaminated groundwater from the Gallia formation under the X-749/120 Solid Waste Management Unit. Three types of reactive materials were placed in canisters and tested in separate treatment trains: 40-mesh iron filings (Master Builders); 40-mesh iron filings chemically plated with palladium $(\mathrm{Pd} / \mathrm{Fe}$ from Fisher Scientific); and $-8+50$ mesh iron filings (Peerless; $90 \%$ or more of this material passes through an 8 -mesh sieve and is retained by a 50 -mesh sieve). The three materials were able to degrade TCE from $150 \mu \mathrm{g} / \mathrm{L}$ to less than $5 \mu \mathrm{g} / \mathrm{L}$, but the Peerless $-8+50$ mesh iron material supported the best performance because it resulted in less clogging. Clogging was identified as a potentially significant impediment to the longterm performance of zerovalent iron PRBs at the Portsmouth facility, even under conditions of sustained iron reactivity (West et al., 1997).

Mineralogical changes to iron filings in treatment canisters were studied after clogging was observed during the demonstration project. Iron filings sampled from the top six inches of canisters were dark- to blackish-brown and cemented together without visible rusting. The dominant mineral phases were metallic iron and iron oxides. Peerless-brand iron samples consisted of elongated particles of average size less than $4 \mathrm{~mm}$, oriented randomly and packed loosely. The initial pore space of Peerless iron, approximately $60 \%$, was partially replaced by iron hydroxide coatings, halving the total porosity and possibly reducing the effective porosity to less than $30 \%$ (West et al., 1997). The porosity of Master Builders and palladized iron samples was impacted to an even greater extent by 10-150 $\mu \mathrm{m}$-thick surface coatings of crystalline and amorphous iron hydroxide. The iron oxyhydroxides lepidocrocite $(\gamma-\mathrm{FeOOH})$ and goethite $(\alpha-\mathrm{FeOOH})$ were identified as dominant crystalline minerals in all three types of iron filings.

Observed iron oxidation exceeded that which could be attributed to the influent dissolved oxygen concentration of $100 \mu \mathrm{g} / \mathrm{L}$. Although oxygen diffusion into the treatment canisters may have occurred, it could not explain differences in the rate of clogging. It was suggested that precipitated iron sulfide and accumulated biomass may have contributed to clogging in the deeper non-sampled zones of the canisters. Sulfate was 
present at greater than $300 \mathrm{mg} / \mathrm{L}$ in influent groundwater, and sulfate-reducing bacteria were confirmed in effluent water.

Gas production was problematic during ZVI-mediated groundwater treatment: West et al. (1997) performed additional tests using the Peerless $-8+50$ mesh filings and CercoFoam -3+20-mesh foamed pellets $\left(90 \% \mathrm{Fe}^{0}, 2.5 \%\right.$ high silica iron, and $7.5 \%$ aluminosilicate; at least $90 \%$ of this material passes through a 3-mesh sieve and is retained by a 20-mesh sieve). The latter material was chosen for its coarse size and high reactivity. For several weeks after the startup of groundwater treatment, gas generation destabilized flow, particularly in CercoFoam material. Gas was predominantly hydrogen from the anaerobic corrosion of zerovalent iron. Two months after treatment commenced, gas production subsided and flows stabilized. The results of this study underscore the need to assess hydrogen-associated hazards for ZVI-based PRBs.

The CercoFoam and Peerless iron filings described above were used in short-duration studies to treat influent TCE concentrations of 70-100 $\mu \mathrm{g} / \mathrm{L}$. Effluent TCE concentrations below $2 \mu \mathrm{g} / \mathrm{L}$ were typically achieved for groundwater residence times of 76-221 minutes in 1997 tests (West et al., 1997). The only detected chlorinated daughter product, vinyl chloride, was present at $5 \mu \mathrm{g} / \mathrm{L}$ or less. The half-life of TCE for new iron filings was on the order of 16-25 minutes for both iron types; however, this value was based on limited data. Tests performed in 1996 with Peerless iron showed that over a period of several months after steady-state had been achieved in treatment canisters, the extent of TCE dechlorination remained consistently high, but the half-life increased from 19 minutes to 43 minutes (Liang et al., 1996). TCE half-life in column systems with Peerless iron increased even more, from 37 minutes to 69 minutes over five months during the first year of operation (Liang et al., 1996). TCE half-life in Master Builders iron canisters and columns was approximately 40 minutes after steady-state was reached in 1996 tests (up to 823 and 895 pore volumes in canisters and columns, respectively).

The $\mathrm{pH}$ of influent groundwater in 1997 tests averaged 5.5 and increased by 1-1.5 points during ZVI treatment (West et al., 1997). Ferrous iron levels also increased, from an influent concentration of approximately $0.3-1.0 \mathrm{mg} / \mathrm{L}$ to effluent concentrations as high as $306 \mathrm{mg} / \mathrm{L}$ for Peerless iron and $86 \mathrm{mg} / \mathrm{L}$ for CercoFoam iron. As groundwater passed through the treatment train, ferrous iron initially increased because of reductive dechlorination and abiotic reaction with anaerobic water, then decreased from adsorption and precipitation. Based on short-term data, ZVI consumption was estimated as $0.2 \mathrm{mg} \cdot \mathrm{kg}^{-1} \cdot \mathrm{min}^{-1}$. However, longer-duration studies of ZVI consumption are needed to predict the realistic field life of an iron PRB.

A number of assumptions must be made to estimate the iron required for a continuous ZVI PRB installed just to the east of the interceptor trench near the leading edge of the X$701 \mathrm{~B}$ plume, in Zone 4 . Peerless iron $(-8+50 \mathrm{mesh})$ is selected as the reactive media because of its propensity for less clogging than the other iron types tested. The average TCE concentration in Zone 4 groundwater following Phase IIe oxidant injections was 7,741 $\mu \mathrm{g} / \mathrm{L}$ (Camp Dresser McKee, 2008). A more conservative estimate of 10,000 $\mu \mathrm{g} / \mathrm{L}$ dissolved TCE is used as the value entering the PRB. Long-term TCE half-life is 
conservatively estimated as 120 minutes $\left(\mathrm{k}=0.00578 \mathrm{~min}^{-1}\right)$, based on the $\mathrm{X}-625$ Groundwater Treatment Facility tests using X-120/X-749 groundwater and Peerless iron. TCE dechlorination is assumed to proceed to near-completion, with no more than $5 \mu \mathrm{g} / \mathrm{L}$ TCE leaving the PRB and all other chlorinated daughter products below regulatory limits. The required residence time to achieve this, based on a 120 minute half-life, is 21.9 hours.

The hydraulic gradient upgradient of the current interceptor trench is approximately 0.05 , based on 2007 first-quarter potentiometric data, and the effective aquifer porosity is estimated as $30 \%$. Using a hydraulic conductivity value of $10 \mathrm{ft} / \mathrm{d}$ for the Gallia zone (the average value is $3.4 \mathrm{ft} / \mathrm{d}$ ), the groundwater velocity is calculated as $1.67 \mathrm{ft} / \mathrm{d}$. From this, the required PRB thickness is 1.5 feet. Applying a safety factor of 3 because of uncertainty in TCE concentrations and degradation kinetics, the required thickness of the reactive zone is 4.5 feet. The length of the iron zone must encompass the edge of the plume, which is approximately 500 feet. The iron zone depth is assumed to extend through 5 feet of the Gallia zone and 3 feet of the Minford zone, and it will be keyed 2 feet into the underlying formation. This corresponds to an iron volume of $22,500 \mathrm{ft}^{3}$. Assuming an iron bulk density of $150 \mathrm{lb} / \mathrm{ft}^{3}, 1683.1$ tons of granular iron would be needed. At an estimated cost of $\$ 0.55 / \mathrm{lb}$, the total cost of iron would be $\$ 1.85$ million.

The total design and installation cost for such a PRB is subject to site-specific expenses, including excavation and waste disposal fees. A similar system implemented at F.E. Warren Air Force Base in Cheyenne, Wyoming cost \$217,000 for design and \$2.4 million for materials, installation, oversight, and licensing fees (RTDF website, accessed 11/20/2008). This PRB was designed for TCE, cis-dichloroethylene, and vinyl chloride concentrations of $21,000 \mu \mathrm{g} / \mathrm{L}, 5600 \mu \mathrm{g} / \mathrm{L}$, and $120 \mu \mathrm{g} / \mathrm{L}$, respectively. The total PRB length of this system was 568 feet, with a depth of 15 feet and a width of 4 feet.

\section{Biowall-based treatment of TCE in groundwater}

Biowalls are permeable reactive barriers that utilize low-cost organic materials, such as mulch and compost, as reactive media for passive anaerobic treatment of contaminated groundwater. They are capable of addressing a variety of contaminants, including chlorinated solvents, perchlorate, chlorate, explosives, nitrate, sulfate, and metals such as chromium. Although generally limited to treating groundwater plumes less than about 35 feet deep, they may be used in aquifers with moderate to low permeability. As with other types of permeable reactive barriers, careful site screening is needed prior to selecting a biowall-based remedy. Unacceptably high or low flow rates, the presence of DNAPL, or excessive soluble contaminant concentrations can all preclude the use of this technology.

Biowalls can be employed in conjunction with other remediation methods, for example, with groundwater recirculation systems for source area treatment. In such a scenario, organic carbon released from mulch or compost can extend the reactive zone, improving performance. Biowall performance may also be enhanced through the addition of amendments, such as iron, that promote desirable contaminant transformation pathways. Multiple reaction zones can also be stimulated through the use of concomitant downgradient air sparging. Groundwater aeration supports aerobic reactions that can 
treat contaminants passing through the biowall or arising from anaerobic transformations within it (e.g., chlorinated solvent daughter products, hydrogen sulfide, fermentation products, or solubilized metals). Negative secondary impacts to groundwater quality can thus be minimized or prevented.

The lifespan of a biowall is limited by depletion of its carbonaceous substrates over time. However, this can be forestalled by augmentation with oil or other liquid carbon sources, which may extend a system's useful life to a decade or longer (AFCEE, 2008).

Infrastructure for substrate addition should be incorporated into the initial system design. As with other PRBs, long-term performance monitoring is essential. Operation and maintenance costs are generally low for biowalls, however, and construction costs are currently about $25-33 \%$ of those for iron-based PRBs (AFCEE, 2008).

Utilization of a biowall for treatment of the Portsmouth X-701B plume could be practical, but as discussed for ZVI PRBs, fairly extensive studies would be necessary to ascertain the type and quantity of organic materials best suited for treating TCE at existing concentrations. A biowall could be used as part of a source area treatment, perhaps in conjunction with surfactant/cosolvent flushing or groundwater recirculation. Alternately or additionally, it could be used at the plume's leading edge as a polishing step following upgradient treatment, or perhaps even as a stand-alone remedy (if influent TCE concentrations are predicted to remain within acceptable limits). The ability to rejuvenate the system as carbon substrate or reactivity is depleted is advantageous for long-term use of a biowall at the X-701B plume compared to use of an iron barrier.

\section{Bioremediation and Constructed Wetland}

\section{In Situ Bioremediation}

Treatment of dissolved-phase chlorinated ethenes, such as TCE, in groundwater using in situ bioremediation has been established and the method has been applied in diverse environments. The predominant approach used for such microbiology-based cleanup is the addition of electron donor and other reagents to optimize biogeochemical conditions for anaerobic degradation and, in some cases, adding key organisms such as Dehalococcoides. These activities are designated as biostimulation and bioaugmentation, respectively. In this anaerobic process, the contaminant acts as an electron acceptor (typically releasing a chlorine atom from the molecule) and the contaminant compound is mineralized through a series of daughters. Much of the past effort has focused on moderate concentrations of contaminant (e.g., $1000 \mu \mathrm{g} / \mathrm{L}$ ), but recent efforts have examined the potential applicability of bioremediation to higher concentration source areas. For example, the Interstate Technology and Regulatory Council recently developed case studies and documents for such sites (ITRC, 2008). This document provides a detailed description of the microbial degradation processes, summarizes case study experiences, and provides technical guidance for applying bioremediation to high concentration source areas such as the X-701B plume at Portsmouth. The ITRC report emphasizes the importance of setting realistic objectives for source zone treatment and integrating those goals with broader remedial action objectives for the target site. 
The sites that have achieved the most success have sufficient permeability to allow injection of treatment reagents and have relatively low dissolved oxygen. Some of the most successful case study sites had predeployment data that indicated the relevant biological degradation processes were occurring and that competing electron acceptors (such as oxygen and sulfate) were relatively low. In these cases, bioremediation accelerates anaerobic degradation and the process is sustained for a reasonable period of time. Another positive feature of bioremediation is the relative lack of contaminant rebound, compared to other source treatment methods, in the post remediation period (McGuire et al., 2006). Recent literature (Lee et al., 2008) highlights the potential role of aerobic microbial processes such as cometabolism in the degradation of TCE and other chlorinated solvents. The rates of aerobic cometabolism are relatively slow compared to anaerobic degradation (assuming each process is occurring in a conducive environment) and there has been limited research on sustainable stimulation of aerobic processes to increase rates. The research indicates, however, that aerobic cometabolism can play a significant role in attenuation of TCE and help achieve remedial goals at sites with large, dilute contaminant plumes. Unfortunately, the X-701B plume at Portsmouth has high source concentrations $(>100,000 \mu \mathrm{g} / \mathrm{L})$ that propagate downgradient and occupy a significant portion of the relatively short flowpath. This limits the potential for significant contribution by aerobic cometabolism.

A significant drawback to traditional anaerobic biodegradation technologies is the fact that the remediation results in the groundwater at the site being maintained in an aesthetically putrid condition - this is necessary to optimize and accelerate the contaminant destruction. This condition must be maintained until the objectives for the bioremediation are achieved. Following remediation, the site will recover to circumbaseline conditions over an extended timeframe. Similar to all in situ methods that require injection of liquid treatment reagents, bioremediation has limited capabilities to address contaminants that have diffused into less permeable zones.

In general, the groundwater at Portsmouth is amenable to bioremediation (with some challenges in particular areas as noted below). Notably, daughter products have been measured in a number of wells in the vicinity of the X-701B plume and have been measured at significant levels near the X-749 landfill in the southern portion of the Portsmouth site. Daughters may actually be present in many additional wells with high TCE concentrations, but the daughters are not reported in those wells because the dilution factor used for the analysis is based on the TCE, resulting in high detection limits.

For the X-701B plume, the target concentrations and the area of high TCE concentration are significant and the plume contains relatively significant levels of competing electron acceptor (e.g., circa $250 \mathrm{mg} / \mathrm{L}$ sulfate). A scoping calculation for the source area $\left(800,000 \mathrm{ft}^{3}\right)$ results in an electron donor requirement of approximately 80,000 lbs (assuming a typical dose of $0.1 \mathrm{lbs}$ carbon donor per cubic foot). The typical cost of donor is approximately $\$ 3$ per pound suggesting a reagent cost of about $\$ 240,000$. Assuming a deployment cost of 3 times the reagent cost, the technology application would be approximately $\$ 1,000,000$ (excluding site preparation and support). Prior bioremediation pilot efforts at this particular site did not strongly support applicability for 
this particular plume. The method may have applicability to other plumes at Portsmouth, however, particularly those with lower concentrations or sites in which there are existing sources of electron donor (such as the landfill).

\section{Constructed Wetland}

A constructed wetland is an engineered treatment system to which contaminated groundwater is introduced and decontaminated by system-scale bioremediation processes followed by release of the treated water into a nearby surface stream. The objective of an engineered wetland is to utilize a readily available type of media (e.g. peat or compost mixed with sand and gravel) that can be bioaugmented with specific bacteria that are highly efficient at sustainably degrading the target contaminants to acceptable levels prior to water release. Selected vegetation is planted on the surface of the wetland and may contribute to decontamination as well as add organic matter and other nutrients to the wetland media to help ensure a long-term sustainable treatment capability. Contaminated groundwater is delivered to a distribution piping system at the base of the wetland and allowed to flow upward through the reactive media. Treated water is withdrawn from the top of the wetland and released.

Although several different wetland designs are possible, passive operation is a highly desirable feature of an engineered wetland system for application to the X-701B site at Portsmouth. Passive recovery of groundwater from the contaminated aquifer by intercepting and capturing the TCE plume as well as delivering a manageable flowthrough volume to the wetland is an important parameter that depends on appropriate hydraulic conditions (e.g. head difference between source wells and the wetland) and a sufficiently robust wetland design.

Design Factors:

Engineered wetlands have been used successfully for treating municipal wastewater and other waste streams for many years. In the past approximately 10 years, development and testing of constructed wetlands designed to treat chlorinated volatile organic compounds (cVOCs) such as TCE and other similar contaminants dissolved in groundwater has been pursued with very promising results. Currently, however, there may not be sufficient information from full-scale field applications from which to reliably estimate the sustainability and long-term effectiveness of the treatment system without further intervention. However, a growing number of successful constructed wetland systems for treating cVOC-contaminated water exist.

Four fate mechanisms contribute to wetland treatment of cVOCs:

- $\quad$ Reductive dechlorination;

- Sorption;

- Methanotrophic biodegradation; and

- $\quad$ Plant uptake.

Reductive dechlorination, the anaerobic biodegradation process catalyzed by specialized halorespiring bacteria, is the most critical to treatment. Conversion of chlorinated 
ethenes and ethanes to lower chlorinated daughter products via reductive dechlorination is particularly rapid in wetland peat. For example, rate constants of 30-40 year ${ }^{-1}$ have been observed for reductive dechlorination of TCE in wetlands as opposed to 1-4 year ${ }^{-1}$ typically observed in aquifers (Lorah et al., 1997). Reductive dechlorination occurs throughout the wetland bed.

Sorption of $\mathrm{cVOCs}$ is another important fate mechanism since it increases the retention time in the wetland peat. Retardation factors of cVOCs in peat can exceed 10, signifying that the $\mathrm{cVOC}$ residence time can exceed water residence time by a factor of 10 . Sorption also occurs throughout the wetland bed.

Methanotrophic biodegradation, the aerobic biodegradation process catalyzed by methanotrophs, is also important. These bacteria colonize the surface of wetland plant roots and have the enzymes necessary to degrade cVOCs to $\mathrm{CO}_{2}$ and $\mathrm{H}_{2} \mathrm{O}$. It is thought that these organisms perform an important polishing step, degrading lower chlorinated daughter products before they reach the overlying water. Methanotrophic biodegradation occurs in the root zone of the wetland plants.

Plant uptake and metabolism is thought to be a relatively minor fate process. Some wetland plants have shown the ability to metabolize parent cVOCs (such as TCE), but the robust biodegradation processes that occur in these peats are thought to be more important.

A set of design principles for wetland cVOC treatment and a design approach has been developed by Pardue et al. (2000b) and Pardue (2002), based on information in the scientific literature. The design approach focuses on predicting wetland bed depth and area required for a given flow rate and plume composition. The design approach uses a simple first-order reactive transport model that incorporates sorption and biodegradation of cVOCs (Kassenga et al., 2003; Kassenga et al., 2004). Dispersion also can be considered using a more complex equation in addition to sequential biodegradation kinetics.

In summary, some design factors that need to be incorporated into selection of a constructed wetland as a groundwater treatment option at X-701B include the following:

- Evaluation of aquifer hydraulics (e.g. plume capture efficiency) and contaminated groundwater transport to the wetland

- Selection and testing of wetland media that provide suitable hydraulic properties and support enhanced TCE treatment

- Selection of a suitable consortium of microorganisms to enhance biodegradation and suitable vegetation for planting

- Estimation of the anticipated range of the volume of infiltrating water to support design of the surface area of the wetland

- Estimation of the anticipated range in concentration of TCE in infiltrating groundwater to support design of the wetland bed depth

- Consideration of the potential impact of released treated groundwater to Little Beaver Creek as it relates to changes in suspended solids and nutrient loading 
- Evaluation of the availability of space to support construction of the wetland

Once these pre-design activities have been completed, a wetland can be designed. The design should specify wetland depth, wetland width, media composition, inoculum characteristics, and recommended planting. A water balance is necessary to estimate the residence time of contaminants in the system and to insure that the wetland integrity can be maintained during periods of high evapotranspiration.

Potential application of a constructed wetland to the Portsmouth X-701B site:

Figure 13 illustrates an example of a possible application of a constructed wetland to the Portsmouth X-701B site. The wetland structure should be placed near Little Beaver Creek at as low an elevation as possible. In principle this permits implementing a Geosiphon delivery system from an upgradient part of the plume as shown in Figure 13 that conceptually captures contaminated groundwater followed by passive flow to the base of the wetland located approximately $1100 \mathrm{ft}$ to the east. For the Geosiphon to function properly the hydraulic head contrast between the groundwater intake wells and the top of the wetland must be sufficient to permit efficient groundwater interception and adequate flow to and through the wetland. The head contrast illustrated in Figure 13 is approximately $15 \mathrm{ft}$, which appears to be adequate, although seasonal and annual variations will occur. There are technical publications that address design factors of Geosiphons and from which groundwater flow rates can be estimated. This type of evaluation will be required as a key design element for a passive constructed wetland system at X-701B.

Another site-specific feature of X-701B that must be incorporated into wetland design is the flow rate and TCE concentration of groundwater that will be introduced to the base of the wetland. As a first approximation to what might be encountered with the system design in Figure 13 one can evaluate recovery data for groundwater captured by the interceptor trench system and sent to the X-624 treatment facility. For FY2008 the flow rate varied from 85,600 to $828,700 \mathrm{gal} / \mathrm{month}(\sim 2-19 \mathrm{gpm})$. The concentration of TCE varied from $2500 \mu \mathrm{g} / \mathrm{L}$ to $19,000 \mu \mathrm{g} / \mathrm{L}$ over the same period of time. These will become important input data to the wetland design process.

Estimates of the cost of a constructed wetland suitable for groundwater treatment at the $\mathrm{X}-701 \mathrm{~B}$ site is not possible currently owing to the requirement to perform a preliminary design analysis based on assessment of site-specific data, key elements of design modeling, and wetland materials testing. First, this evaluation will determine if an engineered wetland is feasible. Then, if deployment is practical the assessment will result in projections of bed thickness and surface area which are important cost drivers. The ITRC (2003) guidance document on constructed treatment wetlands discusses cost factors (capital and operation/maintenance). For a one acre surface area wetland a construction estimate of around $\$ 87,000$ is cited. However, it is unclear if this type of estimate is appropriate for application at X-701B. Additional cost factors are associated with operation and maintenance and include items such as periodic sampling (quarterly or another suitable frequency) and occasional weeding to avoid any negative impact on the wetland plants. 
It is interesting to consider how a constructed wetland might be incorporated into treatment of contaminated groundwater associated with the existing remedial activities at X-701B (e.g., the interceptor trench). The wetland illustrated in Figure 13 is designed to treat groundwater recovered from the plume near the Perimeter Road, and to take advantage of the hydraulic head differential between this part of the aquifer and the location of the wetland to drive passive delivery of groundwater to and through the wetland treatment bed. However, even assuming that the plume interception is effective, groundwater in the downgradient part of the plume will continue to reach the interceptor trench for a period of time (years) where recovery by pumping with subsequent treatment still will be required to prevent discharge into Little Beaver Creek. An option that should be considered involves continued recovery of groundwater into the trench and delivery by pumping to the constructed wetland for passive treatment, thereby avoiding use of the X624 facility. The parallel treatment of contaminated groundwater recovered by the Geosiphon system and the interceptor trench could continue until contamination in the downgradient part of the plume has reached acceptable levels and operation of the trench is no longer required. Careful assessment of robust wetland design features will be require to ensure that integration of both treatment activities is feasible.

Summary:

In summary, there is a growing body of observational data indicating that successful and cost-effective treatment of cVOC contaminated groundwater can be accomplished with constructed wetlands. Although it appears that the X-701B site has many features that can support selection of an engineered wetland treatment option, an essential first step is to perform a more rigorous pre-design assessment than appears in this report. The relatively high concentrations and limited area for constructing a wetland are significant issues that may preclude the use of this technology until the core plume concentrations are addressed with companion methods. If the results of a design assessment prove to be favorable, the site can proceed to a design phase that will include media selection, benchscale testing, modeling, and preliminary cost evaluation steps.

If a constructed wetland appears to be a suitable groundwater treatment alternative for managing the X-701B plume, DOE also may want to consider it as a future (long-term) replacement for active groundwater pumping and treating associated with the interceptor trench. Potentially, the sustainable and passive design features of the wetland will offer significant benefits over treatment approaches currently being used. 


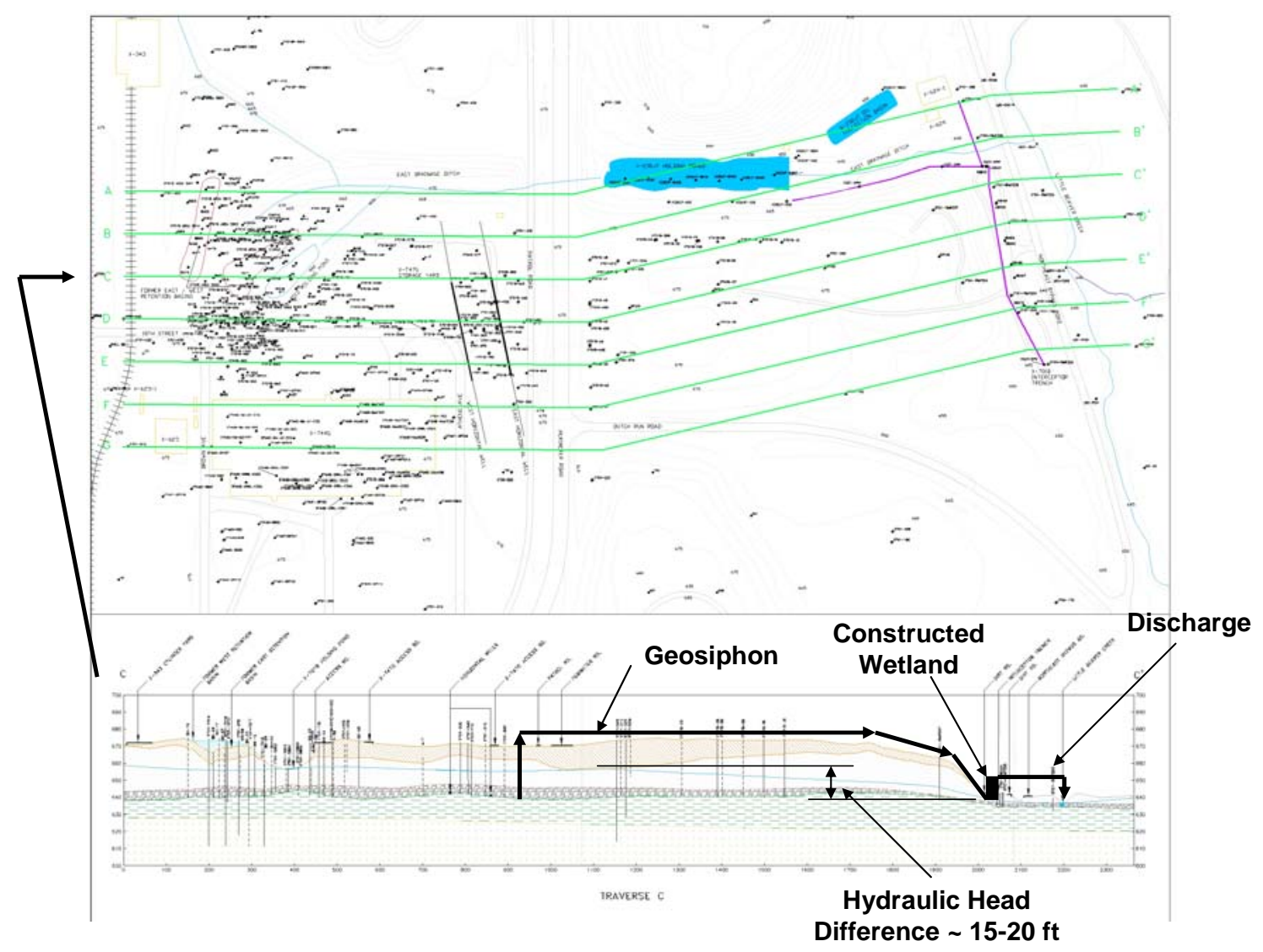

Figure 13. Schematic of potential constructed wetland system at X-701B. 
Physical, Hydraulic and Chemical Isolation/Immobilization

As noted above, there are three basic strategies for addressing the X-701B source removal, destruction or isolation/immobilization. The review panel believes that a combination of these strategies will be needed to make credible progress toward remediation goals. Isolation/immobilization is performed using physical barriers, controlling the quantity and flowpath of water, and/or through the strategic application of materials that chemically sequester or partition contaminants. These approaches do not remove or destroy contaminants. Instead they keep the contaminants in place and extend their release over a longer timeframe (but at a substantially reduced flux) with lower downgradient concentrations. Because of the large amount of source, the panel recommends that isolation and immobilization technologies be strategically used, in combination with technologies that remove and destroy the TCE source, to achieve specific remedial goals (e.g., target concentrations, or reduced fluxes that are compatible with constructed wetlands, PRBs, or other companion technologies).

The simplest isolation and immobilization concept is a surface cap. An extensive capping effort would have a limited impact on the plume because: 1) the Minford is relatively low permeability and 2) the contamination in the Minford appears to be limited to the areas below and immediately adjacent to former releases (e.g., the X-701B pond) and the lower portion of the formation that have been penetrated by diffusive processes from the underlying highly contaminated Gallia. This type of capping would tend to extend the timeframe of groundwater treatment (e.g., pump and treat), increase the diffusive penetration of contaminants into the lower Minford, and be unlikely to substantively impact groundwater concentrations. There are promising alternatives to surface capping, such as oxidant blending into the former sources, and the review panel urges consideration of those opportunities. If surface capping is performed, the review panel recommends that it be limited to only those areas overlying and adjacent to known sources and that other types of surface controls (e.g., engineered and lined drainages) be emphasized in the design. This recommendation is in line with the caps currently under consideration. The current concept is for limited capping of the former X-701B pond and the nearby sludge retention basins (approximately $88,000 \mathrm{ft}^{2}$ or 2 acres). A RCRA Subtitle C cap at a standard unit cost of $\$ 225 \mathrm{~K}$ per acre would result in technology implementation costs of approximately $\$ 450 \mathrm{~K}$ with additional costs for site preparations and support. It may be appropriate, given the limited benefits of capping, to consider elimination of the cap or implementation of a modest (RCRA Subtitle D or non-RCRA) capping system (emphasizing runoff control, etc.) with the potential to reduce costs and to utilize the resources to implement potentially more effective alternatives.

A variety of other physical barriers, such as subsurface walls (slurry or sheet piling), are also feasible. These options would be somewhat more effective than a surface cap because they would partially isolate the TCE source already present in the Gallia and Sunbury Formations. The costs of such barriers would be greater than a surface cap. A fully circumscribing barrier wall for the same area as the proposed cap would be approximately $60,000 \mathrm{ft}^{2}$. At a standard unit cost of $\$ 10$ to $\$ 20$ per $\mathrm{ft}^{2}$ this would result in a technology implementation cost of $\$ 600 \mathrm{~K}$ to $\$ 1,200 \mathrm{~K}$, with additional costs for site 
preparations and support. Note that in this area with potential subsurface interferences and security and other considerations, the actual cost to DOE for subsurface physical barriers is likely to be significantly higher than standard industry norms.

Hydraulic manipulation, either passive or active, is a potentially effective and underutilized concept for isolating sources and reducing the flux and release of contaminants. In this case, "clean" water would be intercepted upgradient and passively diverted downgradient, reducing the flow of water through the plume. This would result in a significant potential reduction in contaminant release - each gallon of diverted water results in a concomitant reduction in the release of contaminated water. At some sites, this is a viable option because the benefits are realized without the need to treat any of the "clean" water being diverted. In the case of the X-701B plume, however, this effort would not improve environmental stewardship since the water in the distal portion of the plume is already being captured in a collection trench and treated. Moreover, the diversion of the water would isolate and "stagnate" the plume in place and significantly extend the amount of time required for the pump and treat (or collect and treat) operations to be performed.

There are a variety of in situ options for chemical isolation/immobilization. The most appropriate for the X-701B plume scenario involve injection of long lived organic materials that would sequester the TCE source or block the migration from finer grained formations (e.g., the Minford and Sunbury). The key to a successful deployment is the emplacement of the material into a small volume immediately adjacent to the area or interface being targeted for control. In the case of the Minford interface, this would require a light material, such as a vegetable oil, to be emplaced in the upper Gallia. This material would float toward the top of the aquifer and collect at the Minford Gallia contact. Placement of sufficient light oil would provide a sink for TCE that would reduce the flux into the groundwater plume and the slow degradation of the oil would contribute to TCE biodegradation. Dense oils (e.g., silicone oils) are also available that could be deployed into the lower Gallia and sink toward the Sunbury contact. This type of sequestration is potentially viable for sites with relatively small amounts of residual source or for polishing after other techniques have removed most of the source. Unfortunately, this type of in situ sequestration is not appropriate for sites such as X701B where large amounts of residual TCE source are present. Over time, the deployed sequestrant would become loaded with TCE and the fluxes would increase toward predeployment levels. At that point, the sequestration would adversely impact effectiveness of many contaminant removal and destruction techniques.

In summary, isolation and immobilization technologies have limited potential to benefit environmental stewardship at X-701B. Importantly, all of these technologies extend the remediation time frame and are generally not effective for sites with significant quantities of residual contamination. The review panel consensus was that the current limited capping is viable and consistent with regulatory policies and expectations for RCRA sites. Nonetheless, the panel concluded that several alternative technology activities would provide more benefit than isolation/immobilization and that resources currently planned for caps and barriers could be more cost-effectively deployed. 


\subsection{Recommendations -- Combined Remedy}

Table 3 provides a snapshot summary of the technical review team assessment of the various individual technologies. This table separates the technologies by class (Oxidant, Pump and Treat, Thermal, Excavation, Surfactant and Cosolvent Flushing, Permeable Reactive Barrier, Bioremediation and Constructed Wetland, and Physical, Hydraulic and Chemical Isolation/Immobilization) and addresses each of the major variants discussed above. For each technology and scenario, the team provides a brief description, summarizes strengths and weaknesses, and provides an overall statement on the potential for the technology at X-701B (used alone or in combination with other methods). It is clear from the table that any of the individual technologies, used alone, would be unlikely to achieve remedial objectives in a timely manner. The technical review panel determined that the site consider a combination of technologies that would work synergistically together. The idea of a "combined remedy" is particularly attractive at this site where the different plume segments can be reasonably identified and accessed.

Many technology combinations are possible and the discussion that follows provides only a few examples. In general, the combinations involve some additional focused source treatment, modified pump and treat and some form of sustainable treatment to protect receptors, such as Little Beaver Creek, until remedial objectives are met. The team recommended implementing the innovative characterization recommendations to better delineate target source zones. This knowledge would provide focus for future source treatment activities, reducing costs and minimizing the collateral damage associated with techniques that employ large quantities of chemicals or energy in the environment. Note that the review team provides constraints on the technology recommendations. For example, oxidants were identified as viable, but only for deployment scenarios significantly different than the lance based catalyzed peroxide currently being used in Phase II. An overarching recommendation by the panel was the need to modify the pump and treat to increase its effectiveness in terms of contaminant extraction rate and to support other selected technologies.

Source remediation techniques identified for consideration by the Portsmouth team included:

- Oxidants - the review panel specifically recommended considering the blending of solid oxidants beneath the former source basin (in lieu of a cap), focusing additional injections toward the Gallia Sunbury contact using high strength longlived oxidants. The panel recommends combining any oxidant method(s) with hydraulic control.

- Thermal - the review panel documented that this technology class remains potentially viable, particularly if deployment can be performed under a fixed price and guaranteed performance contract by a reputable, experienced vendor.

The technical review team concluded that source area techniques such as isolation/immobilization, surfactant/cosolvent flushing, excavation and bioremediation were somewhat less promising for the high strength TCE sources in the X-701B area. 
Further, the team noted that pump and treat and other downgradient interdiction processes (e.g., PRBs and wetland treatment) would not have any substantive benefit in addressing residual high strength TCE sources.

Several technologies to address the dissolved plume were identified by the review team. The review panel believes that a modified pump and treat system could significantly accelerate progress toward remedial objectives by increasing mass removal and assisting companion technologies. This will require an integrated decision process and coordinated implementations. However, high energy or chemical based source treatment methods, in situ bioremediation, and passive methods (e.g., PRBs and wetland treatment) are considered somewhat less promising for high dissolved TCE concentrations in the X701B plume. For example, PRBs and wetland treatment systems are likely to require the current high concentrations/fluxes of TCE to be mitigated to allow successful design and implementation. The review team envisioned a phased process in which the focused source treatment and pump and treat modifications are implemented and the sustainable remedial technology is developed based on the observed performance. This provides time (e.g., 10 to 30 years) for the required concentration reductions to be realized and time to gather data to design and implement a sustainable remediation technology and to develop contingencies to assure remedial objectives are met.

\section{An Example Combined Remedy}

A simple combination of technologies includes soil blending of oxidant, focused DNAPL characterization, targeted injection of long-lived oxidant solution, and modified pumpand-treat. Soil blending of oxidants can be beneficially augmented with modified pump and treat and recirculation strategies in which extraction wells can be placed along the midline of the plume and downgradient, with water reinjected upgradient of the sources and/or outside the midline to encourage outside-in containment and flushing. Reinjection would be especially useful if oxidant breaks through to the extraction wells, because oxidant could be recovered and reinjected. Reinjection would also reduce the potential impact of residual oxidant on surface water outfalls. Current infrastructure could be used for pumping (e.g., horizontal wells for extraction and current pump and treat wells for injection) and these could be augmented as needed. A potential negative of the breakthrough of oxidant into the pump and treat system is the need to make sure that the oxidant does not adversely impact the treatment system or receiving stream. Mitigating oxidant breakthrough impacts might require additional air stripping and elimination of the carbon polishing and implementation of upgradient reinjection or recirculation. Blending can also be augmented by additional targeted injections of liquid oxidant.

After this (or an alternative) portfolio of actions reduces the source mass and plume concentrations/fluxes, a passive technique such as a PRB or wetland treatment system may be feasible and is recommended. This would intercept the advance of any remaining TCE flux by decontaminating groundwater prior to discharge to a receptor. The principal objectives of this long-term approach are selection of a technology with an acceptable cost of implementation and monitoring, a technically based expectation of sustainable operation, and an ability to prevent discharge of contaminants to Little Beaver Creek. 
Table 3.

\begin{tabular}{|c|c|c|c|c|}
\hline Technology & $\begin{array}{c}\text { Description / Target } \\
\text { Zone / Key Assumptions }\end{array}$ & Positives & Negatives & Summary Assessment \\
\hline \multicolumn{5}{|c|}{ Oxidant Injection/Blending } \\
\hline $\begin{array}{l}\text { In situ oxidant } \\
\text { injections }\end{array}$ & $\begin{array}{l}\text { Current baseline activity } \\
\text { (using lance injection of } \\
\text { catalyzed peroxide), } \\
\text { source zone treatment }\end{array}$ & $\begin{array}{l}\text { Treatment can be focused } \\
\text { on specific zones and } \\
\text { locations. Site should } \\
\text { consider modification to } \\
\text { oxidant type (more } \\
\text { persistent oxidant like } \\
\text { permanganate or persulfate) } \\
\text { and injection strategies. } \\
\text { Stakeholders and regulators } \\
\text { are already familiar with } \\
\text { technology. }\end{array}$ & $\begin{array}{l}\text { Complete treatment of } \\
\text { source will require } \\
\text { alternative oxidant and } \\
\text { multiple phases of injection. } \\
\text { It will be difficult to contact } \\
\text { contaminants outside of } \\
\text { established flow paths. Can } \\
\text { be expensive with full dose } \\
\text { of oxidant. Some types of } \\
\text { oxidant may temporarily } \\
\text { impact secondary drinking } \\
\text { water standards. }\end{array}$ & $\begin{array}{l}\text { Review team recommends } \\
\text { consideration of long-lived oxidant } \\
\text { to address persistent sources. More } \\
\text { focused high oxidant injection and } \\
\text { control on the pattern of injection } \\
\text { should be used if oxidant is } \\
\text { continued. Review team } \\
\text { discourages use of long screens for } \\
\text { injection. Should consider coupling } \\
\text { treatment with hydraulic control and } \\
\text { recirculating systems. Better } \\
\text { characterization used to target } \\
\text { treatment areas. }\end{array}$ \\
\hline $\begin{array}{l}\text { In situ Soil } \\
\text { Mixing/Blending } \\
\text { Oxidant }\end{array}$ & $\begin{array}{l}\text { In former release areas, } \\
\text { e.g., X-701B Basin for the } \\
\text { entire thickness } \\
\text { (approximately } 21 \text { feet } \\
\text { target thickness down to } \\
\text { upper Sunbury Shale). }\end{array}$ & $\begin{array}{l}\text { Blending will provide better } \\
\text { contact with contaminants } \\
\text { than injection. Will } \\
\text { eliminate need for } \\
\text { excavation/treatment/ } \\
\text { disposal of basin material. } \\
\text { Consider blending a longer } \\
\text { lasting oxidant ( } 2 \text { yrs or } \\
\text { longer), e.g., solid } \\
\text { potassium permanganate } \\
\text { that will dissolve and } \\
\text { transport through plume- } \\
\text { affected volume. }\end{array}$ & $\begin{array}{l}\text { Expensive for large } \\
\text { volumes. Would not be } \\
\text { cost-effective for entire } \\
\text { plume area treatment or } \\
\text { similar volume. }\end{array}$ & $\begin{array}{l}\text { In-situ treatment that would achieve } \\
\text { better contact of treatment chemical } \\
\text { with contaminants. Is appropriate } \\
\text { for source area where large amounts } \\
\text { of residual source may still exist. } \\
\text { Consider coupling with targeted } \\
\text { injections or recirculating systems. } \\
\text { Additional focused characterization } \\
\text { will help limit costs. The technical } \\
\text { review team considered this a } \\
\text { potentially useful approach that is } \\
\text { generally superior to capping for the } \\
\text { source area at a similar cost. }\end{array}$ \\
\hline
\end{tabular}




\begin{tabular}{|c|c|c|c|c|}
\hline Technology & $\begin{array}{c}\text { Description / Target } \\
\text { Zone / Key Assumptions }\end{array}$ & Positives & Negatives & Summary Assessment \\
\hline \multicolumn{5}{|l|}{ Pump and Treat } \\
\hline $\begin{array}{l}\text { Baseline Pump and } \\
\text { Treat System }\end{array}$ & $\begin{array}{l}\text { Continue operation of X- } \\
623 \text { and X-624 treatment } \\
\text { systems using existing } \\
\text { three extraction wells and } \\
\text { downgradient collection } \\
\text { trenches, respectively. }\end{array}$ & $\begin{array}{l}\text { Currently operating system } \\
\text { - simple to continue. X-623 } \\
\text { currently removes } \\
\text { approximately } 60 \mathrm{lbs} \text { of } \\
\text { TCE per year and X-624 } \\
\text { currently removes } \\
\text { approximately } 24 \mathrm{lbs} \text { per } \\
\text { year. }\end{array}$ & $\begin{array}{l}\text { Removal of mass at these } \\
\text { rates is useful but unlikely } \\
\text { to promote rapid progress } \\
\text { toward remediation goals } \\
\text { because initial TCE releases } \\
\text { were on the order of } 50,000 \\
\text { to } 100,000 \text { lbs. Should be } \\
\text { considered an interdiction } \\
\text { process and requires } \\
\text { operation until the source is } \\
\text { depleted and the diffusion } \\
\text { from the Minford and } \\
\text { Sunbury are complete. }\end{array}$ & $\begin{array}{l}\text { If selected, needs to be implemented } \\
\text { in combination with other } \\
\text { techniques and/or be operated for a } \\
\text { extended timeframe (several } \\
\text { hundred years) }\end{array}$ \\
\hline $\begin{array}{l}\text { Modified Pump and } \\
\text { Treat }\end{array}$ & $\begin{array}{l}\text { Continue operation of X- } \\
623 \text { and X-624 systems } \\
\text { but relocate extraction } \\
\text { wells or utilize horizontal } \\
\text { wells for extraction. }\end{array}$ & $\begin{array}{l}\text { Relocation of the X-623 } \\
\text { extraction wells (or use of } \\
\text { the horizontal wells) for } \\
\text { extraction should increase } \\
\text { mass removal to }>300 \text { lbs of } \\
\text { TCE per year. May provide } \\
\text { better hydraulic control in } \\
\text { combination with certain } \\
\text { types of companion source } \\
\text { treatment (e.g., flushing) } \\
\text { techniques }\end{array}$ & $\begin{array}{l}\text { Similar to baseline, the main } \\
\text { issue is the extended } \\
\text { timeframe. }\end{array}$ & $\begin{array}{l}\text { If selected, needs to be implemented } \\
\text { in combination with other } \\
\text { techniques and/or be operated for a } \\
\text { extended timeframe (modifications } \\
\text { should reduce timeframe to about } \\
100 \text { years or less) }\end{array}$ \\
\hline $\begin{array}{l}\text { Passive "Collect and } \\
\text { Treat" System }\end{array}$ & $\begin{array}{l}\text { Collect water that crops } \\
\text { out. Establishes an } \\
\text { environment that } \\
\text { encourages attenuation } \\
\text { prior to agreed exposure } \\
\text { point. }\end{array}$ & $\begin{array}{l}\text { Provides for sorption by } \\
\text { biomass, biodegradation, } \\
\text { attenuation mechanisms } \\
\text { including volatilization, } \\
\text { mixing, etc. See wetland } \\
\text { treatment option and PRB } \\
\text { sections for more detailed } \\
\text { analysis. }\end{array}$ & $\begin{array}{l}\text { See wetland treatment } \\
\text { option }\end{array}$ & $\begin{array}{l}\text { Potentially challenging in an } \\
\text { environment where the TCE } \\
\text { concentrations in water entering the } \\
\text { surface environment are in the range } \\
\text { of } 2,000 \text { to } 20,000 \mu \mathrm{g} / \mathrm{L} \text {. }\end{array}$ \\
\hline
\end{tabular}




\begin{tabular}{|c|c|c|c|c|}
\hline Technology & $\begin{array}{l}\text { Description / Target } \\
\text { Zone / Key Assumptions }\end{array}$ & Positives & Negatives & Summary Assessment \\
\hline \multicolumn{5}{|c|}{ Physical Removal } \\
\hline Excavation & $\begin{array}{l}\text { Excavation of selected } \\
\text { areas }\end{array}$ & $\begin{array}{l}\text { Low tech, nonproprietary, } \\
\text { standard practice and } \\
\text { standard cost assessment. } \\
\text { Source is removed from } \\
\text { system - no rebound. } \\
\text { If not transported or } \\
\text { disposed of offsite, can be } \\
\text { reasonable in cost } \\
\text { (approximately } \$ 100 \text { per } \\
\text { ton). } \\
\text { Relatively rapid activity, } \\
\text { approximately } 300 \text { to } 500 \\
\text { tons per day addressed. }\end{array}$ & $\begin{array}{l}\text { Transport and disposal } \\
\text { offsite, if necessary, will be } \\
\text { expensive (probably > } \\
\$ 500 / \text { ton) } \\
\text { Large amounts of soil will } \\
\text { be cost prohibitive. }\end{array}$ & $\begin{array}{l}\text { May be appropriate if: } \\
\text { 1. No offsite disposal } \\
\text { required. } \\
\text { 2. Volume excavated can be } \\
\text { limited, i.e. only within the X- } \\
701 \mathrm{~B} \text { basin. This should be } \\
\text { coordinated with additional } \\
\text { characterization (e.g., LIF or } \\
\text { MIP). } \\
\text { 3. "Clean soil" can be staged } \\
\text { on site and only contaminated } \\
\text { soil removed. }\end{array}$ \\
\hline
\end{tabular}




\begin{tabular}{|c|c|c|c|c|}
\hline Technology & $\begin{array}{c}\text { Description / Target } \\
\text { Zone / Key Assumptions }\end{array}$ & Positives & Negatives & Summary Assessment \\
\hline \multicolumn{5}{|l|}{ Thermal } \\
\hline Steam Flood & $\begin{array}{l}\text { Flood steam through the } \\
\text { Gallia member in the } \\
\text { source area. Assumes that } \\
\text { system provides hydraulic } \\
\text { control of Gallia } \\
\text { groundwater and that } \\
\text { steam can heat fine } \\
\text { grained components. }\end{array}$ & $\begin{array}{l}\text { System can be used to } \\
\text { sweep multiple pore } \\
\text { volumes of entire source } \\
\text { zone with steam. Easy to } \\
\text { determine the mass of TCE } \\
\text { recovered. SteamTech pilot } \\
\text { test demonstrated that steam } \\
\text { was effective in lower } \\
\text { Gallia member where they } \\
\text { recovered } 256 \mathrm{~L} \text { of TCE } \\
\text { NAPL or } 80 \% \text { estimated. }\end{array}$ & $\begin{array}{l}\text { SteamTech recommended } \\
\text { pressure cycling, high } \\
\text { injection pressures, and } \\
\text { close injection well spacing } \\
\text { to heat fine grained } \\
\text { sediments. Requires large- } \\
\text { scale process equipment, } \\
\text { and treatment/disposal of } \\
\text { large volumes of } \\
\text { contaminated water. Also } \\
\text { had issues with fines } \\
\text { clogging air stripper. May } \\
\text { require extended heating } \\
\text { time (i.e., }>6 \text { months) to } \\
\text { recover TCE from fine } \\
\text { grained zones. }\end{array}$ & $\begin{array}{l}\text { Steam demonstrated to work in } \\
\text { Gallia member with } 67 \text { gal of TCE } \\
\text { recovered during pilot test. } \\
\text { However, SteamTech required high } \\
\text { injection pressures, steam cycling, } \\
\text { and extended heating time to reach } \\
\text { temperature in fine grain areas. } \\
\text { SteamTech recommended injection } \\
\text { wells spaced at less than } 40 \text { feet. } \\
\text { While steam was demonstrated to be } \\
\text { effective, it may not fully address } \\
\text { TCE remaining in fine grained } \\
\text { zones. Given the site specific } \\
\text { success of this heating technique, it } \\
\text { could be considered as part of a } \\
\text { thermal treatment approach. }\end{array}$ \\
\hline Conductive Heating & $\begin{array}{l}\text { Install heater wells in the } \\
\text { Gallia and Sunbury } \\
\text { members in the source } \\
\text { area. Assumes hydraulic } \\
\text { control of Gallia member } \\
\text { groundwater. }\end{array}$ & $\begin{array}{l}\text { Can target heating to } \\
\text { Sunbury member and } \\
\text { weathered shale. Simple and } \\
\text { reliable technology. Easy to } \\
\text { determine the mass of TCE } \\
\text { recovered. }\end{array}$ & $\begin{array}{l}\text { May require close heater } \\
\text { well spacing to uniformly } \\
\text { heat source zone area. } \\
\text { Conductive heater wells } \\
\text { operate at high temperatures } \\
(800 \text { deg C) and may create } \\
\text { byproducts. Requires large- } \\
\text { scale process equipment, } \\
\text { and treatment and disposal } \\
\text { of large volumes of } \\
\text { contaminated water. May } \\
\text { require extended heating } \\
\text { time (i.e., }>6 \text { months) to } \\
\text { recover TCE from fine } \\
\text { grained zones. }\end{array}$ & $\begin{array}{l}\text { Conductive heating is very effective } \\
\text { at delivering heat to targeted areas. } \\
\text { However, radius of heating can be } \\
\text { limited, requiring close spacing (i.e., } \\
5 \text { to } 10 \text { feet) of heater wells. Given } \\
\text { the reliability of this heating } \\
\text { technique, it could be considered as } \\
\text { part of a thermal treatment } \\
\text { approach. }\end{array}$ \\
\hline
\end{tabular}




\begin{tabular}{|c|c|c|c|c|}
\hline Technology & $\begin{array}{c}\text { Description / Target } \\
\text { Zone / Key Assumptions }\end{array}$ & Positives & Negatives & Summary Assessment \\
\hline \multicolumn{5}{|c|}{ Thermal (continued) } \\
\hline $\begin{array}{l}\text { Electrical Resistive } \\
\text { Heating }\end{array}$ & $\begin{array}{l}\text { Install electrical heater } \\
\text { wells in the Gallia and } \\
\text { Sunbury members in the } \\
\text { source area. Assumes } \\
\text { hydraulic control of } \\
\text { Gallia member } \\
\text { groundwater and good } \\
\text { electrical distribution } \\
\text { characteristics. }\end{array}$ & $\begin{array}{l}\text { Ability to uniformly heat } \\
\text { Milford, Gallia and Sunbury } \\
\text { members. Proven treatment } \\
\text { technology for fine-grained } \\
\text { soils and sediments. Easy to } \\
\text { determine the mass of TCE } \\
\text { recovered. }\end{array}$ & $\begin{array}{l}\text { May require close electrical } \\
\text { heater well spacing to } \\
\text { uniformly heat source zone } \\
\text { area. Potential for stray } \\
\text { electrical current to reach } \\
\text { utilities. Requires large- } \\
\text { scale process equipment, } \\
\text { and treatment and disposal } \\
\text { of large volumes of } \\
\text { contaminated water. May } \\
\text { require extended heating } \\
\text { time (i.e., }>6 \text { months) to } \\
\text { recover TCE from fine } \\
\text { grained zones. }\end{array}$ & $\begin{array}{l}\text { Electrical resistive heating is } \\
\text { considered to be a presumptive } \\
\text { remedy for TCE in fine-grained } \\
\text { sediments. Even in areas of high } \\
\text { electrical conductivity, electrical } \\
\text { heating has been demonstrated to be } \\
\text { applicable. However, electrical } \\
\text { heating faces challenges in areas } \\
\text { with contrasting layers of electrical } \\
\text { conductivity, such as between the } \\
\text { Minford, Gallia, and Sunbury } \\
\text { members. Thus, while electrical } \\
\text { heating would likely succeed in } \\
\text { heating the Minford and Sunbury, } \\
\text { additional electrical heater wells } \\
\text { may be required to direct the heat } \\
\text { into the Gallia member. Electrical } \\
\text { resistive heating could be } \\
\text { considered as part of a thermal } \\
\text { treatment approach. }\end{array}$ \\
\hline $\begin{array}{l}\text { Combined Thermal } \\
\text { Treatment } \\
\text { Technologies }\end{array}$ & $\begin{array}{l}\text { Install conductive heater } \\
\text { wells in the Sunbury } \\
\text { member in the source area } \\
\text { and sweep the Gallia with } \\
\text { steam. Assumes hydraulic } \\
\text { control of Gallia member } \\
\text { groundwater. }\end{array}$ & $\begin{array}{l}\text { Combining technologies has } \\
\text { the potential to reduce } \\
\text { overall treatment energy and } \\
\text { time, along with volume of } \\
\text { recovered fluids. Combining } \\
\text { overcomes limitations of } \\
\text { individual techniques. }\end{array}$ & $\begin{array}{l}\text { Combining multiple thermal } \\
\text { technologies increases the } \\
\text { number and variety of } \\
\text { process equipment and } \\
\text { complexity in managing the } \\
\text { treatment. Adding multiple } \\
\text { processes results in an } \\
\text { infrastructure and } \\
\text { equipment cost associated } \\
\text { with each of the component } \\
\text { technologies. }\end{array}$ & $\begin{array}{l}\text { The combination of thermal } \\
\text { technologies potentially leverages } \\
\text { each technology's strengths while } \\
\text { minimizing weaknesses. One } \\
\text { example would be to heat the } \\
\text { Sunbury member with conductive } \\
\text { heater wells followed by flushing } \\
\text { the Gallia with steam. A combined } \\
\text { heating approach could be } \\
\text { considered as part of a robust source } \\
\text { treatment approach. }\end{array}$ \\
\hline
\end{tabular}




\begin{tabular}{|c|c|c|c|c|}
\hline Technology & $\begin{array}{l}\text { Description / Target } \\
\text { Zone / Key Assumptions }\end{array}$ & Positives & Negatives & Summary Assessment \\
\hline \multicolumn{5}{|c|}{ Surfactant/Cosolvent Flushing } \\
\hline $\begin{array}{l}\text { Surfactant/Cosolvent } \\
\text { Flushing }\end{array}$ & $\begin{array}{l}\text { Inject surfactant/cosolvent } \\
\text { to flush through the Gallia } \\
\text { member in the source } \\
\text { area. Assumes hydraulic } \\
\text { control of Gallia } \\
\text { groundwater and that the } \\
\text { surfactant can penetrate } \\
\text { isolated fine-grained } \\
\text { zones. }\end{array}$ & $\begin{array}{l}\text { Can sweep multiple pore } \\
\text { volumes of entire source } \\
\text { zone with surfactant// } \\
\text { cosolvent. Can determine } \\
\text { the mass of TCE recovered. } \\
\text { The Intera pilot test } \\
\text { demonstrated that MA-80 } \\
\text { was effective with Gallia } \\
\text { sediments. Residual } \\
\text { surfactant/cosolvent can } \\
\text { stimulate reducing aquifer } \\
\text { conditions. }\end{array}$ & $\begin{array}{l}\text { Surfactant/cosolvent may } \\
\text { not reach isolated fine } \\
\text { grained zones. Large } \\
\text { volume of surfactant/ } \\
\text { cosolvent requires large } \\
\text { scale process equipment, } \\
\text { and treatment and disposal } \\
\text { of large volumes of } \\
\text { contaminated water. Intera } \\
\text { pilot test required } 28 \text { pore } \\
\text { volumes of flushing to } \\
\text { recover } 67 \% \text { of TCE NAPL. }\end{array}$ & $\begin{array}{l}\text { Surfactant/cosolvents are capable of } \\
\text { sweeping multiple pore volumes of } \\
\text { source area. However, the large } \\
\text { volume of surfactant/cosolvent } \\
\text { requires large-scale process } \\
\text { equipment. Intera pilot test results } \\
\text { suggest surfactant/cosolvent did not } \\
\text { enhance TCE solubility. Thus, } \\
\text { surfactant/cosolvent injection would } \\
\text { be high risk given the relatively high } \\
\text { cost and results of the pilot test. }\end{array}$ \\
\hline
\end{tabular}




\begin{tabular}{|c|c|c|c|c|}
\hline Technology & $\begin{array}{c}\text { Description / Target } \\
\text { Zone / Key Assumptions }\end{array}$ & Positives & Negatives & Summary Assessment \\
\hline \multicolumn{5}{|c|}{ Permeable Reactive Barriers } \\
\hline $\begin{array}{l}\text { Zerovalent iron } \\
\text { (ZVI) PRBs }\end{array}$ & $\begin{array}{l}\text { A passive groundwater } \\
\text { treatment system that uses } \\
\text { a subsurface "barrier" of } \\
\text { zerovalent iron to } \\
\text { reductively transform } \\
\text { chlorinated solvents. } \\
\text { Effective treatment } \\
\text { requires adequate PRB } \\
\text { thickness (residence time) } \\
\text { and accommodation of } \\
\text { the entire plume width. }\end{array}$ & $\begin{array}{l}\text { Able to remediate a variety } \\
\text { of contaminant types to } \\
\text { regulatory concentrations. } \\
\text { Low operating and } \\
\text { maintenance costs. Iron } \\
\text { may be used in combination } \\
\text { with other reactive materials } \\
\text { in a single PRB to address } \\
\text { multiple contaminants, e.g., } \\
\text { sulfate generated by } \\
\text { upgradient persulfate } \\
\text { oxidation. PRBs may be } \\
\text { used as a polishing step in } \\
\text { conjunction with source } \\
\text { area treatments; resulting } \\
\text { lowered influent } \\
\text { concentrations can reduce } \\
\text { PRB dimensions and costs. }\end{array}$ & $\begin{array}{l}\text { Reactive zone is subject to } \\
\text { mineral and biological } \\
\text { clogging and iron } \\
\text { passivation. Long-term iron } \\
\text { reactivity is difficult to } \\
\text { extrapolate to field } \\
\text { conditions from lab or pilot } \\
\text { studies. High solvent } \\
\text { concentrations may require } \\
\text { long residence times and } \\
\text { prohibitive PRB } \\
\text { thicknesses. Not useful for } \\
\text { environments with } \\
\text { significant fluctuations in } \\
\text { groundwater flow direction. } \\
\text { Requires long-term } \\
\text { monitoring. }\end{array}$ & $\begin{array}{l}\text { Offers an alternative to long-term } \\
\text { pump and treat, but efficacy } \\
\text { depends on iron lifespan and } \\
\text { sustained permeability. } \\
\text { Uncertainties in design parameters } \\
\text { underscore the need for longer-term } \\
\text { studies of iron reactivity against } \\
\text { TCE in Portsmouth X-701B } \\
\text { groundwater. }\end{array}$ \\
\hline Biowalls & $\begin{array}{l}\text { A permeable reactive } \\
\text { barrier with a reactive } \\
\text { zone comprised primarily } \\
\text { of mulch, compost, or } \\
\text { other organic materials. } \\
\text { Design and } \\
\text { implementation } \\
\text { considerations are similar } \\
\text { to those of PRBs. }\end{array}$ & $\begin{array}{l}\text { Able to treat chlorinated } \\
\text { solvents and other } \\
\text { contaminant classes. More } \\
\text { cost-effective than iron } \\
\text { PRBs. Can be used in } \\
\text { combination with other } \\
\text { technologies. }\end{array}$ & $\begin{array}{l}\text { System life may be shorter } \\
\text { than that of iron PRBs, but } \\
\text { biowalls can be rejuvenated } \\
\text { through addition of oil or } \\
\text { other organic substrates. } \\
\text { Requires long-term } \\
\text { monitoring. Negative } \\
\text { secondary impacts to } \\
\text { groundwater quality can } \\
\text { occur (e.g., formation of } \\
\text { fermentation products). }\end{array}$ & $\begin{array}{l}\text { May be used alone, but at the X- } \\
\text { 701B plume would likely be used } \\
\text { more effectively in conjunction with } \\
\text { other methods, such as a source-area } \\
\text { groundwater recirculation system or } \\
\text { other source-area treatment. } \\
\text { Selection of suitably reactive } \\
\text { organic biowall materials would } \\
\text { require laboratory or pilot-scale } \\
\text { studies. }\end{array}$ \\
\hline
\end{tabular}




\begin{tabular}{|c|c|c|c|c|}
\hline Technology & $\begin{array}{c}\text { Description / Target } \\
\text { Zone / Key Assumptions }\end{array}$ & Positives & Negatives & Summary Assessment \\
\hline \multicolumn{5}{|l|}{ Bioremediation } \\
\hline $\begin{array}{l}\text { In Situ } \\
\text { Bioremediation }\end{array}$ & $\begin{array}{l}\text { Amendments and/or } \\
\text { microorganisms are added } \\
\text { to the subsurface to } \\
\text { stimulate degradation of } \\
\text { the TCE contamination. } \\
\text { Traditional } \\
\text { bioremediation for TCE } \\
\text { involves addition of } \\
\text { carbon (lactate, } \\
\text { polylactate, molasses, } \\
\text { vegetable oil, whey, etc.) } \\
\text { to stimulate anaerobic } \\
\text { degradation. }\end{array}$ & $\begin{array}{l}\text { Significant industry } \\
\text { experience over the past ten } \\
\text { years to support design and } \\
\text { understanding of the } \\
\text { process. Literature suggests } \\
\text { some persistence of the } \\
\text { treatment effectiveness. } \\
\text { Recent information suggests } \\
\text { that the process may be } \\
\text { applicable at relatively high } \\
\text { dissolved phase source area } \\
\text { concentrations similar to the } \\
\text { X-701B plume. }\end{array}$ & $\begin{array}{l}\text { When applied in an aerobic } \\
\text { aquifer, putrefies the water } \\
\text { in the treated area. Does not } \\
\text { treat DNAPL and does not } \\
\text { directly treat material } \\
\text { trapped in fine-grained } \\
\text { persistent source zones. } \\
\text { When applied in an aerobic } \\
\text { aquifer, the process may not } \\
\text { be sustainable for a high } \\
\text { strength source because } \\
\text { much of the added electron } \\
\text { donor (carbon) will be } \\
\text { burned up by oxygen } \\
\text { flowing in to the treatment } \\
\text { zone over time. }\end{array}$ & $\begin{array}{l}\text { Potentially viable but the adverse } \\
\text { collateral impacts in an aerobic } \\
\text { setting are a significant negative. }\end{array}$ \\
\hline $\begin{array}{l}\text { Constructed } \\
\text { Wetland }\end{array}$ & $\begin{array}{l}\text { A passive treatment } \\
\text { system that includes } \\
\text { interception and capture } \\
\text { of contaminated } \\
\text { groundwater in the Gallia } \\
\text { Formation followed by } \\
\text { transport to an engineered } \\
\text { wetland. Groundwater } \\
\text { infiltrates the wetland bed } \\
\text { in an up-flow } \\
\text { configuration and TCE is } \\
\text { treated by biodegradation. } \\
\text { Treated water is } \\
\text { discharged to an adjacent } \\
\text { stream. }\end{array}$ & $\begin{array}{l}\text { The groundwater } \\
\text { withdrawal and wetland } \\
\text { treatment systems are } \\
\text { passive. Wells and } \\
\text { groundwater transfer piping } \\
\text { may be able to incorporate } \\
\text { the Geosiphon principle. } \\
\text { Constructed wetlands have } \\
\text { been designed, tested, and } \\
\text { deployed at full-scale for } \\
\text { treatment of cVOCs (e.g. } \\
\text { TCE). Treatment has proven } \\
\text { to be robust in many } \\
\text { settings. The economics of } \\
\text { wetland construction and } \\
\text { operation is favorable. }\end{array}$ & $\begin{array}{l}\text { Long-term, sustainable } \\
\text { performance of wetlands } \\
\text { designed to treat cVOCs has } \\
\text { undergone only limited } \\
\text { assessment. Application of } \\
\text { wetland design guidance to } \\
\text { site-specific criteria of X- } \\
701 B \text { has not been done and } \\
\text { may not support deployment } \\
\text { of the technology. It is } \\
\text { unclear that the passive } \\
\text { Geosiphon system will } \\
\text { result in adequate plume } \\
\text { capture. }\end{array}$ & $\begin{array}{l}\text { Approximately } 10 \text { years of design, } \\
\text { testing, deployment, and assessment } \\
\text { of full-scale wetlands for treating } \\
\text { cVOCs have been successful at } \\
\text { various sites. A reasonable first step } \\
\text { at Portsmouth would be to initiate a } \\
\text { limited site-specific wetland system } \\
\text { design from which the potential } \\
\text { success and cost-effectiveness of a } \\
\text { full-scale deployment can be } \\
\text { evaluated. }\end{array}$ \\
\hline
\end{tabular}




\begin{tabular}{|c|c|c|c|c|}
\hline Technology & $\begin{array}{c}\text { Description / Target } \\
\text { Zone / Key Assumptions }\end{array}$ & Positives & Negatives & Summary Assessment \\
\hline \multicolumn{5}{|c|}{ Physical, Hydraulic, and Chemical Isolation } \\
\hline Surface Cap & $\begin{array}{l}\text { Install a cap system to } \\
\text { reduce infiltration / target } \\
\text { residual TCE source in } \\
\text { the vadose zone beneath } \\
\text { and adjacent to the former } \\
\text { disposal facilities. } \\
\text { Assumes limited capping } \\
\text { (rather than extensive } \\
\text { areal capping). }\end{array}$ & $\begin{array}{l}\text { Standard technology that is } \\
\text { consistent with regulatory } \\
\text { expectations and norms for } \\
\text { closure of contaminated } \\
\text { RCRA facilities. }\end{array}$ & $\begin{array}{l}\text { Technology is expected to } \\
\text { have limited benefit and } \\
\text { minimal impact on plume } \\
\text { concentrations and source } \\
\text { flux since a significant } \\
\text { fraction of source TCE is } \\
\text { already below the water } \\
\text { table in the Gallia and } \\
\text { Sunbury formations. }\end{array}$ & $\begin{array}{l}\text { More effective alternatives to } \\
\text { address the targeted contamination } \\
\text { are available (e.g., see oxidant } \\
\text { technologies) and the panel } \\
\text { recommends directing resources to } \\
\text { those technologies. Capping alone } \\
\text { will not meet remedial goals and } \\
\text { will require combination with } \\
\text { technologies that operate over an } \\
\text { extended timeframe. If a cap is } \\
\text { implemented, the review panel } \\
\text { recommends simplifying the design } \\
\text { and utilizing surface ditches and } \\
\text { diversion. }\end{array}$ \\
\hline Subsurface Walls & $\begin{array}{l}\text { Vertical barriers installed } \\
\text { using slurry trenches or } \\
\text { sheet pilings to minimize } \\
\text { the flow of water through } \\
\text { the contaminated source } \\
\text { zone. Option assumes } \\
\text { isolation of the vadose } \\
\text { and groundwater beneath } \\
\text { and adjacent to former } \\
\text { source disposal locations. }\end{array}$ & $\begin{array}{l}\text { Reduces flux of } \\
\text { contaminant from source } \\
\text { into plume (more effective } \\
\text { at this objective than a cap } \\
\text { because it addresses source } \\
\text { material in the Gallia and } \\
\text { Sunbury). Technology } \\
\text { vendors are available but } \\
\text { tend to be specialty } \\
\text { companies. }\end{array}$ & $\begin{array}{l}\text { Potentially extends } \\
\text { timeframe of companion } \\
\text { technologies such as pump } \\
\text { and treat if isolation is not } \\
100 \text { percent effective and if } \\
\text { strict remediation goals are } \\
\text { set. Some technologies } \\
\text { release large amounts of } \\
\text { water, potentially spreading } \\
\text { contamination during } \\
\text { deployment. }\end{array}$ & $\begin{array}{l}\text { There are more effective alternatives } \\
\text { to address the targeted } \\
\text { contamination. Subsurface walls, if } \\
\text { used alone, are unlikely to meet } \\
\text { remedial goals and will require } \\
\text { combination with technologies that } \\
\text { operate over an extended timeframe. }\end{array}$ \\
\hline $\begin{array}{l}\text { Hydraulic } \\
\text { Manipulation }\end{array}$ & $\begin{array}{l}\text { Diverts clean water from } \\
\text { upgradient around the } \\
\text { contaminated source zone } \\
\text { (e.g., delivering it to Little } \\
\text { Beaver Creek) isolating } \\
\text { the contaminant and } \\
\text { stagnating the plume. }\end{array}$ & $\begin{array}{l}\text { Reduces contaminant flux } \\
\text { from source into plume } \\
\text { (more effective at this } \\
\text { objective than a cap because } \\
\text { it addresses source material } \\
\text { in the Gallia and Sunbury). } \\
\text { Simple to implement/ not } \\
\text { commonly used. }\end{array}$ & $\begin{array}{l}\text { Extends timeframe of } \\
\text { companion technologies } \\
\text { such as pump and treat. }\end{array}$ & $\begin{array}{l}\text { Lower cost but similar issues to } \\
\text { subsurface walls. }\end{array}$ \\
\hline
\end{tabular}




\begin{tabular}{|c|c|c|c|c|}
\hline Technology & $\begin{array}{c}\text { Description / Target } \\
\text { Zone / Key Assumptions }\end{array}$ & Positives & Negatives & Summary Assessment \\
\hline \multicolumn{5}{|c|}{ Physical, Hydraulic, and Chemical Isolation (continued) } \\
\hline $\begin{array}{l}\text { In Situ Chemical } \\
\text { Isolation / } \\
\text { Immobilization }\end{array}$ & $\begin{array}{l}\text { Injection of sequestrants } \\
\text { (e.g., oil phases or other } \\
\text { organic amendments) that } \\
\text { mitigate TCE sources by } \\
\text { partitioning and blocking. } \\
\text { Sequestrant selection and } \\
\text { deployment options } \\
\text { consider the target } \\
\text { interface (e.g., Minford or } \\
\text { Sunbury) to achieve the } \\
\text { most effective geometry. }\end{array}$ & $\begin{array}{l}\text { Reduces flux of } \\
\text { contaminant from source } \\
\text { into plume (addresses } \\
\text { source material in the Gallia } \\
\text { and Sunbury). }\end{array}$ & $\begin{array}{l}\text { Limited experience to } \\
\text { support design and } \\
\text { somewhat speculative. Not } \\
\text { well suited to a site like X- } \\
701 \mathrm{~B} \text { because of the large } \\
\text { amount of residual source } \\
\text { TCE. Extends timeframe of } \\
\text { companion technologies } \\
\text { such as pump and treat. }\end{array}$ & $\begin{array}{l}\text { Not recommended because of } \\
\text { technology uncertainty and } \\
\text { associated deployment risks and the } \\
\text { issues identified under subsurface } \\
\text { walls. }\end{array}$ \\
\hline
\end{tabular}




\section{References}

AFCEE (Air Force Center for Environmental Excellence). 2008. Technical Protocol for Enhanced Anaerobic Bioremediation Using Permeable Mulch Biowalls and Bioreactors. Prepared by Parsons Infrastructure \& Technology Group, Inc. under contracts F4162400-D-8024 and F41624-03-D-8613.

Camp Dresser McKee. "X-701B Technical Approach, Phase II”, Presentation, Portsmouth ITR meeting, Nov. 18, 2008.

DOE. 2007. Phase IIc Report for the Groundwater Remediation of the X-701B Solid Waste Management Unit at the Portsmouth Gaseous Diffusion Plant, Piketon, Ohio, DOE/PPPO/03-0052\&D1, U.S. Department of Energy, November, 2007.

DOE. 2006. Work Plan for the Groundwater Remediation of the X-701B Solid Waste Management Unit at the Portsmouth Gaseous Diffusion Plant, Piketon, Ohio, DOE/PPPO/03-0020\&D3, U.S. Department of Energy, September 2006.

DOE. 2005. Analytical Report for Portsmouth Quadrant II-X-701B Soil Oxidant Demand Study, SOW No. BXPT02033 MCLinc Project No. BJC001535, Submitted by Materials and Chemistry Laboratory, Inc., East Tennessee Technology Park, Building K10062010 Highway 58, Suite 1000 Oak Ridge, Tennessee 37830-1702, January 28, 2005.

DOE. 2004. Analytical Report BJC BXPT01976, Lionville, Laboratory, Inc., 4/2/04.

DOE. 2003. Soil Oxidant Demand Study - BXPT01892D, Mountain States Analytical, LLC, 2003

Feenstra, S., D.M. Mackay, and J.A. Cherry. 1991. A Method for Assessing Residual NAPL Based on Organic Chemical Concentrations in Soil Samples. Ground Water Monitoring Review, 11(2):128-136.

ITRC. 2003. Technical and regulatory guidance document for constructed treatment wetlands. Interstate Technology and Regulatory Council.

ITRC. 2008. In Situ Bioremediation of Chlorinated Ethene: DNAPL Source Zones, Interstate Technology and Regulatory Council. Available at: http://www.itrcweb.org/Documents/bioDNPL Docs/BioDNAPL3.pdf

Kassenga, G., J.H. Pardue, S. Blair and T. Ferraro. 2003. Treatment of chlorinated VOCs using treatment wetlands. Ecological Engineering, 19(5): 305-323.

Kassenga, G., J.H. Pardue, W.A. Moe, and K. Bowman. 2004. Hydrogen thresholds as indicators of dehalorespiration in constructed treatment wetlands. Environmental Science and Technology, 38(4): 1024-1030. 
Lee, M.H., S.C. Clingenpeel, O.P. Leiser, R.A. Wymore, K.S. Sorenson, Jr., and M.E. Watwood, 2008. Activity-Dependent Labeling of Oxygenase Enzymes in a Trichloroethene-Contaminated Groundwater Site. Environmental Pollution. 153, pp. 238-246.

Liang, L., O. R. West, N. E. Korte, J. D. Goodlaxson, D. A. Pickering, J. L. Zutman, F. J. Anderson, C. A. Welch, and M. J. Pelfrey. The X-625 Groundwater Treatment Facility: A Field-Scale Test of Trichloroethylene Dechlorination Using Iron Filings for the $X$ 120/X-749 Groundwater Plume. Prepared by Oak Ridge National Laboratory for the U. S. Department of Energy under contract DE-AC05-96OR22464.

Lorah, M.M., L.D. Olsen, B.L. Smith, M.A. Johnson, and W.B. Fleck. 1997. Natural attenuation of chlorinated volatile organic compounds in a freshwater tidal wetland, Aberdeen Proving Ground, Maryland. U.S. Geological Survey Water-Resources Investigations Report 97-4171, 95.

McGuire, T.M., J.M. McDade, and C.J. Newell, 2006. Performance of DNAPL Source Depletion Technologies at 59 Chlorinated Solvent-Impacted Sites Ground Water Monitoring \& Remediation 26, pp 73-84.

Ohio EPA. 2003. Decision Document for the X-701B SWMU in Quadrant II of the U.S. DOE Portsmouth Facility, Piketon, Ohio.

Pardue, J.H., G. R. Kassenga, and W.S. Shin. 2000b. Design approaches for chlorinated VOC treatment wetlands. Presented at Wetlands and Remediation, An International Conference, Salt Lake City, Utah, November 1999, Battelle Press, 301-308.

Pardue, J.H. 2002. Remediating chlorinated solvents in wetlands: active processes or a natural approach? Keynote address at Wetlands and Remediation II, Second International Conference, Burlington, Vermont, September 5-6, 2001, Battelle Press.

RTDF (Remediation Technologies Development Forum), http://www.rtdf.org/public/permbarr/prbsumms/profile.cfm?mid=81. Accessed Nov. 20, 2008.

TetraTech Inc. 2005. Groundwater and Soil Kinetics Treatability Project of Site X-701 B, Pace Analytical, Tetra Tech, Inc., April 14, 2005

West, O.R., R. L. Siegrist, T. C. Houk, L. Liang, S. Y. Lee, A. Laase, D. Pickering, M. Dickey, X. Yin, and B. Gu. 1997. The X-625 Treatment Facility: Assessment of Reactive Barrier Technology at PORTS: Summary of 1997 Activities. Report POEFLMES-174 by Lockheed Martin Energy Systems, Inc., for the U. S. Department of Energy under contract DE-AC05-84OR21400 


\title{
Appendix A: Independent Technical Review Team Charter
}

\author{
Charter for DOE Independent Technical Review Team \\ Technical Evaluation of the Path Forward for the X-701B Groundwater Remedy \\ Portsmouth Gaseous Diffusion Plant \\ Portsmouth, Ohio
}

The Department of Energy (DOE) Portsmouth Paducah Project Office (PPPO) is conducting the X-701B groundwater remedy for trichloroethene (TCE) in accordance with a Decision Document that was issued by Ohio EPA on December 8, 2003 (Ohio EPA's Decision Document for the X$701 B$ SWMU in Quadrant II of the US DOE Portsmouth Facility Piketon Ohio), and a Work Plan that was approved by Ohio EPA on September 22, 2006 (Work Plan for the Groundwater Remediation of the X-701B Solid Waste Management Unit at the Portsmouth Gaseous Diffusion Plant, Piketon, Ohio). The Work Plan divides the remedy into the following phases: Phase I Initial Source Area Treatment, Phase II - Expanded Source Area Treatment, Phase III Evaluation and Reporting, and Phase IV - Downgradient Remediation and Confirmation of Source Area Treatment.

Phase I of the remedy was completed during fiscal year (FY) 2006, and DOE has now completed five injection events within Phase II. The Independent Technical Review (ITR) Team will focus their evaluation on completing Phase II of the remedy. Results of the ITR Team evaluation will be used in Phase III (i.e., Evaluation and Reporting).

Section 3.2.3.1 of the Work Plan contains specific criteria for the Phase II end point. According to the Work Plan, Phase II will be complete when:

1. Groundwater samples from the identified source area monitoring wells are below the Preliminary Remediation Goal (PRG) for TCE in groundwater, or

2. The remedy is no longer effective in removing TCE mass from the source area.

The Work Plan further identifies two distinct processes that are to be used to determine when the remedy is no longer effective in removing TCE mass. These are described in detail in the Work Plan, but in summary they are:

a) TCE concentrations in soil are less than the PRG for soil, or

b) A smooth curve of the average TCE concentration in soil over time shows less than a $10 \%$ change between the last two injection events. 
The Charter for the DOE HQ ITR Team is to:

- Review the Work Plan (see Attachment) for the remedy with specific emphasis on the determination of the Phase II end point

- Review the letter report that was transmitted to Ohio EPA following the third series of injection events (e.g., Phase IIc Report)

- Review groundwater and soil data from the baseline, Phase IIb, Phase IIc, Phase IId, and Phase IIe sampling events.

- If additional injection events are recommended, identify the target soil horizon for these injections. Examples are:

1. Mid-Gallia

2. Mid-Gallia and Top of Gallia

3. Lower Gallia (Gallia-Sunbury interface)

4. All horizons

- Determine the feasibility of declaring Technical Impracticability (see Decision Document) and proceeding with the RCRA Cap for the X-701B.

- If Technical Impracticability is recommended for the current technology, then provide a summary of other cost effective technologies that could be implemented (especially for the lower Gallia).

- Provide a briefing and report to DOE-PPPO and site contractors that summarizes the team's evaluation and makes recommendations for the completion of the remedy.

- Prepare for and participate in up to two meetings with the DOE, regulatory agencies, and/or the public, as required.

In completing this scope, the ITR Team should plan for one day-long site visit to the Portsmouth Gaseous Diffusion Plant. During the site visit, DOE-PPPO and contractors will present information concerning the X-701B site and remedial activities at the site, and the ITR Team will be allowed to visit the X-701B site. Additionally, the ITR Team should plan on providing a draft report for factual accuracy review and a final report. The schedule for ITR Team activities will be developed after the team in created; however, the draft report is expected within 4 weeks following the site visit. The final report is expected 2 weeks following the team's receipt of any factual accuracy comments.

The DOE-PPPO program contact for the team will be Richard Bonczek (859-219-4051; rich.bonczek@lex.doe.gov). The DOE-PPPO project and technical contact for the team will be Melda Rafferty (740-897-5521; melda.rafferty@lex.doe.gov). 


\section{X-701B Documents}

\begin{tabular}{|c|c|c|}
\hline & Document Title & FTP Site Folder \\
\hline 1 & $\begin{array}{l}\text { Ohio EPA's Decision Document for the X-701B SWMU in } \\
\text { Quadrant II of the US DOE Portsmouth Facility Piketon Ohio, Ohio } \\
\text { EPA, December } 2003 \text {. }\end{array}$ & \\
\hline 2 & $\begin{array}{l}\text { Work Plan for the Groundwater Remediation of the X-701B } \\
\text { Solid Waste Management Unit at the Portsmouth Gaseous Diffusion } \\
\text { Plant, Piketon, Ohio, DOE/PPPO/03-0020\&D3, U.S. Department of } \\
\text { Energy, September 2006. }\end{array}$ & \\
\hline 3 & $\begin{array}{l}\text { Phase IIc Report for the Groundwater Remediation of the } \\
\text { X-701B Solid Waste Management Unit at the Portsmouth Gaseous } \\
\text { Diffusion Plant, Piketon, Ohio, DOE/PPPO/03-0052\&D1, U.S. } \\
\text { Department of Energy, November, } 2007 .\end{array}$ & \\
\hline 4 & $\begin{array}{l}\text { Untitled data packet containing background information on the } \\
\text { X-701B unit. Includes a presentation from 2005, miscellaneous photos } \\
\text { and a video of the injection operations. }\end{array}$ & \\
\hline 5 & $\begin{array}{l}\text { Untitled data packet containing the analytical results from } \\
\text { Phase II soil samples. Includes a TCE summary, VOC-SVOC } \\
\text { summary, and the whole database of soil results. }\end{array}$ & \\
\hline 6 & $\begin{array}{l}\text { Untitled data packet containing the analytical results from } \\
\text { Phase II groundwater samples. Includes a TCE summary, and the } \\
\text { whole database of groundwater results. }\end{array}$ & \\
\hline
\end{tabular}




\section{Appendix B: Technical Review Team Biographies}

\section{THOMAS O. EARLY}

\section{Senior Geochemist}

Dr. Early is a senior geochemist at GeoConsultants, LLC. He has broad experience in environmental geochemistry gained from over 35 years of professional experience working in the federal and private sectors. He has extensive experience with DNAPL and fuel contamination, high-level radioactive waste disposal, and environmental impacts to soil and groundwater as well as knowledge of RCRA and CERCLA site assessments. Prior to his retirement from the Oak Ridge National Laboratory, he severed in a variety of technical and management positions including Geology and Geophysics Group Leader in the Environmental Sciences Division. Over the last twenty years, he has provided expert technical guidance to a series of environmental technology development programs including the Subsurface Contaminants Focus Area) within DOE's Environmental Management Program.

\section{BRIAN B. LOONEY Areas of Expertise:}

Dr. Looney (Ph.D. Environmental Engineering) is a senior fellow at the Department of Energy Savannah River National Laboratory in Aiken SC. For the past 23 years, he has coordinated development and deployment of environmental characterization and clean-up methods based on the fundamental principles of geochemistry, geohydrology and engineering. His efforts resulted in the successful development or application of improved subsurface access methods (environmental horizontal drilling and cone penetrometer), improved remediation (e.g., sparging, bioremediation and thermal methods), and improved characterization (e.g., tracer testing, soil gas methods and geophysics). Dr. Looney has conducted research targeting clean up of source zone contamination using destruction, stabilization and/or enhanced removal methods. He has also conducted research on methods for dilute fringe contamination using barometric pumping, phytoremediation and the like. Dr. Looney has authored and edited many publications including the recent book, Vadose Zone Science and Technology Solutions. He currently holds ten U.S. and one foreign patent for environmental technologies. Dr. Looney received the 2006 National Groundwater Association Technology Award, 2005 American Chemical Society Industrial Innovation Award, 1996 and 2000 Federal Laboratory Award of Excellence in Technology Transfer, 2004 Worlds Best Technology Award, and 2000 Energy 100 Award.

\section{JOE ROSSABI}

Joe Rossabi is principal scientist and part owner of Redox Tech, LLC where he applies innovative remediation solutions, including hydraulic fracturing, steam injection, chemical injection (for oxidation or reduction of contaminants), and metals stabilization, to soil and groundwater contamination. Prior to Redox Tech, he was a fellow engineer in the Environmental Sciences and Technology Division of the Department of Energy's Savannah River National Laboratory where he performed applied research and development of environmental characterization and remediation technologies and strategies. His research involved field-testing and implementation of cone penetrometer- 
based characterization and remediation methods, multiphase flow processes including DNAPL fate and transport, and passive and renewable energy powered methods for characterization and remediation of subsurface contaminants. He has a Ph.D. in Environmental Engineering from Clemson University, an MS in Environmental Engineering from the University of North Carolina at Chapel Hill, and MS and BA degrees in Physics from the State University of New York at Binghamton.

\section{KAREN L. SKUBAL}

Dr. Skubal coordinates national applied science research activities for EM-22, the DOE EM Office of Groundwater and Soil Remediation. She received her undergraduate degree in chemical engineering from Northwestern University, her M.S. degree in environmental engineering from Carnegie Mellon University, and her Ph.D. in environmental engineering from the University of Michigan. Dr. Skubal served on the faculty in the Department of Civil Engineering at Case Western University from 20002007. Internationally, she has collaborated as a visiting researcher at the Korea Advanced Institute of Science and Technology (KAIST) in Taejon, South Korea, and the Institute of Physical and Chemical Research (RIKEN) in Japan. Her research has focused on biotic and abiotic dechlorination processes for halogenated solvents in contaminated aquifer sediments. Other research interests include chromium biotransformation, biodegradation of deicing compounds, bioconversion of agricultural and food-processing wastes, and phytoextraction of heavy metals for brownfield restoration. 
Appendix C: Attendance Log for November 18, 2008 Technical Review Team Meeting with CDM personnel, Department of Energy, and Ohio EPA representatives. 


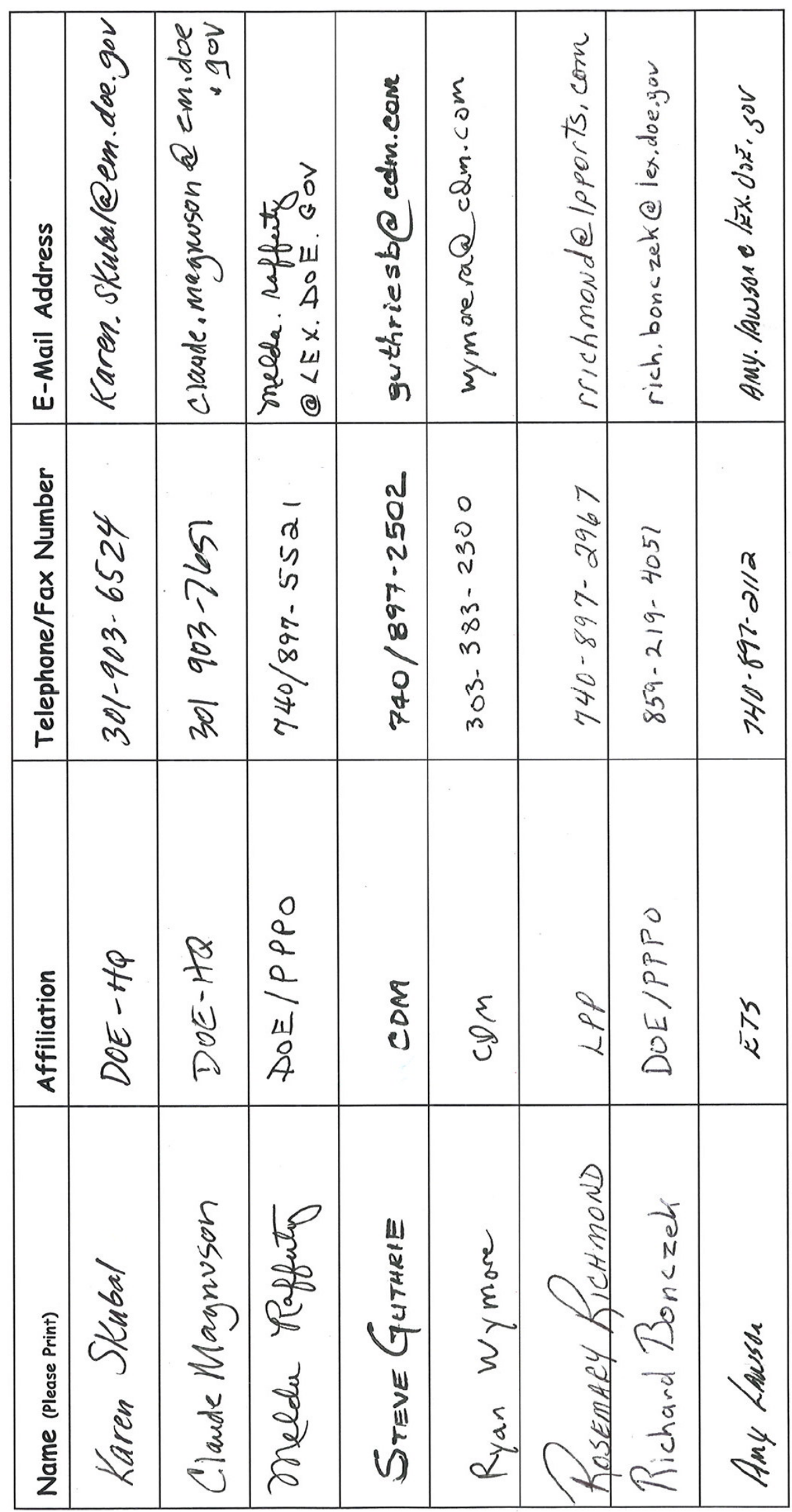




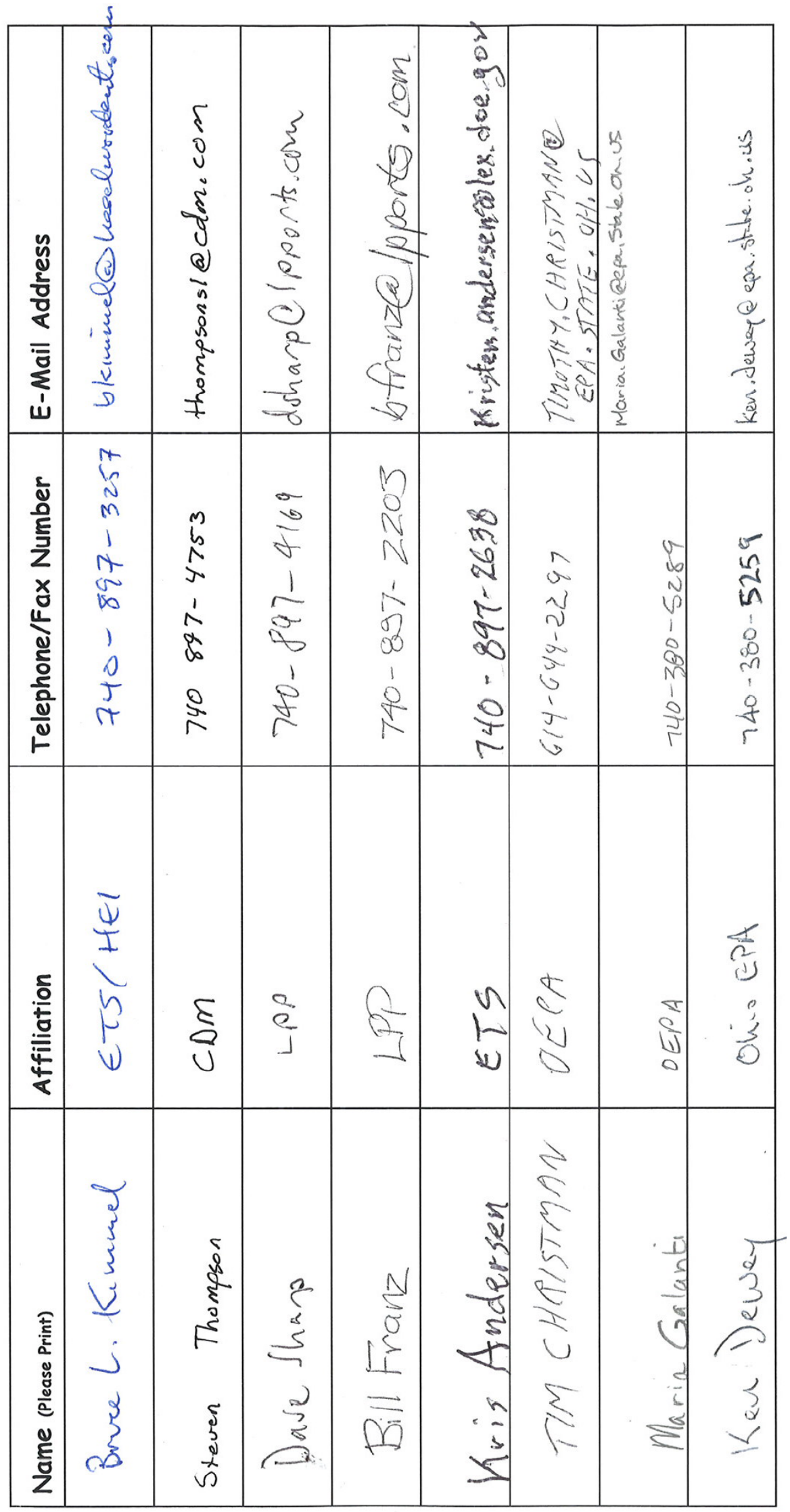




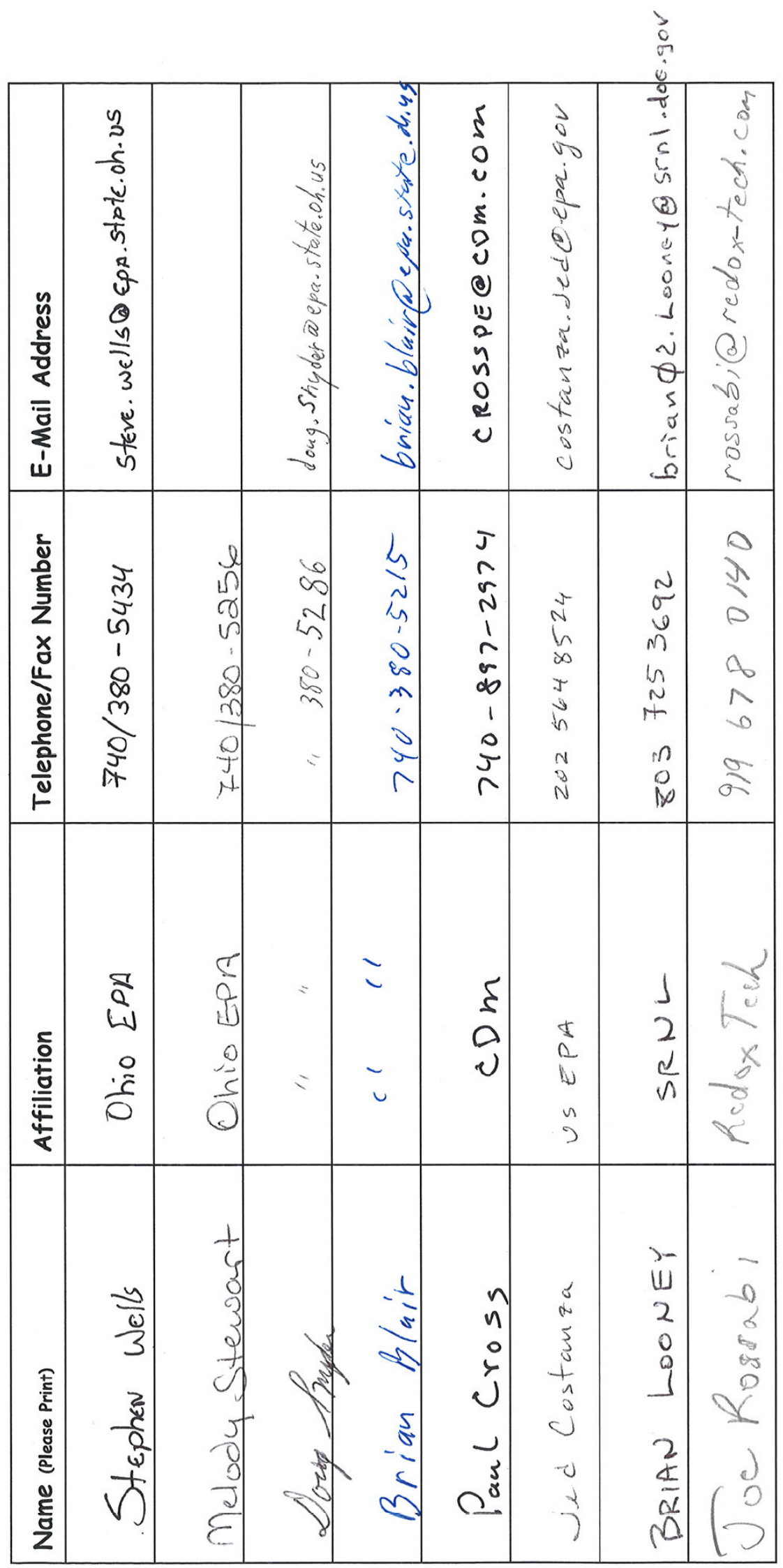




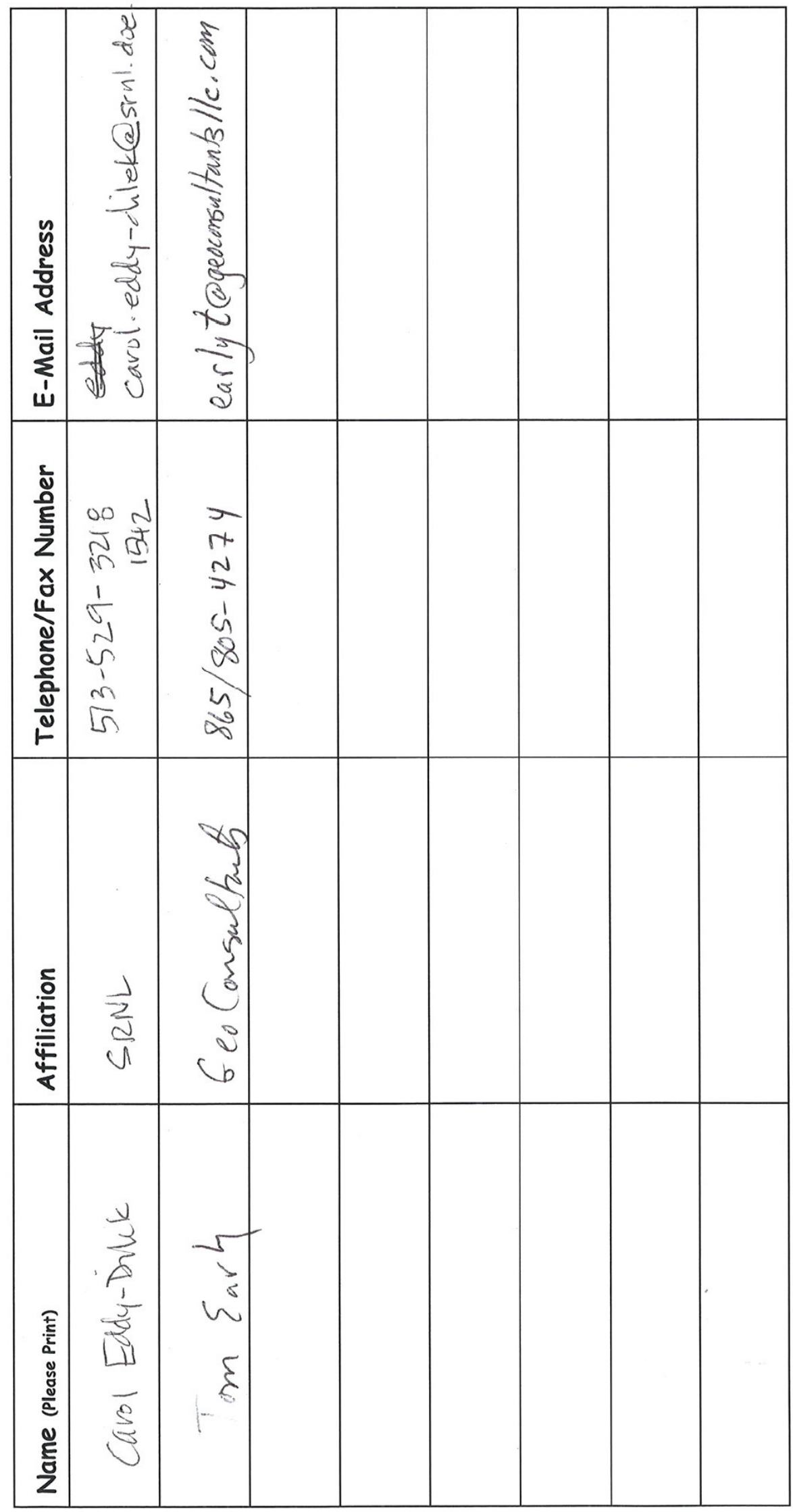

